$$
\begin{gathered}
\text { Universidade de São Paulo } \\
\text { Instituto de Física de São Carlos }
\end{gathered}
$$

Osvaldo Vargas Jaques

Evolução do relacionamento entre dinâmica

e topologia em redes neuronais: uma abordagem computacional 

Osvaldo Vargas Jaques

\section{Evolução do relacionamento entre dinâmica e topologia em redes neuronais: uma abordagem computacional}

Tese apresentada ao Programa de PósGraduação em Física do Instituto de Física de São Carlos da Universidade de São Paulo, para obtenção do título de Doutor em Ciências.

Área de Concentração: Física Aplicada

Opção: Física Computacional

Orientador: Prof. Dr. Luciano da Fontoura Costa

Versão Corrigida

(versão original disponível na Unidade que aloja o Programa)

São Carlos, SP 
AUTORIZO A REPRODUÇÃO E DIVULGAÇÃO TOTAL OU PARCIAL DESTE TRABALHO, POR QUALQUER MEIO CONVENCIONAL OU ELETRÔNICO PARA FINS DE ESTUDO E PESQUISA, DESDE QUE CITADA A FONTE.

Ficha catalográfica elaborada pelo Serviço de Biblioteca e Informação do IFSC, com os dados fornecidos pelo(a) autor(a)

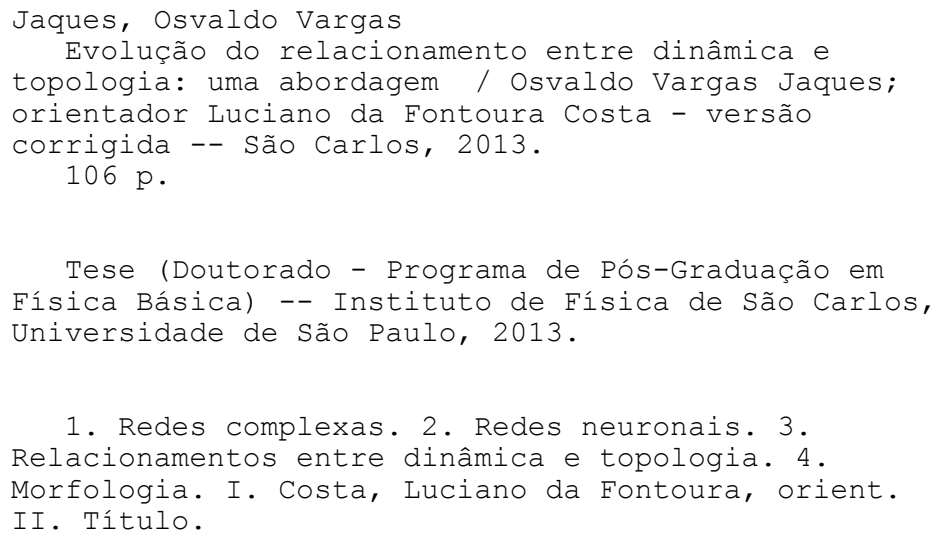




Tese apresentada ao Programa de Pós-Graduação em Física do Instituto de Física de São Carlos da Universidade de São Paulo, para obtenção do título de Doutor em Ciências. 

Aos meus falecido pais, Floriano e Raquela. Deixaram seu corpo em São Carlos e a saudade sem fim como paga destes meus estudos. 'Seo' Jaques foi um homem cento por cento, como os conhecidos e amigos diziam. Eu tenho orgulho de herdar seu nome. Que o Grande Arquiteto do Universo os ampare e guarde. 



\section{AGRADECIMENTOS}

Ao Altíssimo Não Revelado, mas cuja manifestação está em todo lugar, pois estamos aqui para aprender. Não temos meios científicos para provar sua existência, mas também não temos como provar sua não existência.

À FUNDECT - Fundação de Apoio ao Ensino, Ciência e Tecnologia do Estado de Mato Grosso do Sul, pelos três anos de bolsa, Edital Chamada FUNDECT/CAPES No 07/2006 Doutorado no País, protocolo 5727.240.4438.12022007.

À UEMS e Comissão de Capacitação Docente pelo afastamento para qualificação docente.

À esposa Marisa, mulher forte e guerreira, minha admiração por você cresce cada vez mais.

Ao meu orientador, professor doutor Luciano da Fontoura Costa, que teve paciência durante meu processo depressivo, além de tenacidade para dirigir o término deste trabalho.

Ao colega e 'pythonista' César Comin, cujo conhecimento de script Python ajudaram a não reinventar a roda.

Aos demais colegas do CYVISION GROUP pelas sugestões e inquirições. 

'Aqui há dragões, escreviam os antigos cartógrafos, demarcando os desconhecido ameaçador. ...ainda há muitas áreas infestadas de dragões em nosso mapa mental a respeito de como as diferentes partes do mundo se encaixam, do universo microscópico fechado dentro de uma célula ao mundo ilimitado da Internet. Uma boa notícia é que recentemente os cientistas começaram a mapear nossa interconectividade.' 



\section{RESUMO}

JAQUES, Osvaldo V. Evolução do relacionamento entre dinâmica e topologia: uma abordagem computacional. 2013. 106 p. Tese (Doutorado) - Instituto de Física de São Carlos, Universidade de São Paulo, São Carlos, 2013.

Esta tese aborda o interrelacionamento entre morfologia, topologia e dinâmica de ativação em redes neuronais morfologicamente realistas, construídas com neurônios da base pública Neuromorpho. Foi desenvolvido um arcabouço computacional capaz de simular a dinâmica de ativação neuronal (através do modelo integra-e-dispara) ao longo do desenvolvimento da conexão das redes tridimensionais respectivas. Tal arcabouço permitiu investigar como aspectos da dinâmica de ativação variam ao longo das épocas de desenvolvimento das redes, incluindo antes, durante e depois da percolação. Em particular, calcularam-se correlações de Pearson entre várias medidas dinâmicas e topológicas ao longo das épocas de evolução, de forma a se quantificar de maneira objetiva os possíveis relacionamentos entre a ativação neuronal e a topologia das redes. Foram considerados três tipos de neurônios piramidais: occipitais e préfrontais de humanos e células piramidais de macado (macaco Rhesus). Os dois primeiros tipos foram verificados (através de histogramas de médias e análise por componentes principais) possuírem características morfológicas semelhantes, enquanto o grupo de células piramidais do macaco apresentaram substancial diferenciação. Vários resultados foram obtidos respectivamente às correlações entre medidas dinâmicas e topológicas. Em particular, verificou-se que os graus médios de entrada e saída das redes estão significativamente correlacionados com as taxas médias de ativação, convergindo rapidamente após a formação do componente fraco. A correlação do grau de entrada mostrou-se mais elevada do que a obtida para o grau de saída. Além disto, a correlação entre o grau de entrada e a taxa média de disparos tendeu a diminuir ao longo das épocas finais das simulações. Verificou-se também como os perfis de evolução de várias correlações entre dinâmica e topologia implicam na diferenciação dos tipos neuronais considerados.

PALAVRAS-CHAVE: Redes complexas. Redes neuronais. Relacionamento entre dinâmica e topologia. Morfologia. 



\section{ABSTRACT}

JAQUES, Osvaldo V. Evolution of the relationship between dynamics and topology a computational approach. 2013. 106 p. Thesis (PhD) - Instituto de Física de São Carlos, Universidade de São Paulo, São Carlos, 2013.

This thesis addresses the interrelationships between morphology, topology and activation dynamics in morphologically realistic neuronal networks, derived from the public data base Neuromorpho. A computational framework has been developed that is capable of simulating the dynamics of neuronal activation (via the integrate-and-fire dynamics) during the development of the network connection in three-dimensional spaces. This framework allowed to investigate how aspects of the activation dynamics vary over the epochs of network development, including before, during and after the critical event of percolation. In particular, we calculated Pearson correlation coefficients between various topological and dynamical measurements throughout the epochs of evolution, in order to quantify in an objective way how the relationships between neuronal activation and network topology changed along the development of the connectivity. We considered three types of neurons: occipital and prefrontal pyramidal cells of human and diverse pyramidal cells of monkey individuals (monkey Rhesus). The first two types were found (via histograms and principal component analysis) to have mostly similar morphological characteristics, while the group of pyramidal cells from apes showed substantial differentiation. Several results were obtained respectively to the correlations between measurements of dynamics and morphology along the epochs of development. In particular, it was found that the input and output average degrees of the network are significantly correlated with the average rates of activation. After a period of large variation that precedes the formation of the weakly connected component, these correlation values converge rapidly to a regime of smooth decrease which suggests saturation of the activation in the network. The correlation implied by the indegree proved to be clearly higher than that obtained for the outdegree. It was also investigated how the profiles of the various correlations along the development epochs implied in the differentiation between the neuronal types considered.

KEYWORDS: Complex networks. Neuronal networks. Relashionship between dynamics and topology. Morphology. 



\section{LISTA DE FIGURAS}

1.1 - Principais temas abordados na tese. . . . . . . . . . . . 26

2.1 - Estrutura de um neurônio. . . . . . . . . . . . . . . . . . 28

2.2 - Sinapse. . . . . . . . . . . . . . . . . 30

2.3 - Potencial de ação. . . . . . . . . . . . . . . . . . . . 30

2.4 - Tipos de neurônios. . . . . . . . . . . . . . . . . . . 32

2.5 - Células de Purkinje. . . . . . . . . . . . . . . . . . 32

2.6 - Neurônio piramidal. . . . . . . . . . . . . . . . . . 33

2.7 - Base neuromorpho. . . . . . . . . . . . . . . . . . . 35

2.8 - Arquivo em notação swc. . . . . . . . . . . . . . . . . 36

2.9 - Descrição do soma em swc. . . . . . . . . . . . . . . . . 37

2.10 - Segmento em traçado swc. . . . . . . . . . . . . . . . 37

2.11 - Componentes de um neurônio. . . . . . . . . . . . . . . . . . . 39

2.12 - Grafo. . . . . . . . . . . . . . . . . . 44

2.13 - Digrafo. . . . . . . . . . . . . . . . . . 44

2.14 - Grafo de custos. . . . . . . . . . . . . . . . . . 45

2.15 - Grafos regulares. . . . . . . . . . . . . . . . . 46

2.16 - Grafos isomorfos. . . . . . . . . . . . . . . . . . 46

2.17 - Subgrafo. . . . . . . . . . . . . . . . . . . . 46

2.18 - Grafo bipartido. . . . . . . . . . . . . . 47

2.19 - Hiper grafo. . . . . . . . . . . . . . . . . . . . 48

2.20 - Componentes Conexos. . . . . . . . . . . . . . . . . . . . 48

2.21 - Árvores. . . . . . . . . . . . . . . . . . . . . . . 49 49

2.22 - Histograma dos graus de uma rede ER. . . . . . . . . . . 53

2.23 - Componente gigante. . . . . . . . . . . . . . . . . . . 54 
2.24 - Redes WS. . . . . . . . . . . . . . . . . . . . . 56

2.25 - Redes BA. . . . . . . . . . . . . . . . . . . . 57

2.26 - Distribuição BA em escala logarítmica . . . . . . . . . . . . . . 58

2.27 - Rede Waxman. . . . . . . . . . . . . . . . . . . . . . . 59

2.28 - Exemplo de percolação. . . . . . . . . . . . . . . . . . . . 62

2.29 - Momento da percolação. . . . . . . . . . . . . . . . . . . . . . 63

2.30 - Ponto crítico. . . . . . . . . . . . . . . . . . . . . 64

2.31 - Formação do componente gigante em redes neuronais. . . . . . . . . 65

2.32 - Tipo de dinâmica em rede. . . . . . . . . . . . . . . . . . 66

2.33 - Ativação por limiar. . . . . . . . . . . . . . . . . . . 66

2.34 - Modelo Integra e dispara. . . . . . . . . . . . . . . . 67

2.35 - Número de disparos para redes formadas por neurônios do hipocampo. . 69

2.36 - Um modelo de rede morfológica. . . . . . . . . . . . . . 71

3.1 - Ilustração da organização das redes simuladas ao longo de um plano-xz.

O eixo principal das células é orientado ao longo do eixo y. . . . . . . 74

3.2 - Transformada Karhunen-Loève. . . . . . . . . . . . . . . . . . . 74

3.3 - Normalização na projeção do plano-xz. . . . . . . . . . . . . . . 75

3.4 - Exemplo dinâmica neuronal. . . . . . . . . . . . . . . . . 77

3.5 - Matriz de disparos (spikegram) . . . . . . . . . . . . 78

3.6 - Neurônios piramidais occipitais. . . . . . . . . . . . . . . . . 80

3.7 - Neurônios piramidais pré-frontais. . . . . . . . . . . . . . . . 81

3.8 - Neurônios piramidais córtex macaco. . . . . . . . . . . . . . . 82

3.9 - Histograma de medidas neuromorpho das três classes. . . . . . . . 83

3.10 - PCA para medidas das três classes neuronais, occipital, pré-frontal e córtex de macaco. . . . . . . . . . . . . . . . . . . . . . 84

3.11 - Função discriminante canônica para medidas das três classes neuronais, occipital, pré-frontal e córtex de macaco. . . . . . . . . . . . 85 
3.12 - Medidas de topologia e dinâmica para redes de neurônios do córtex de macaco ao longo das épocas. . . . . . . . . . . . . . . . . . . . . . . . 86

3.13 - Medidas de topologia e dinâmica para redes de neurônios occipitais. . 87

3.14 - Medidas de topologia e dinâmica para redes de neurônios pré-frontais do macaco ao longo das épocas. . . . . . . . . . . . . . . . . . . . . . . 88

3.15 - Medidas de topologia e dinâmica com raio de alcance do axônio igual a 10, de neurônios do córtex do macaco. . . . . . . . . . . . . . . . 90

3.16 - Medidas de topologia e dinâmica com raio maior de neurônios occipital humano.

3.17 - Medidas de topologia e dinâmica com raio maior de neurônios préfrontal humano.

3.18 - Médias e desvios padrão do número de neurônios ativos; reciprocidade da rede e média de disparos no tempo ao longo das épocas para as três categorias de neurônios piramidais.

3.19 - Médias e desvios padrão para as correlações de Pearson entre as medidas topológicas ao longo das épocas de desenvolvimento para as três categorias de neurônios piramidais

3.20 - Médias e desvios padrão para as correlações Pearson entre as medidas dinâmicas ao longo das épocas de desenvolvimento para as três categorias de neurônios piramidais.

3.21 - Médias e desvios padrão das correlações as correlações entre as medidas dinâmicas e topológicas ao longo das épocas de desnvolvimento para as três categorias de neurônios piramidais.

3.22 - Análise de componentes principais tomando-se medidas o número de neurônios ativos; reciprocidade da rede e média de disparos no tempo ao longo das épocas. . . . . . . . . . . . . . . . . . . . . . . 9

3.23 - Análise de componentes principais tomando-se como vetores de atributos as correlações entre medidas topológicas ao longo das épocas.

3.24 - Análise de componentes principais tomando-se como vetores de atributos as correlações entre medidas dinâmicas ao longo das épocas. . . . . 
3.25 - Análise de componentes principais tomando-se como vetores de atributos as correlações entre medidas topológicas e dinâmicas ao longo das épocas. . . . . . . . . . . . . . . . . . . . . . . . . . . . 98 


\section{LISTA DE TABELAS}

2.1 - Definição pontos na notação swc. . . . . . . . . . . . . . . 36

2.2 - Componentes de um neurônio. . . . . . . . . . . . . . . . . . . . . 38

2.3 - Medidas para caracterização de neurônios. . . . . . . . . . . . . . . . 40 



\section{SUMÁRIO}

1 Introdução

2 Revisão 27

2.1 Princípios de Neurociência . . . . . . . . . . . . . . . . . . . . . . . . 27

2.1 .1 Partes da célula neural . . . . . . . . . . . . . . . . . . . . 28

2.1 .2 Potencial de ação . . . . . . . . . . . . . . . . . . . 28

2.1.3 Tipos de células neuronais . . . . . . . . . . . . . . . . . . . . . 31

2.1.3.1 Número de ramificações . . . . . . . . . . . . . . . . . . . . 31

2.1.3.2 Formato do corpo celular . . . . . . . . . . . . . . . 31

2.1.3.3 Função . . . . . . . . . . . . . . . . . . . . . . 33

2.1.3.4 Tamanho ou ausência de axônios . . . . . . . . . . . . . . . 34

2.2 Forma e função neuronal . . . . . . . . . . . . . . . . . . . . . . . . . . . 34

2.3 A base neuromorpho e medidas de morfologia de neurônios . . . . . . . . . 34

2.3.1 Notação de traçado swc . . . . . . . . . . . . . . . . . . . . . . 35

2.3.2 Medidas de morfologia neuronal . . . . . . . . . . . . . . . . 38

2.4 Análise de dados . . . . . . . . . . . . . . . . . . . . . . . . . . . . . . 41

2.5 Redes complexas e medidas de topologia de redes . . . . . . . . . . . . . . 42

2.5 .1 Grafos . . . . . . . . . . . . . . . . . . . . 43

2.5 .2 Modelos de Redes . . . . . . . . . . . . . . . . . . . . . 52

2.5.2.1 Redes aleatórias . . . . . . . . . . . . . . . . 53

2.5.2.2 Redes pequeno mundo. . . . . . . . . . . . . . 55

2.5.2.3 Redes livres de escala . . . . . . . . . . . . . . . . . 56

2.5.2.4 Redes espaciais ou geográficas . . . . . . . . . . . . . 58 
2.5.2.5 Redes Biológicas . . . . . . . . . . . . . . . . . . . . 58

2.5.2.5.1 Redes neuronais . . . . . . . . . . . . . 60

2.5.2.5.2 Redes de proteínas . . . . . . . . . . . . . . 60

2.5.2.5.3 Redes metabólicas . . . . . . . . . . . . . . . 60

2.5.2.6 Redes de Informação . . . . . . . . . . . . . . . . . . . . 61

2.5.2.7 Outras redes . . . . . . . . . . . . . . . . . . 61

2.6 Crescimento e percolação de redes morfológicas artificiais e reais . . . . . . . . 61

2.7 Dinâmica em redes . . . . . . . . . . . . . . . . . . . . . . . . . . . . . . 64

2.7.1 Modelo integra e dispara . . . . . . . . . . . . . . . . 66

2.7.2 Medidas de dinâmica do integra e dispara . . . . . . . . . . . . . . 69

2.7.3 Estrutura e dinâmica em redes morfológicas: trabalho relacionados . . 70

3 Desenvolvimentos e Resultados $\quad 73$

3.1 Metodologia . . . . . . . . . . . . . . . . . . 73

3.2 Recursos computacionais . . . . . . . . . . . . . . . . . . . . . . . 79

3.3 Caracterização dos neurônios através de Medidas Morfológicas . . . . . . . . . 79

3.4 Correlações dinâmica $x$ topologia em relação ao crescimento das redes: redes individuais . . . . . . . . . . . . . . . . . . . . . . . 84

3.5 Correlações dinâmica $x$ topologia em relação ao crescimento das redes: médias sobre redes . . . . . . . . . . . . . . . . . . . . . . . . . . . . 89

3.6 Discriminação das categorias neuronais a partir dos perfis das medidas e correlações . . . . . . . . . . . . . . . . . . . . . . . . . . 96

4 Conclusões $\quad 99$

$\begin{array}{ll}\text { REFERÊNCIAS } & 103\end{array}$ 


\section{Capítulo 1}

\section{Introdução}

O sistema nervoso dos mamíferos apresenta uma das estruturas mais complexas da natureza, quer seja por sua intrincada estrutura de conexão, ou por sua dinâmica variada e muitas vezes surpreendente. Vários esforços foram e continuam a ser dedicados à compreensão do funcionamento destes sistemas, o que pode contribuir não apenas para a solução de vários problemas neurológicos como para a implementação de inteligência em máquinas. O neurocientista espanhol Santiago Ramon-y-Cajal $(1,2)$, considerado por muitos como o fundador da neurociência moderna, dedicou muito do seu interesse ao estudo da variedade dos neurônios e sua possível influência na dinâmica neuronal. De fato, existe uma grande variedade de formas neuronais no sistema nervoso dos mamíferos, que podem estar relacionadas à padrões específicos de conectividade e de processamento da informação neuronal.

Um outro aspecto fascinante do sistema nervoso, também relacionado à forma neuronal, é o desenvolvimento das conexões ao longo dos primeiros estágios da vida dos indivíduos. As células neuronais iniciam-se como neuroblastos desprovidos de ramos, que se desenvolvem posteriormente em estruturas específicas de conexão. Sabe-se que a história de estímulos recebidos, assim como a ação de vários fatores neurotróficos como campos de concentrações iônicas ou moleculares e campos elétricos, também contribui decisivamente no estabelecimento das conexões do sistema nervoso. O estudo da evolução da conectividade em sistemas como a teia mundial (WWW), relações de amizade, e as redes neuronais tem motivado muitos trabalhos fundamentados no conceito de percolação. Iniciando-se com indivíduos desconectados, o acréscimo de ligações tende a produzir grupos conectados que eventualmente se conectam num grande grupo, o que, informalmente, caracteriza a percolação, implicando em uma variação abrupta das propriedades de conexão do sistema. Permanece um assunto de grande interesse entender como as propriedades topológicas e dinâmicas (ativação de disparos) de um sistema neuronal se comportam antes, durante e depois da percolação.

Tal relacionamento entres dinâmica e topologia tornou-se um assunto de destaque em pesquisas de sistemas complexos, pois a identificação de uma forte correlação entre tais aspectos não apenas indica que a dinâmica está fortemente relacionada à topologia, mas também permite que propriedades dinâmicas sejam previstas a partir de características topológicas do 
sistema. Desnecessário dizer que estruturas ramificadas desempenham um importante papel na percolação da rede como por exemplo, como os trabalhos de (3), abordando a conectividade neuronal, e o mais recente trabalhos de (4), abordando a complexidade e anisotropia em surtos epidêmicos. Delineia-se então uma oportunidade de integração do estudo destas várias influências, ou seja, como a forma neuronal, topologia e dinâmica das redes respectivas, se relacionam antes, durante e depois do evento crítico da percolação. Este é o principal tema de interesse desta tese, que envolveu o desenvolvimento de um arcabouço computacional para a simulação da evolução da topologia e dinâmica de ativação de sistemas neuronais morfológicamente realistas. A fig. 1.1 ilustra os principais temas abordados nesta tese (caixas redondas), assim como seu respectivo tratamento nos desenvolvimentos realizados (caixas retangulares).

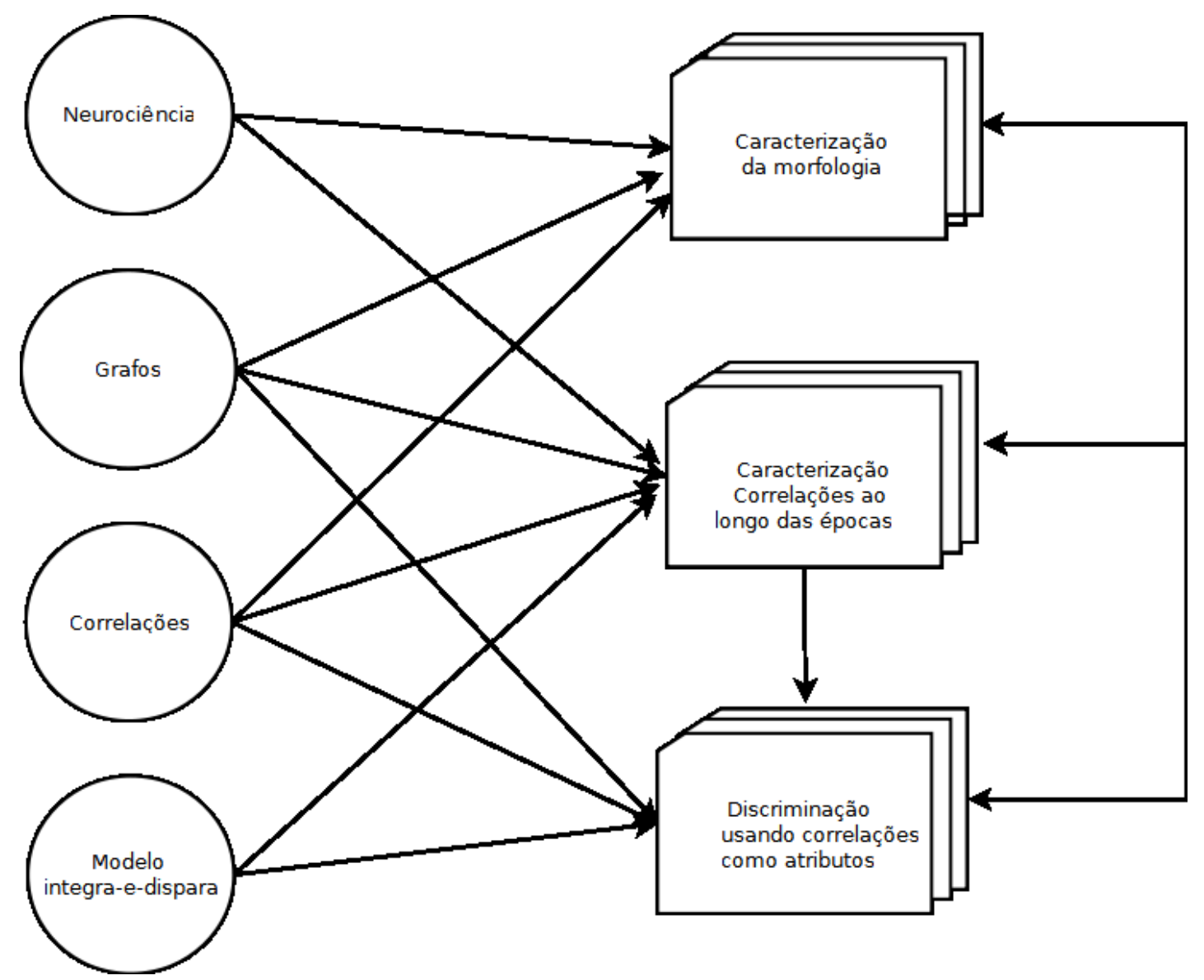

Figura 1.1 - Principais temas abordados nesta tese e sua integração nos desenvolvimentos realizados.

Esta tese começa com uma revisão dos conceitos de neurociência, seguindo para as definições dos conceitos de grafos e redes complexas, desenvolvimento e dinâmica em redes. A seguir, descreve-se os vários desenvolvimentos iniciando-se com a metodologia adotada seguido dos resultados e discussão. O trabalho finaliza-se com as conclusões, sugestões de trabalhos futuros e apêndices. 
Capítulo 2

\section{Revisão}

\subsection{Princípios de Neurociência}

O sistema nervoso e o sistema endócrino são responsáveis pela maior parte das funções do organismo. O sistema nervoso pode ser dividido em duas partes: sensorial e motora. As experiências sensoriais são transmitidas através dos receptores sensoriais, podendo permanecer na memória desde minutos até períodos mais longos (5). A divisão motora é responsável pela coordenação das atividades corporais como contração dos músculos e secreção glandular. Os músculos e glândulas, neste caso, são chamados de efetores (6).

Processar informações sensoriais e produzir respostas motoras adequadas é uma das principais funções do sistema nervoso. As principais células responsáveis pela emissão de informações são os neurônios (7), que distinguem-se de outras células pela capacidade de processar e transmitir informações através de impulsos elétricos. As células neuronais apresentam grande variabilidade morfológica. Esta variação morfológica está relacionada com a função do neurônio. Quanto mais evoluído o organismo, maior é a variação da morfologia neuronal (6).

Podemos comparar o sistema nervoso a um computador. Enquanto que nos computadores as informações são processadas e enviadas através de bits, as células neuronais enviam transmissões através de pequenos impulsos elétricos (8). A decodificação destes sinais podem ser simplesmente de identificação de sensações, como de ações modificadoras dos ambientes externo e interno do organismo. O cérebro humano tem aproximadamente 100 bilhões de neurônios $(8,9)$, bem menos que a capacidade de armazenamento de um computador. A diferença está na capacidade destes neurônios formarem uma rede de neurônios que se comunicam entre si (9). 


\subsubsection{Partes da célula neural}

Pode-se dizer que um neurônio é composto de três partes, corpo celular ou soma, axônio e dendritos (também chamados de neuritos), conforme ilustra a fig. 2.1. Cada neurônio possui um axônio único que surge de uma região específica do corpo celular, chamada de cone axônico, ou cone de implantação (8). Os axônios apresentam comprimento variável. Um tipo específico de motoneurônio da medula espinhal, responsável pelo comando dos músculos dos pés, possui um axônio que pode atingir um metro, aproximadamente 200.000 vezes o diâmetro do soma (9).

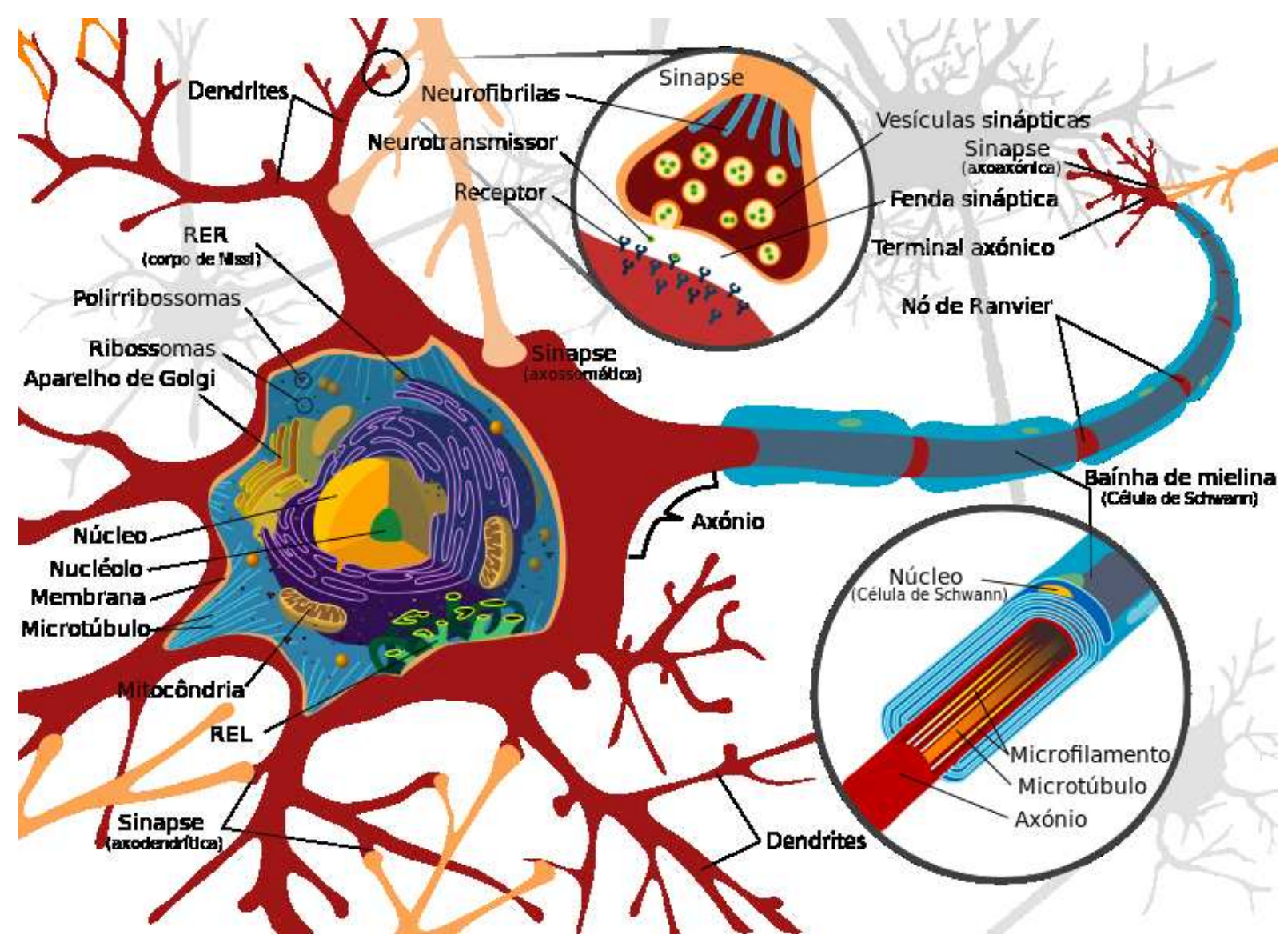

Figura 2.1 - Estrutura de um neurônio. Fonte: Wikimedia Commons.

\subsubsection{Potencial de ação}

Na superfície do soma e na superfície dos dendritos encontra-se uma grande quantidade de pequenos botões, denominados botões sinápticos ou nós terminais. Aproximadamente 80 a 90 por cento destes botões encontram-se na superfície dos dendritos (9). 
Segundo (10), sinapse é o lugar onde o axônio pré-sináptico de uma célula faz contato com o dendrito ou soma de uma célula pós-sináptica. Há dois tipos de sinapses: química e elétrica (8).

Quase todas as sinapses do sistema nervoso humano são químicas (8). Na sinapse química, o contato é feito com os dendritos alvo através de substâncias químicas, chamadas de neurotransmissores. Na sinapse elétrica, a sinapse ocorre através de canais tubulares chamadas junções comunicantes, permitindo a passagem livre de íons de uma célula para a próxima.

Cada terminal sináptico é composto por vesículas sinápticas, que liberam substâncias excitatórias ou inibitórias da sinapse. O espaço entre o terminal emissor da sinapse (terminal pré-sináptico) e a membrana receptora da sinapse (membrana pós-sináptica) é chamado de fenda sináptica e tem uma distância de 200 a 300 angstroms (7).

Quando um impulso se propaga através de um terminal pré-sináptico, as vesículas liberam as substâncias transmissoras através da fenda sináptica, produzindo uma alteração na permeabilidade da membrana do neurônio receptor, produzindo excitação ou inibição do receptor, dependendo da substância liberada (fig. 2.2). Este processo ocorre porque o impulso provoca a penetração de íons cálcio no terminal, atraindo as vesículas para a membrana, provocando a ruptura de uma ou mais delas, derramando as substâncias transmissoras na fenda sináptica.

Acredita-se que a membrana do neurônio pós-sináptico contenha moléculas receptoras específicas que se ligam à substância transmissora (8). Geralmente, isto ocorre entre 1 e 2 milissegundos. Durante esse curto espaço de tempo o interior da membrana celular pode criar um potencial pós-sináptico excitatório (PPSE) ou um potencial pós-sináptico inibitório (PPSI). Este potencial tende a decair (subir) no intervalo de 15 milissegundos, tempo necessário para a membrana entrar novamente em um estado de equilíbrio potencial ou repouso. Contudo, algumas substâncias podem inibir um neurônio pós-sináptico por um período mais longo desde centenas de milissegundos, segundos, minutos ou horas (7).

A sinapse de um único neurônio quase sempre não é suficiente para excitar um neurônio. A razão é que a sinapse de um único neurônio causa uma variação de potencial muito baixa, insuficiente para fazer a membrana pós-sináptica atingir um potencial excitatório (8). Contudo, muitos terminais pré-sinápticos estimulam a membrana ao mesmo tempo. Isso causa um aumento gradativo de potencial até que este atinge um limiar. Neste momento o neurônio realiza uma transição abrupta de diferença de potencial, definido como potencial de ação (spyke). Este potencial de ação emite uma corrente elétrica que parte do cone axônico para todos os dendritos de seus neurônios pós-sinápticos. No intervalo de 15 milissegundos o potencial da membrana então cai até um pouco abaixo do potencial de equilíbrio para logo 
entrar novamente em equilíbrio potencial. A fig. 2.3 mostra um gráfico representando a emissão de um potencial de ação.

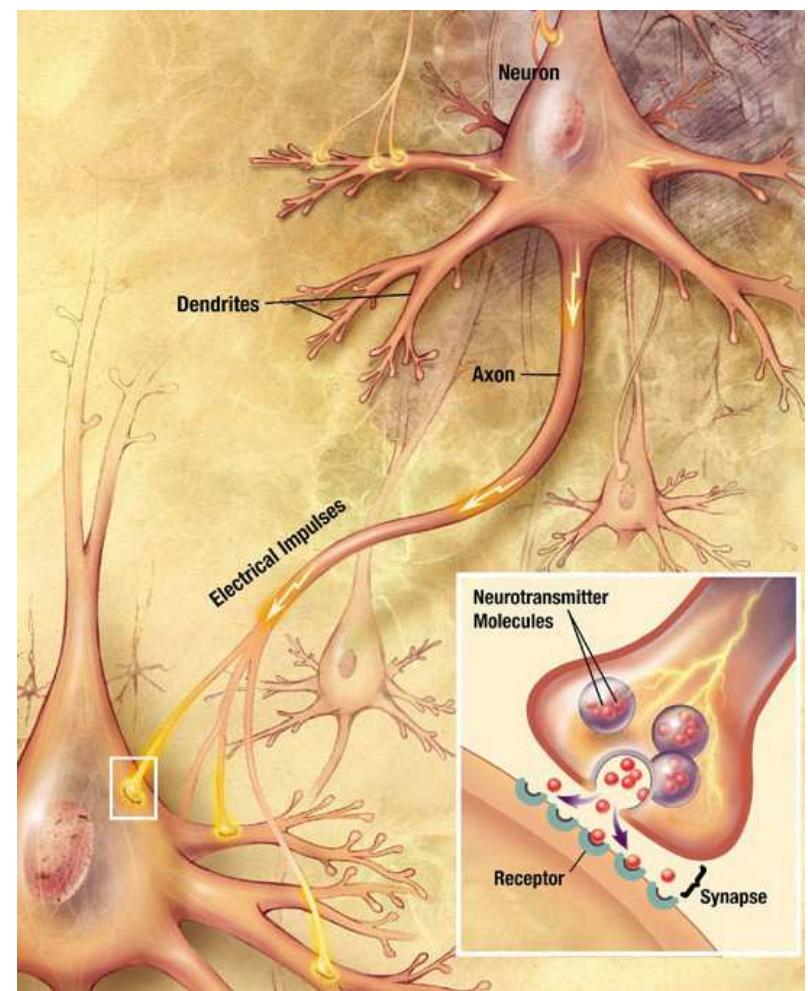

Figura 2.2 - Sinapse. Um terminal axônico libera substâncias excitatórias ou inibitórias na fenda sináptica que é capturado pelo terminal axônico. Fonte: Repositório Wikimedia Commons.

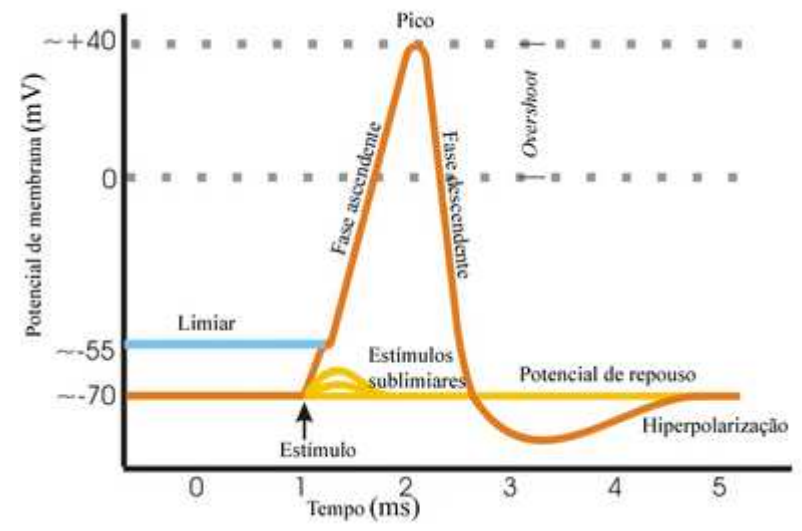

Figura 2.3 - Potencial de ação. Fonte: Repositório Wikimedia Commons.

Em um circuito elétrico a membrana plasmática funciona como um capacitor que vai armazenando cargas de acordo com uma diferença de potencial (7). Matematicamente, o capacitor é um integrador de impulsos pré-sinápticos. 


\subsubsection{Tipos de células neuronais}

Os neurônios podem ser classificados por diversos fatores como:

- Número de arborizações que se originam do soma;

- Formato da célula;

- Função;

- Tamanho ou ausência de espículas.

Deste modo um neurônio pode ser classificado por um ou mais fatores. A seguir, veremos a descrição dos neurônios conforme cada um destes fatores.

\subsubsection{Número de ramificações}

Aqui podemos classificar os neurônios como unipolares, bipolares e multipolares (fig. 2.4). Nas células unipolares, de uma única ramificação do soma surge o axônio que se ramifica. Tal tipo de neurônios são mais predominantes nos invertebrados (7). As células bipolares são compostas por um dendrito e um axônio. Já nas multipolares, os dendritos partem de diferentes partes do soma, sendo que um axônio pode surgir a partir do soma ou de um dos dendritos. Como exceção, temos as células piramidais e as de Purkinje, localizadas no cerebelo, possuindo uma grande ramificação dendrítica que não se ramificam de qualquer parte do soma, mas de locais específicos (fig. 2.5). Este tipo de estrutura permite uma quantidade imensa de entradas sinápticas (7).

\subsubsection{Formato do corpo celular}

O córtex, do latim casca, é dividido em camadas sendo as primeiras camadas as mais próximas ao topo da cabeça (6). No córtex do cerebelo estão as células de Purkinje, com formato de pera e as células granulares, com formato esferoidal. Um pouco maiores, mas com formato esferoidal, são as células dos neurônios sensitivos dos gânglios espinhais. A fig. 2.6 mostra um tipo de neurônio com soma em forma de pirâmide. São as células piramidais, 


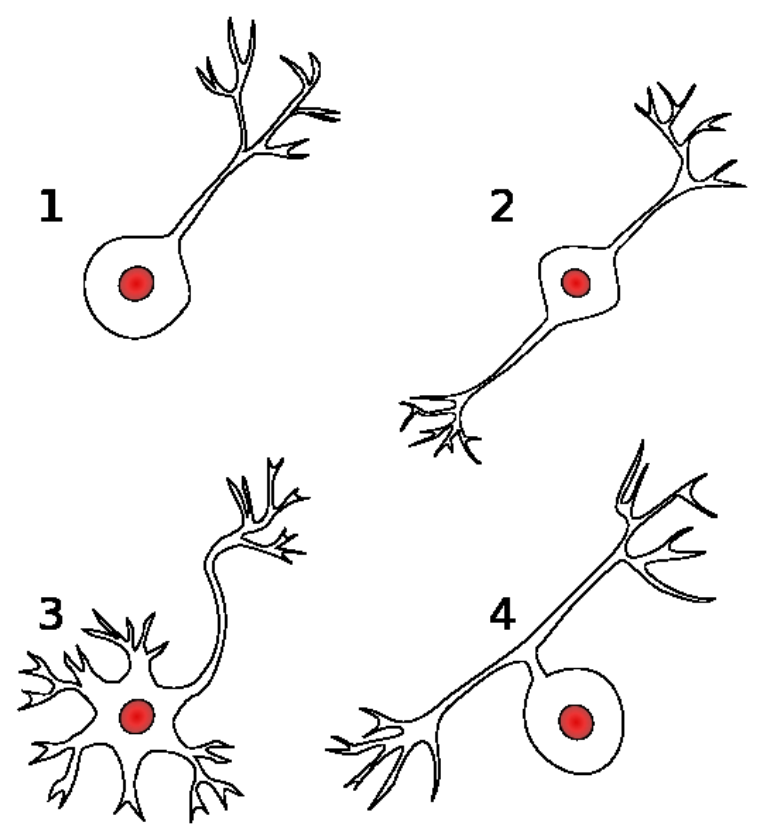

Figura 2.4 - Tipos de neurônios, conforme ramificação. De 1 a 4, células unipolares,bipolares, multipolares e pseudounipolares. Fonte: Repositório Wikimedia Commons.

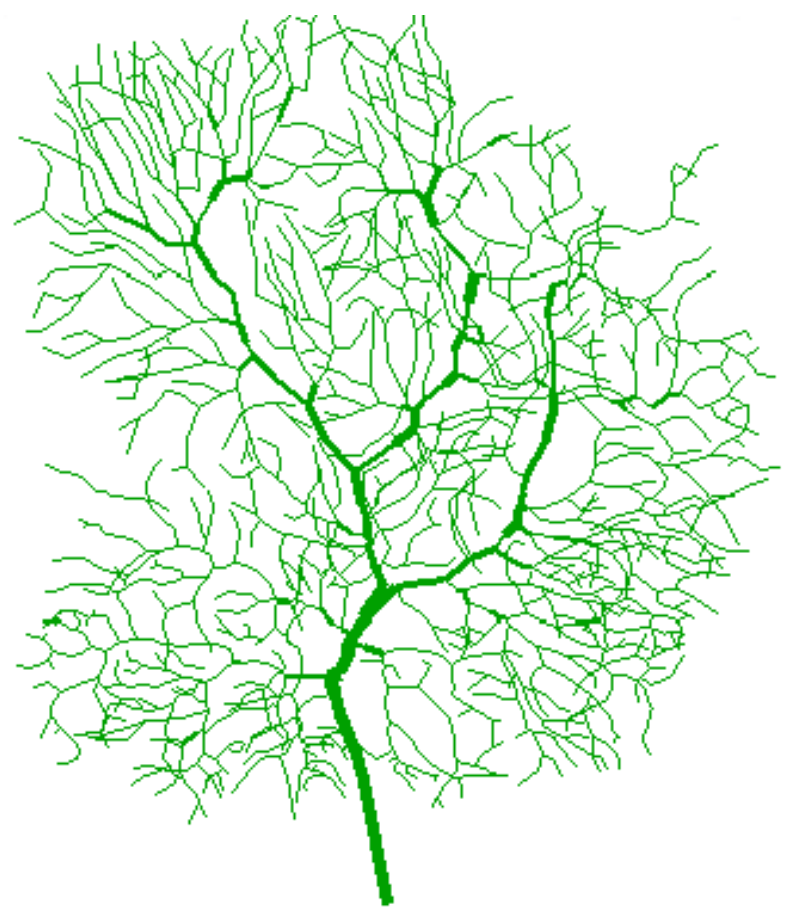

Figura 2.5 - Células de Purkinje.Fonte:Repositório Wikimedia Commons. 
distribuídas na maior parte do córtex, onde as cores servem para destacar os seus componentes. Consideramos o topo do soma a sua parte mais próxima às primeiras camadas do córtex. Da base do soma surgem o axônio (cor cinza) e os dendritos basais (cor vermelha), com ampla distribuição. Do topo do soma ramificam-se os dendritos apicais (cor azul) que possuem pouca ramificação porém são mais longos que os basais. Ambos os dendritos basais e apicais são cobertos por espículas. Seus axônios projetam-se para outras regiões do córtex e até mesmo para outras regiões do encéfalo. Em seguida, temos os neurônios estelares, que permanecem sempre na mesma região cortical, são geralmente pequenos e seus corpos celulares lembram o formato de estrela (11). Seus dendritos também podem ter espículas. Finalmente, temos os interneurônios, com corpo celular arredondado e seus dendritos com pouca ou nenhuma espícula.

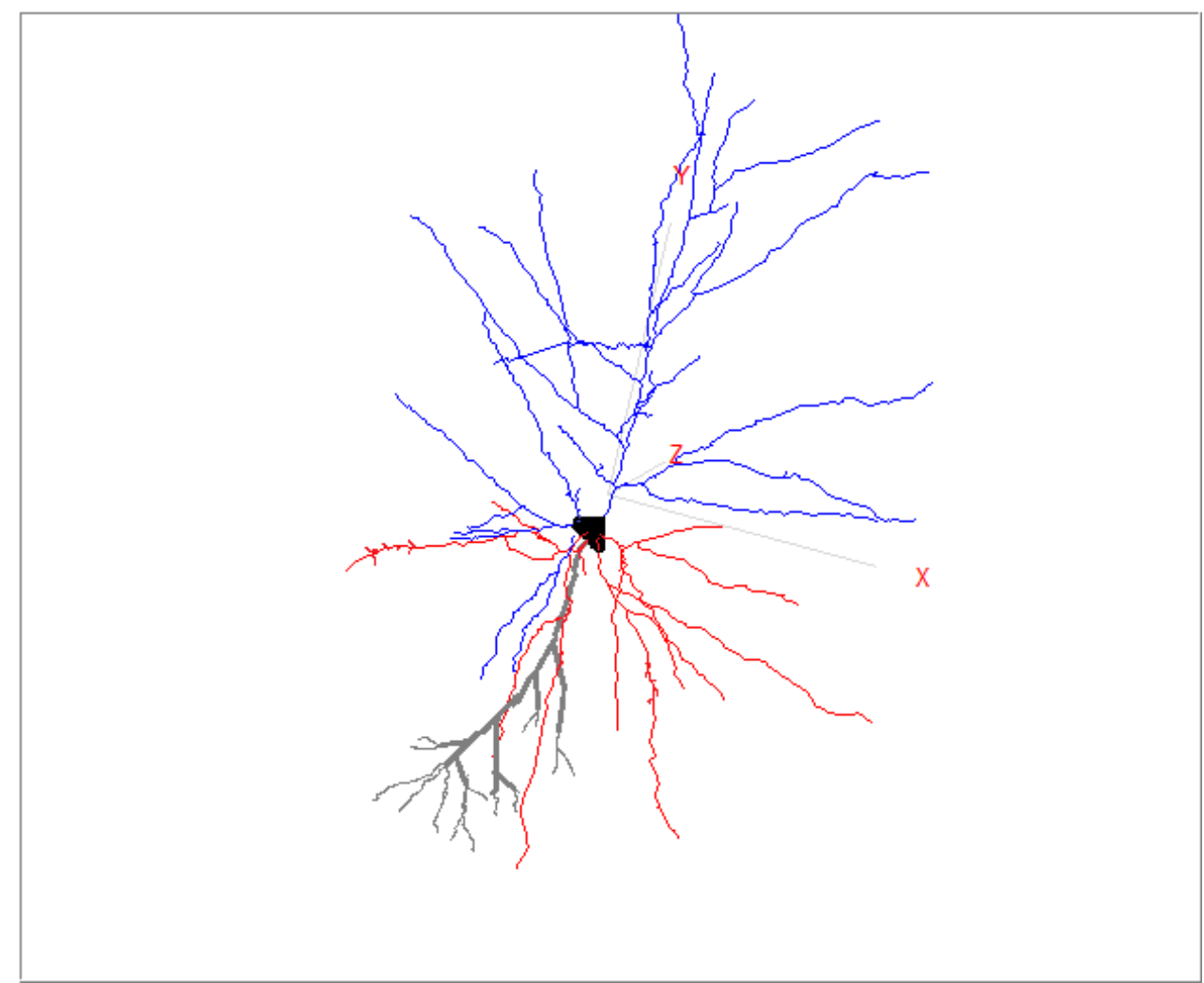

Figura 2.6 - Neurônio piramidal. Na cor vermelha temos os dendritos basais e azul os dendritos apicais. O axônio está na cor cinza.

\subsubsection{Função}

Quanto à função, temos os neurônios motores, interneurônios e sensitivos. Os neurônios motores transmitem sinais sinápticos. Já os interneurônios têm a função de estabelecer conexões entre os neurônios. Os neurônios sensitivos têm a função de receber os sinais exteriores 
e retransmiti-los até o sistema nervoso central.

\subsubsection{Tamanho ou ausência de axônios}

As células com axônio longo são do tipo Golgi I e as com axônio curto ou sem axônio são do tipo Golgi II. As do tipo Golgi I são responsáveis pela conexão entre diferentes regiões do cérebro ou da medula até os órgãos efetores. Como exemplo, temos as células piramidais. No cérebro dos animais mais desenvolvidos, as células Golgi II apresentam maior concentração que as células Golgi I (6). Estas células (Golgi II) não se interconectam com outras regiões, realizando somente interações locais em pequenas regiões.

\subsection{Forma e função neuronal}

Quanto a variação morfológica, alguns neurônios podem possuir arborescências axonais e dendríticas relativamente complexas se comparadas com outras células do sistema nervoso. A eletrofisiologia, através da inclusão de eletrodos e marcadores em neurônios particulares, permitiram relacionar a forma com a função celular. Anatomias do sistema nervoso de animais simples apresentam pouca variabilidade no formato de suas células. Isto mostra que à medida que aumenta a complexidade do animal, surge a necessidade de um maior número de conexões, ocorrendo também uma grande variabilidade dendrítica e axonal $(6,12)$. As diferenças morfológicas em animais de diferentes tamanhos e formas têm uma variedade de implicações funcionais. O aumento da variação dendrítica permite entradas de uma maior quantidade de neurônios pré-sinápticos, interagindo também com uma maior quantidade de unidades neuronais, ampliando as suas características funcionais (13).

\subsection{A base neuromorpho e medidas de morfologia de neurônios}

O repositório neuromorpho.org é a maior base de neurônios digitalizados e disponíveis eletronicamente. Até 26 de outubro de 2013 possuía 9936 células neuronais digitalizadas. O gráfico da fig. 2.7 mostra o crescimento da base desde a primeira versão. A base pode 
ser consultada por tipo de neurônio, região, espécie ou também por certas características desejadas (metadados).

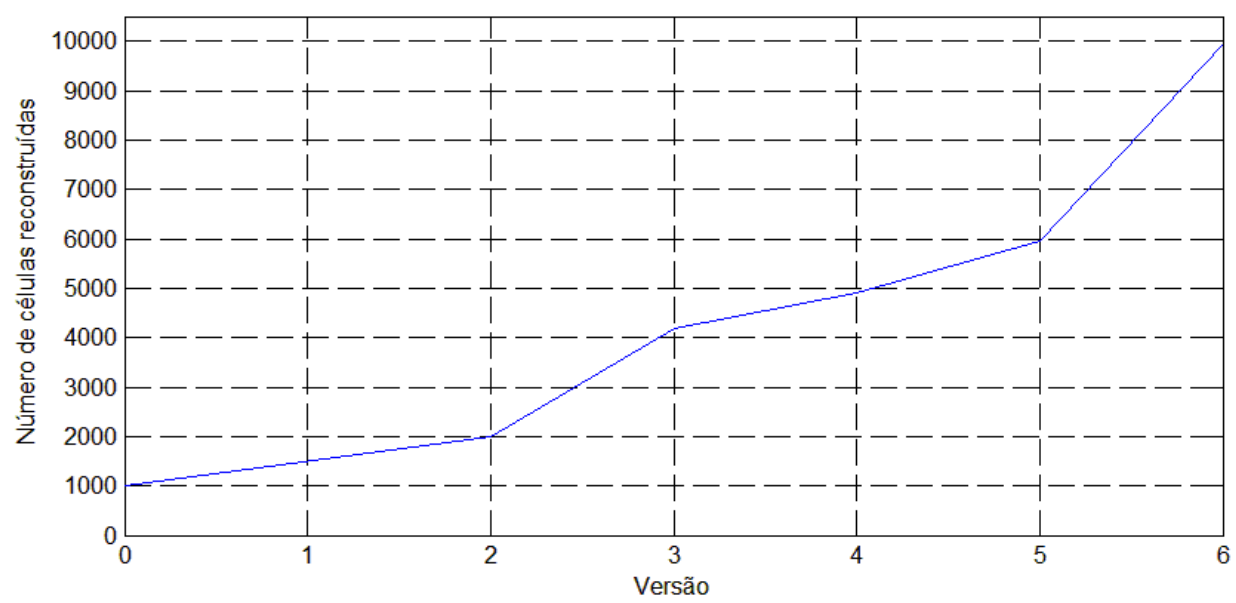

Figura 2.7 - Base neuromorpho. Número de células reconstruídas.

\subsubsection{Notação de traçado swc}

Definida em 1998, por Cannon et alli (14), a notação swc permite a reconstrução tridimensional de células neuronais laminadas. Ao laminar a célula são anotadas as informações tridimensionais necessárias para uma reconstrução digital. Nesta notação, um neurônio é representado, simplificadamente, pela combinação de duas figuras geométricas tridimensionais: cilindro e esfera. A esfera representa o soma, enquanto os cilindros justapostos representam os dendritos ou axônios.

A fig. 2.8 mostra um arquivo texto contendo as informações da notação swc. Estes arquivos vem geralmente com um cabeçalho, cujas linhas são identificadas pelo caractere ' $\sharp$ ', com informações gerais como notação de traçado original, autor, tipo de animal, idade, sexo, etc. Após o cabeçalho, as linhas definem a distribuição espacial do neurônio através dos seguintes atributos: Ponto, Tipo, $x, y, z$, Raio, Anterior. Cada um dos atributos é definido abaixo:

- Ponto: um número sequencial, que identifica os demais atributos;

- Tipo : indica se é um ponto de soma, de axônio, dendrito basal ou apical, conforme a tab. 2.1; 
- $x, y, z$ : eixos das coordenadas no espaço tridimensional;

- Raio: raio final de um segmento ou raio do soma;

- Anterior: identifica o ponto anterior (inicial) do segmento;

Tabela 2.1 - Definição pontos na notação swc.

\begin{tabular}{cc}
\hline Tipo & Descrição \\
\hline 0 & Indefinido \\
1 & Soma \\
2 & Axônio \\
3 & Dendrito Basal \\
4 & Dendrito Apical \\
\hline
\end{tabular}

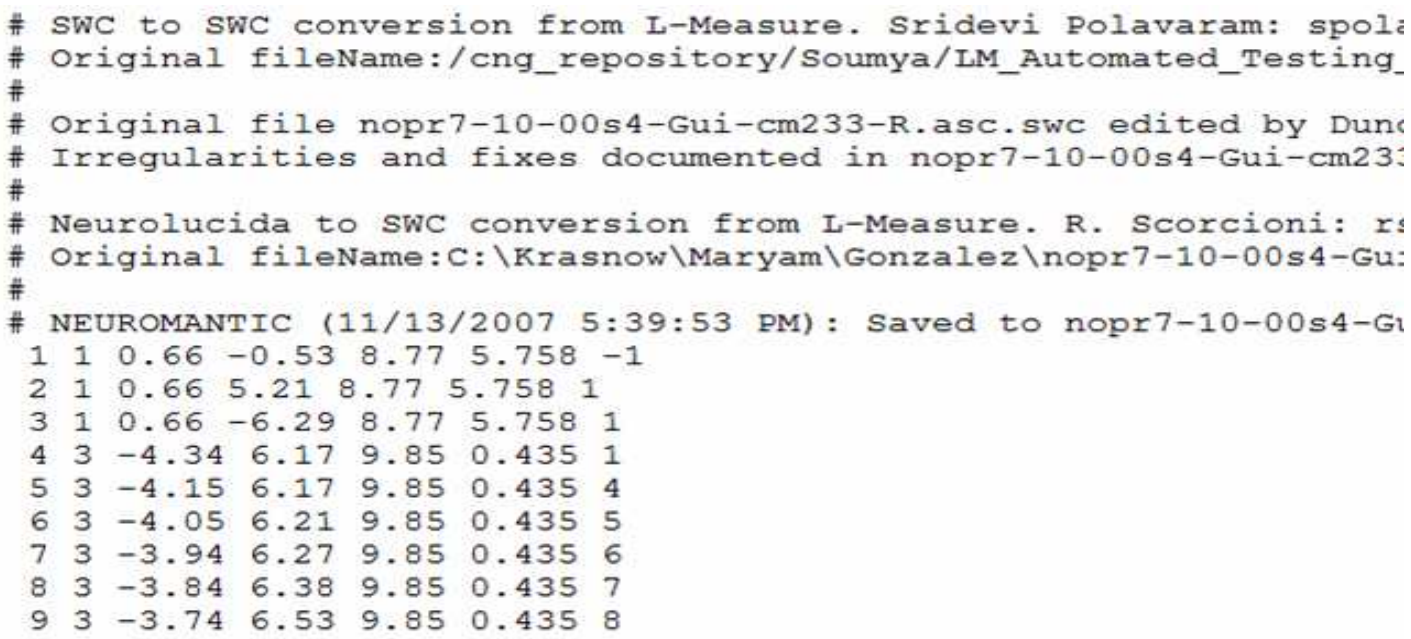

Figura 2.8 - Arquivo em notação swc.

As definições espaciais começam com os dados do soma, no Ponto 1. O próximo valor 1 identifica que este é um ponto de soma, seguido pelas coordenadas do centro do soma $x_{s}, y_{s}, z_{s}$, o raio $r_{s}$ do soma seguido do valor -1 indicando que não há ponto anterior. $\mathrm{A}$ seguir, o texto segue com mais dois pontos de soma, sendo que o Ponto 2 corresponde aos pontos $\left(x_{s}, y_{s}-r_{s}, z_{s}\right)$, a parte de baixo do soma. O Ponto 3 corresponde aos pontos $\left(x_{s}, y_{s}+r_{s}, z_{s}\right)$, a parte de cima do soma. Em ambos os pontos a identificação do ponto anterior é 1, o ponto central do soma. A fig. 2.9 ilustra esses três pontos iniciais. Da quarta linha em diante vem as definições dos segmentos dendrítricos ou axonais. Cada segmento é representado como um cilíndro, onde seu final é representado pelas coordenadas dos eixos $x, y, z$ e a sua origem são as coordenadas do ponto identificado como anterior.

Os demais pontos descrevem os segmentos dos neuritos, conforme ilustra a fig. 2.10. Cada linha ou ponto no arquivo guarda o ponto final do segmento. O ponto inicial corresponde às coordenadas definidas no ponto anterior. 


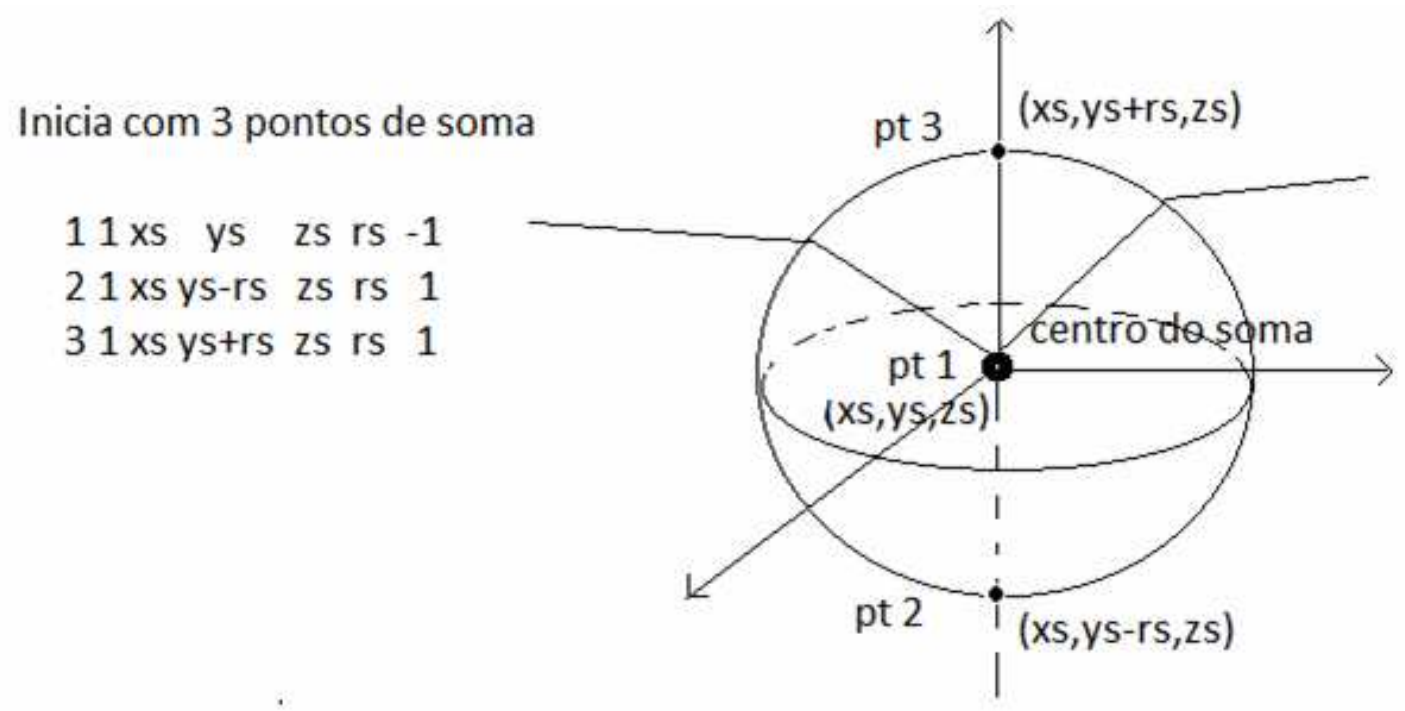

Figura 2.9 - Descrição do soma em swc.

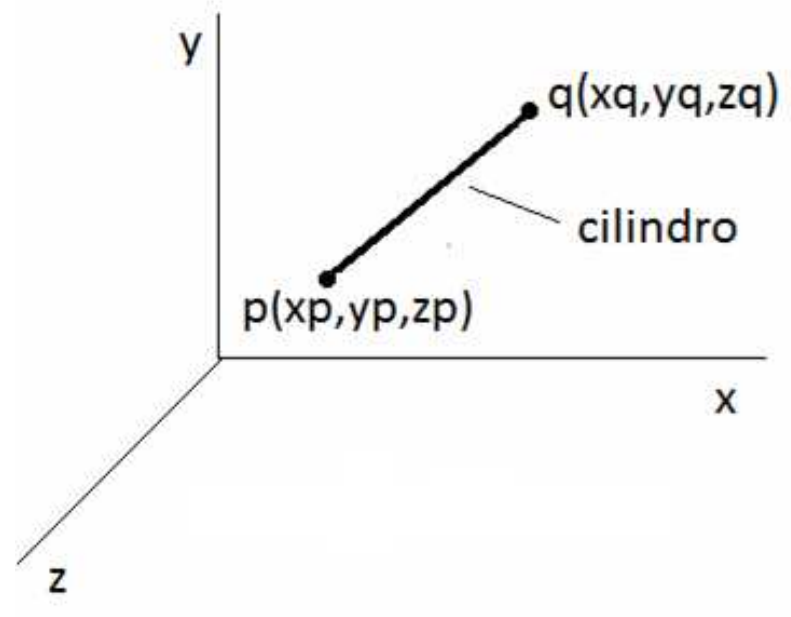
Ponto Tipo $x$ y $z$ raio ant
p tipop хр ур zp rp antp
q tipoq xq yq zq rq $p$

Figura 2.10 - Segmento em traçado swc. 
Como a base neuromorpho recebe contribuições de diferentes laboratórios e colaboradores, algumas notações mais antigas não utilizavam a sequencia de 3 linhas para definir o soma. Em muitos arquivos é definido simplesmente o centro do soma e o raio, e em outros são definidos todo o contorno do soma não como esfera mas como uma composição de cilíndros. Algumas notações ainda contém erros de notação como definir um neurito como sendo do tipo soma, entre outros. Nos dados fornecidos inicialmente pelo repositório de Cannon * era comum encontrar o tipo -1 , significando que o pesquisador ao laminar não conseguiu identificar o tipo do neurito.

\subsubsection{Medidas de morfologia neuronal}

As informações digitalizadas permite que o neurônio seja tratado como um grafo geométrico do tipo árvore (seção 2.5.1), onde cada aresta corresponde a um compartimento, tendo um vértice central correspondendo ao soma, partindo daí várias sub-árvores, conforme ilustra a fig. 2.11, onde as cores iguais representam ramos de mesma ordem, podendos estes ramos serem de axônios, dendritos basais ou apicais.

A tabela 2.2 mostra os componentes que fazem parte da estrutura neuronal considerada pelo repositório.

Tabela 2.2 - Componentes de um neurônio.

\begin{tabular}{ll}
\hline Componente & Descrição \\
\hline Compartimento & $\begin{array}{l}\text { No arquivo swc é o segmento definido pelo ponto atual e o ponto } \\
\text { anterior. }\end{array}$ \\
Bifurcação & $\begin{array}{l}\text { Ponto onde se originam dois compartimentos. } \\
\text { Ramo }\end{array}$ \\
& $\begin{array}{l}\text { Formado pela junção de vários compartimentos. Seus extremos são } \\
\text { definidos entre pontos de bifurcação ou pelos compartimentos pontas } \\
\text { (pontos terminais). }\end{array}$ \\
Ordem de ramificação & $\begin{array}{l}\text { O soma tem ordem ou nível 0. Todos os ramos partindo do soma tem } \\
\text { ordem 1 seguindo por seu consequente na ordem 2 e assim sucessiva- } \\
\text { mente. }\end{array}$ \\
\hline
\end{tabular}

Dado um conjunto de arquivos swc, podemos classificar estes arquivos através de um conjunto de medidas tais como número de ramificação, ordem média, número de compartimentos, entre outros. O software L-measure, disponível gratuitamente na base neuromorpho dispõe um conjuntos de medidas e funções para que possamos com isso caracterizar as células neuronais. O software produz como saída os valores mínimos, médios e máximos das medidas de cada 


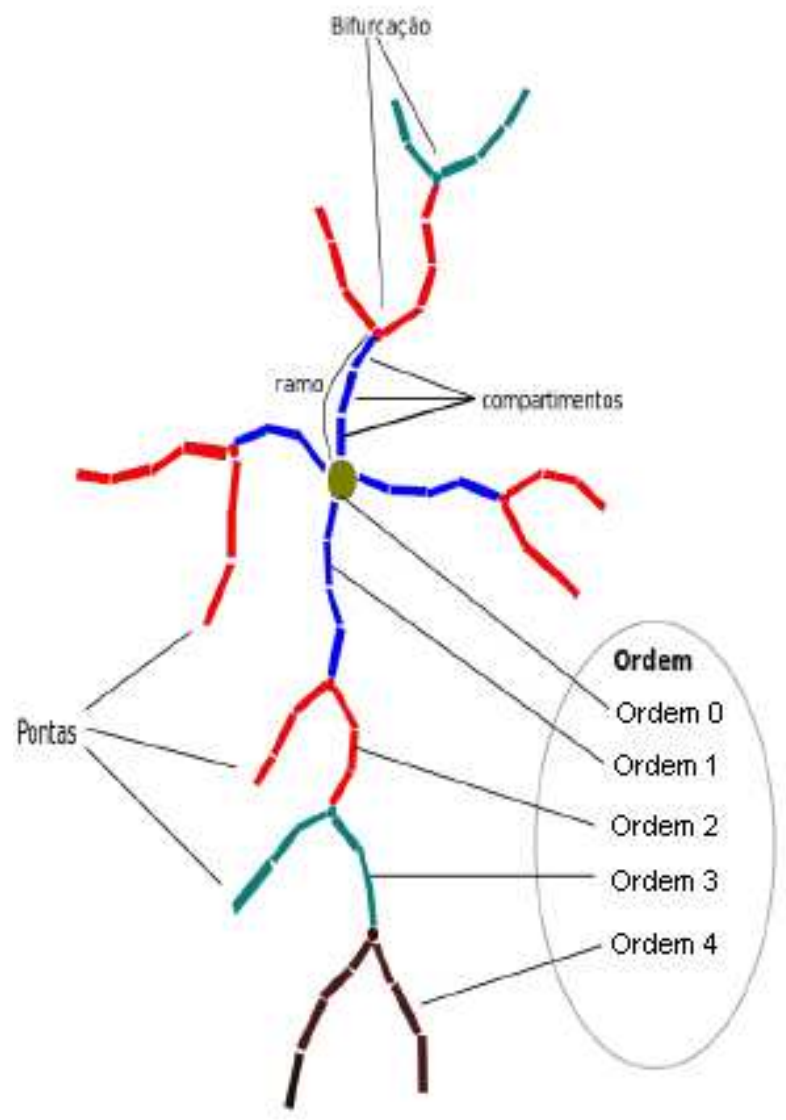

Figura 2.11 - Componentes de um neurônio descritos na base neuromorpho. Os ramos da ordem 1 estão na cor azul, sucedidos pelos ramos da ordem 2, na cor vermelha, ordem 3 na cor verde e assim sucessivamente. 
neurônio, além oferecer uma função de comparação estatística entre grupos de neurônios. Na tab. 2.3, temos as medidas que utilizamos neste trabalho.

Tabela 2.3 - Medidas para caracterização de neurônios.

\begin{tabular}{|c|c|c|}
\hline ID & Medida & Descrição \\
\hline 1 & Height & Altura do neurônio (eixo y). \\
\hline 2 & Width & Largura do neurônio (eixo x). \\
\hline 3 & Depth & Profundidade do neurônio (eixo z). \\
\hline 4 & N_stems & $\begin{array}{l}\text { Número de troncos. Número de ramificações que partem } \\
\text { do soma. }\end{array}$ \\
\hline 5 & N_bifs & Número de bifurcações. \\
\hline 6 & N_Branch & Número de ramos. \\
\hline 7 & Diameter & Diâmetro do compartimento. \\
\hline 8 & Length & Comprimento do compartimento. \\
\hline 9 & Surface & Área da superfície do compartimento. \\
\hline 10 & Volume & Volume do compartimento. \\
\hline 11 & EucDistance & Distância euclidiana entre um compartimento e o soma. \\
\hline 12 & PathDistance & $\begin{array}{l}\text { Distância do caminho. Soma dos tamanhos dos comparti- } \\
\text { mentos entre dois pontos. }\end{array}$ \\
\hline 13 & Contraction & Razão entre distância euclidiana e distância do caminho. \\
\hline 4 & Branch Order & Ordem do ramo. \\
\hline 15 & Fragmentation & Número de compartimentos em um ramo. \\
\hline 16 & Soma_surface & Área da superfície do soma. \\
\hline 17 & Pk_classic & $\begin{array}{l}\text { E a razão entre }\left(d_{1}^{r}+d_{2}^{r}\right) \text { e } b^{r} \text {. Sendo b o diâmetro da } \\
\text { origem da bifurcação, } d_{1} \text { e } d_{2} \text { são o diâmetro dos dois novos } \\
\text { compartimentos na bifurcação, e } r=1.5 \text { obedecendo lei } \\
\text { de potência de Rall. }\end{array}$ \\
\hline 18 & Partition_assimmetry & $\begin{array}{l}\text { Dada duas sub-árvores com uma mesma ordem, sendo } n 1 \text { o } \\
\text { número de pontas da árvore à direita e } n 2 \text { as pontas da ár- } \\
\text { vore à esquerda, a assimetria é definida como } \frac{|n 1-n 2|}{}\end{array}$ \\
\hline 19 & Bif_ampl_local & $\begin{array}{l}n 1+n 2-2 \\
\text { Ângulo entre dois compartimentos em uma bifurcação. }\end{array}$ \\
\hline 20 & Bif_ampl_remote & Ângulo entre dois ramos numa bifurcação. \\
\hline 21 & Dimensão Fractal & Razão entre $\frac{\log (\text { Distância euclidiana })}{\log (\text { distância do caminho })}$ \\
\hline
\end{tabular}




\subsection{Análise de dados}

Seja $X=\left[x_{1}, x_{2}, \ldots, x_{p}\right]$ um vetor de $p$ variáveis aleatórias, onde $x_{i}=\left[\begin{array}{c}x_{i 1} \\ x_{i 2} \\ \vdots \\ x_{i n}\end{array}\right]$

Define-se a média $\mu_{i}$ de uma variável aleatória $x_{i}$ como

$$
\mu_{i}=\frac{1}{n} \sum_{k=1}^{n} x_{i k}
$$

A variância é a média dos desvios quadrados em relação à média (dispersão) de $x_{i}$, sendo

$$
\sigma^{2}=\frac{1}{n} \sum_{k=1}^{n}\left(x_{i k}-\mu_{i}\right)^{2}
$$

A média dos desvios em relação à média (desvio médio) é o desvio padrão $\sigma$, a raiz quadrada positiva da variância. A covariância entre duas variáveis $x_{i}$ e $x_{j}$ indica o quanto as duas variáveis variam conjuntamente, podendo ser positiva, negativa, ou 0 . A covariância é definida como

$$
\sigma_{i j}=\frac{1}{n} \sum\left(x_{i}-\mu_{i}\right)\left(x_{j}-m u_{j}\right)
$$

O coeficiente de correlação serve para medir o grau de dependência linear entre duas variáveis aleatórias. Uma das medidas mais comuns utilizadas é o coeficiente de correlação de Pearson $c_{i j}(15)$, onde esse coeficiente é independente das unidades de medidas de cada variável, variando então entre -1 a 1 . Estatísticamente, valores entre -0.5 a 0.5 são pouco correlacionados.

$$
c_{i j}=\frac{\sigma_{i j}}{\sigma_{i} \sigma_{j}}
$$

Em uma matriz de correlação de $X$, cada elemento da linha $i$ e coluna $j$ corresponde a correlação entre as variáveis aleatórias $x_{i}$ e $x_{j}$. Se $X$ tem $p$ variáveis aleatórias teremos uma matriz quadrada $C_{p x p}$. Assim,

$$
C=\left[\begin{array}{cccc}
1 & r_{12} & \ldots & r_{1 p} \\
r_{21} & 1 & \ldots & r_{2 p} \\
\vdots & \vdots & \ddots & \vdots \\
r_{p 1} & \ldots & \ldots & 1
\end{array}\right]
$$


$C$ é uma matriz simétrica e os elementos de sua diagonal, $c_{i i}$, é sempre 1 . Nesta tese, quando usamos o termo correlação estamos tratando do coeficiente de correlação de Pearson.

\subsection{Redes complexas e medidas de topologia de redes}

Dado um conjunto de elementos, uma rede é uma representação das relações existentes entre os pares de elementos desse conjunto (16). Aos elementos damos o nome de nós ou vértices e às relações damos o nome de ligações. As ligações podem ser unilaterais, quando a relação é de um elemento origem para um destino, como no caso de um artigo citar um ou mais artigos, ou recíproca, como no caso de uma relação de amizade. Relações unilaterais, são também denominadas ligações direcionadas.

A Teoria de redes complexas(17) trata do estudo de redes com uma grande quantidade de vértices e sua variação estrutural no decorrer do tempo, envolvendo diferentes abordagens. A análise de estruturas sociais, de informação, biológicas ou tecnológicas além da dinâmica das mesmas, podem ser abordados com redes complexas. É, portanto, uma escolha natural para representação e modelagem de vários sistemas complexos biológicos tais como redes neuronais (18), neoplasia de células cancerosas (19) ou disseminação de doenças em um rebanho. Numa rede neuronal, cada neurônio corresponde a um vértice, enquanto as sinapses são as suas respectivas ligações. Uma rede neuronal formadas por neurônios de uma determinada classe, pode ser mais ou menos ativa na propagação de sinapses do que redes com neurônios de outro tipo. O tratamento para evitar o espalhamento de uma doença em um rebanho envolve a compreensão de como a espécie em estudo se comporta, bem como a sua distribuição no espaço geográfico. O processo de neoplasia de tumores cancerosos, seu surgimento em diferente lugares do corpo, bem como a morte de um tumor, são exemplos de rede dinâmicas, onde nesse caso, o tumor seria um vértice ou um grupo de vértices (19). Enfim, o mundo é dinâmico e conectado. Novas epidemias surgem e desaparecem, permanecendo em estado de hibernação como o caso do vírus Ebola, para depois manifestarem-se novamente. Nas redes sociais, a cada momento novas relações de amizade ou de colaboração são feitas ou desfeitas.

Embora estas estruturas estejam sendo estudadas a um bom tempo, despontaram em 1999, quando pesquisadores como Barabási e Albert, Watts e Strogatz publicaram seus trabalhos.

A teoria de redes complexas utiliza tanto dos conceitos da Teoria dos grafos bem como conceitos provindos de analogias relacionadas com teoria de sistemas dinâmicos tais como percolação e difusão (20). Doravante, utilizaremos o termo rede no lugar de rede complexa. 
Na seção 2.5.1, abordaremos os conceitos básicos para caracterização de uma rede, envolvendo métricas e medidas. Na seção 2.5.2, trataremos de alguns tipos de rede utilizadas, bem como alguns modelos reais. A ênfase será dada nos modelos biológicos, em especial o modelo integra e dispara, modelo que será utilizado para investigação das redes neuronais, objeto de nosso estudo.

\subsubsection{Grafos}

Um grafo é uma abstração de uma rede, onde não estamos preocupados se a ligação corresponde à amizade, ódio, colaboração ou qualquer outra denominação. A teoria dos grafos é um ramo da ciência que estuda as características topológicas das redes (21).

Define-se grafo como uma tupla $G=(V, E)$, onde $V$ é o conjunto de $n$ vértices ou nós e $E$ é o conjunto de $m$ arestas ou ligações. Dado dois vértices $i$ e $j$ distintos, uma aresta é representada por $\{i, j\}$ se existe uma ligação ou relação recíproca entre estes dois vértices. Quando não há reciprocidade, isto é, temos uma relação somente de $i$ para $j$, representamos por $(i, j)$. As arestas não recíprocas são denotadas por arcos, e um grafos com arco são denotado por digrafo ou grafo orientado.

Representamos visualmente um grafo através de um diagrama onde o vértice pode ser um ponto, círculo ou qualquer outra figura geométrica que seja adequado ao modelo estudado. As arestas são representadas como uma linha ligando os dois vértices. No caso de um arco, usamos uma linha partindo de um vértice origem $i$ com uma seta apontando para o vértice destino $j$. A fig. 2.12(a) representa um grafo e a fig. 2.13(a) representa um digrafo. Quando usarmos o termo grafo estamos nos referindo a um grafo não orientado.

Uma estrutura para representar um grafo é a matriz de adjacência. É uma matriz quadrada de ordem $n$ tal que :

$$
a_{i j}= \begin{cases}1, & \text { se existe }(j, i) \\ 0, & \text { caso contrário }\end{cases}
$$

Em um grafo a matriz de adjacência é simétrica. Devido à matriz de adjacência frequentemente apresentar a característica de matriz esparsa, um modo econômico computacionalmente de representar grafos é a estrutura de listas ligadas, onde cada vértice tem o conjunto vértices para a qual apontam seus arcos ou arestas (18).

Pode-se associar valores nas arestas de um grafo, sendo denominados de pesos ou cus- 


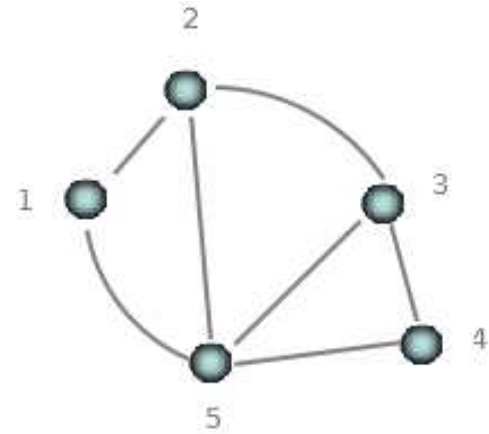

(a)

$$
A=\left[\begin{array}{lllll}
0 & 1 & 0 & 0 & 1 \\
1 & 0 & 1 & 0 & 1 \\
0 & 1 & 0 & 1 & 1 \\
0 & 0 & 1 & 0 & 1 \\
1 & 1 & 1 & 1 & 0
\end{array}\right]
$$

(b)

Figura 2.12 - Grafo: (a) diagrama representativo; (b) matriz de adjacência.

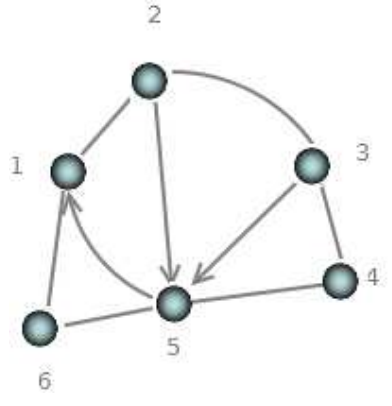

(a)

$$
A=\left[\begin{array}{llllll}
0 & 1 & 0 & 0 & 1 & 1 \\
1 & 0 & 1 & 0 & 0 & 0 \\
0 & 1 & 0 & 1 & 0 & 0 \\
0 & 0 & 1 & 0 & 1 & 0 \\
0 & 1 & 1 & 1 & 0 & 1 \\
1 & 0 & 0 & 0 & 1 & 0
\end{array}\right]
$$

(b)

Figura 2.13 - Digrafo:(a) diagrama representativo ;(b)matriz de adjacência. 
tos(fig. 2.14(a)). Um exemplo seria uma matriz representando a distância entre cidades. As cidades que não fossem adjacentes teriam o valor $\infty$. Representa-se um grafo de custos por uma matriz quadrada de ordem $n$ tal que:

$$
w_{i j}=\left\{\begin{array}{cl}
v \in \Re, & \text { se existe }(j, i) \\
\infty, & \text { caso contrário }
\end{array}\right.
$$

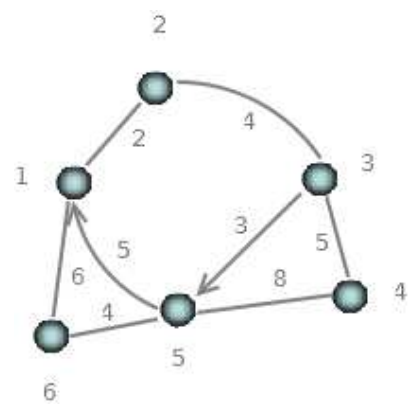

(a)

$$
W=\left[\begin{array}{cccccc}
0 & 2 & \infty & \infty & 5 & 6 \\
2 & 0 & 4 & \infty & \infty & \infty \\
\infty & 4 & 0 & 5 & \infty & \infty \\
\infty & \infty & 5 & 0 & 8 & \infty \\
\infty & \infty & 3 & 8 & 0 & 4 \\
6 & \infty & \infty & \infty & 4 & 0
\end{array}\right]
$$

Figura 2.14 - Grafo de custos: (a) diagrama representativo;(b) matriz de custos.

Os grafos, digrafos e grafo de custos, são mostradas nas fig. 2.12(a), fig. 2.13(a) e fig. 2.14(a), ao lado de suas matrizes correspondentes.

Dado um vértice $i$ de um digrafo, denota-se por grau de entrada $k_{i}^{i n}$ ao número de arestas que incidem em $i$ e por grau de saída $k_{i}^{\text {out }}$ ao número de arestas que saem de $i$. Em um grafo $k_{i}^{\text {in }}=k_{i}^{\text {out }}$ e denotamos apenas por $k_{i}$.

Um grafo é dito regular se todos os vértices tem o mesmo grau.

Em um digrafo, o grau total de um vértice $i$ é $k_{i}=k_{i}^{i n}+k_{i}^{\text {out }}$. No caso de um grafo, $k_{i}=\sum_{j} A_{i j}=\sum_{j} A_{j i}$ e $\sum_{i} \sum_{j} A_{i j}=2 m$. Define-se grau médio ou conectividade do grafo como

$$
\langle k\rangle=\frac{1}{n} \sum_{i, j}^{n} A_{i j}=\frac{2 m}{n} .
$$

O grau médio de entrada e de saída de um digrafo é o mesmo, pois para cada aresta que sai de um vértice, temos a mesma entrando em outro vértice.

Em um grafo, o número máximo de arestas possíveis é $\frac{n(n-1)}{2}$, pois de cada vértice podem partir no máximo $n-1$ arestas, mas cada aresta é a combinação de dois vértices. Já em um digrafo, o número máximo de arestas é $n(n-1)$.

Um grafo é completo se todos os seu vértices tem grau $n-1$, ou seja, cada vértice relaciona-se com todos os outros $n-1$ vértices restantes. 

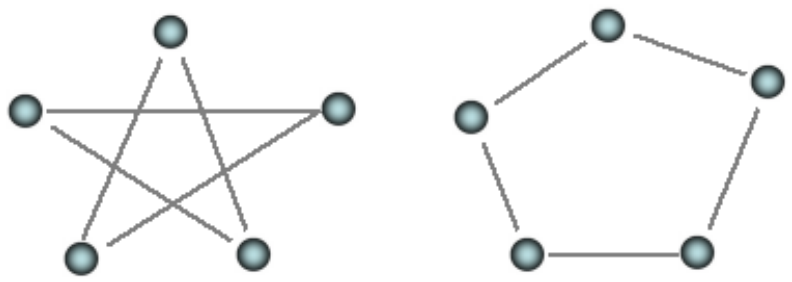

Figura 2.15 - Dois grafos regulares de graus 2

Dois grafos $G=\left(V_{G}, E_{G}\right)$ e $H=\left(V_{H}, E_{H}\right)$ são isomorfos se para cada vértice $u \in V_{G}$ temos um único vértice $u^{\prime} \in V_{H}$, e para cada aresta $e_{G} \in E_{G}$ temos uma aresta $e^{\prime} \in E_{H}$ tal que se $e_{G}=\{u, v\}$ então $e^{\prime}=\left\{u^{\prime}, v^{\prime}\right\}$. Isto é, existem bijeções entre vértices e arestas de $G$ com $H$. $G$ e $H$ tem a mesma estrutura, mas diferem nos rótulos dos vértices e arestas. Na fig. 2.16, temos um exemplo, onde sua forma e seus vértices são diferentes. Quando somente a representação visual é diferente tais grafos são idênticos, conforme ilustrado na fig. 2.18 .
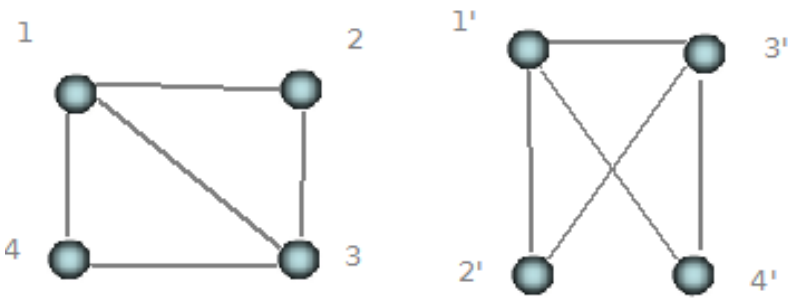

Figura 2.16 - Dois grafos isomorfos

Dado um grafo $G=(V, E)$, um subgrafo de $G$ é um grafo $G^{\prime}=\left(V^{\prime}, E^{\prime}\right)$ onde $V^{\prime} \subset V$, e $E^{\prime} \subset E$ (Fig2.17). Diz-se ainda que $G$ é um super grafo de $G^{\prime}$.

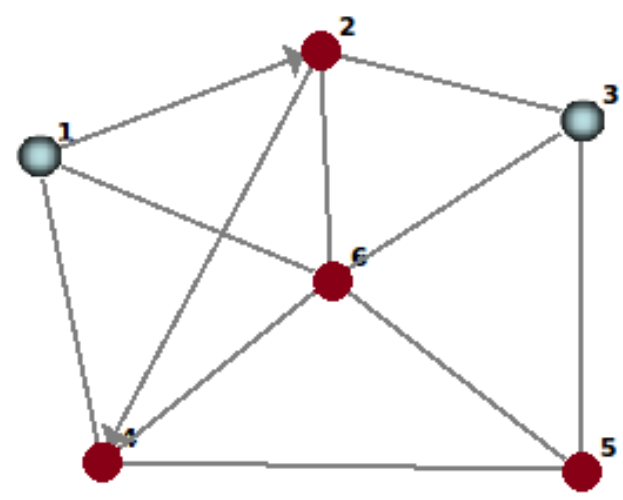

(a) Grafo G

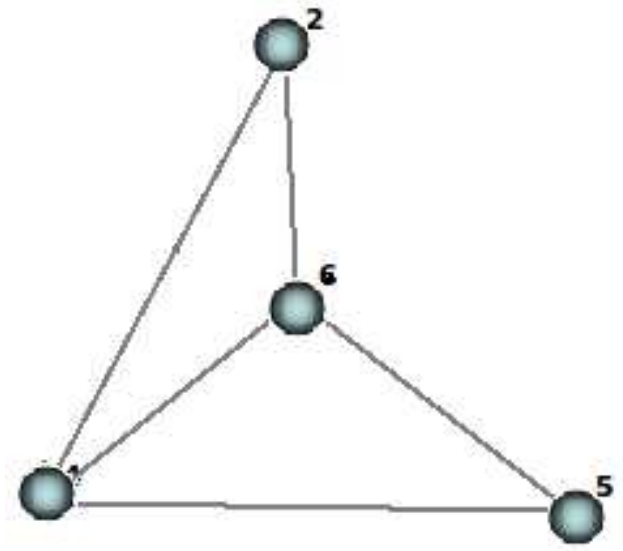

(b) Subgrafo de G

Figura 2.17 - Grafo e subgrafo. 
Um grafo é bipartido se é possível separar os vértices em duas classes e todas as ligações só ocorrem entre vértices de classes distintas. Considere uma agência de casamentos, composta de candidatos e candidatas. Nem todos os casais são compatíveis, mas podem ser representados por uma rede onde os casais seriam os vértices e as ligações entre estes a compatibilidade. A fig. 2.18 mostra um mesmo grafo bipartido representado por diagramas diferentes.

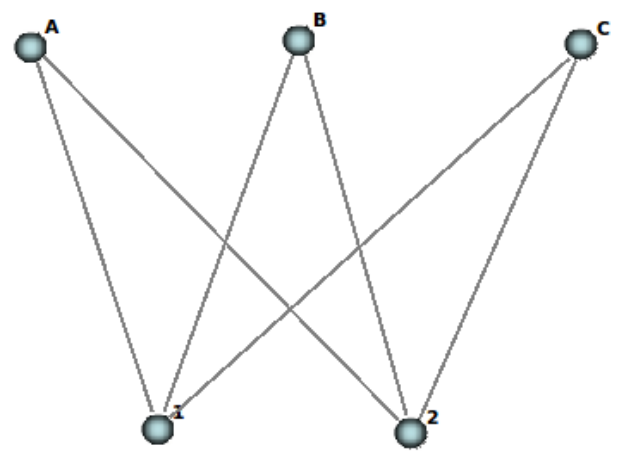

(a)

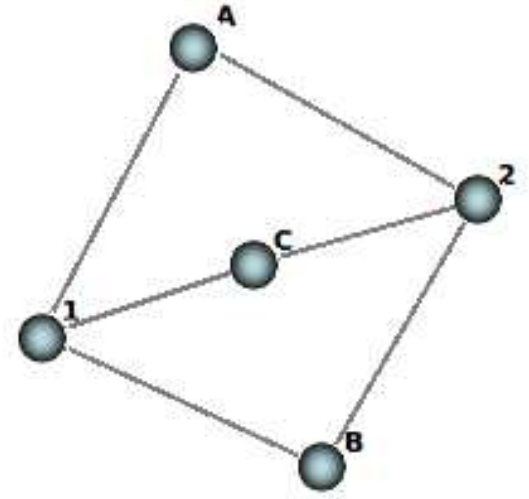

(b)

Figura 2.18 - Um mesmo grafo bipartido representado em diagramas espacialmente distintos.

Em uma rede representando uma grande comunidade de pessoas pode-se usar um tipo especial de ligação para relacionar laços familiares ou associações. Nessa comunidade, uma pessoa pode pertencer à família $F$, e também pertencer ao clube $C$ e também torcer para o time $T$. Assim, podemos ter conjuntos com intersecções entre os mesmos dentro dessa comunidade, já que nem todos pertencem a mesma família e nem torcem para o mesmo time. Ao grafo compatível para abstrair este tipo de rede é chamado de hiper grafo e a ligação entre cada subconjunto de vértices, denotamos por hiper aresta. A fig. 2.19(a) mostra um hiper grafo, separado em quatro diferentes grupos através de hiper arestas. A fig. 2.19(b), um grafo bipartido representa os grupos através dos quatro vértices abertos. Em um hiper grafo, o número de vértices da rede é mantido. Diferentemente, para representar esta mesma rede através de um grafo bipartido, teríamos que adicionar vértices para representar os grupos.

Um percurso ou passeio em um grafo é uma sequência de vértices $W=v_{1}, v_{2}, \ldots, v_{k}$, não necessariamente distintos, onde sempre existe uma aresta $\left(v_{i}, v_{i+1}\right)$. Um caminho $P=$ 


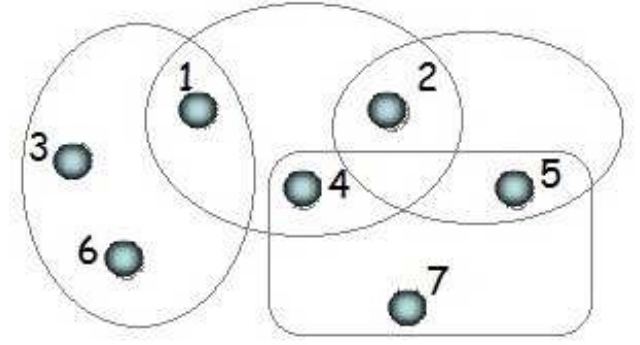

(a)

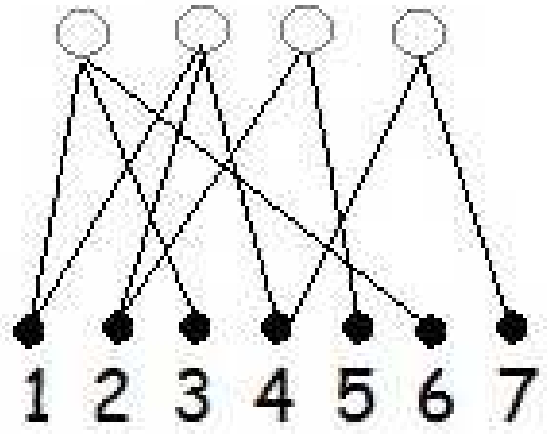

(b)

Figura 2.19 - Hiper grafo (a) e representação através de bipartição (b).

$v_{1}, v_{2}, \ldots, v_{k}$ é um percurso com vértices distintos. Um sequência $T=e_{1}, e_{2}, \ldots, e_{k}$ de arestas distintas denotamos por trilha (21). O tamanho de um percurso, caminho ou trilha com $k$ vértices é $|S|=k-1$, o número de arestas na sequência. Um percurso fechado é aquele percurso cujo vértice inicial é o mesmo que o final. Um percurso fechado onde somente o vértice inicial é igual ao final, é denominado circuito ou caminho fechado.

Um grafo é conexo se existe um caminho de qualquer vértice a outro. Um conjunto de componentes $C=\left\{C_{1}, C_{2}, \ldots, C_{c}\right\}$ particiona um grafo $G$ onde cada $C_{i}$ é um subgrafo de $\mathrm{G}$ que é conexo com o número máximo de vértices e arestas possível, sendo $V_{C_{1}} \cup V_{C_{2}} \cup \ldots \cup V_{C_{c}}=$ $V$, e $C_{i} \cap C_{j}=\emptyset$. Isto é, as arestas e vértices de um componente $C_{i}$ não pertencem a um outro componente $C_{j}$ (fig. 2.20).

Um digrafo é dito fracamente conexo se ao aplicarmos reciprocidade em todas as suas arestas obtivermos um grafo conexo. Geralmente, redes orientadas são fracamente conexas, sendo compostas de vários componentes (subgrafos conexos).

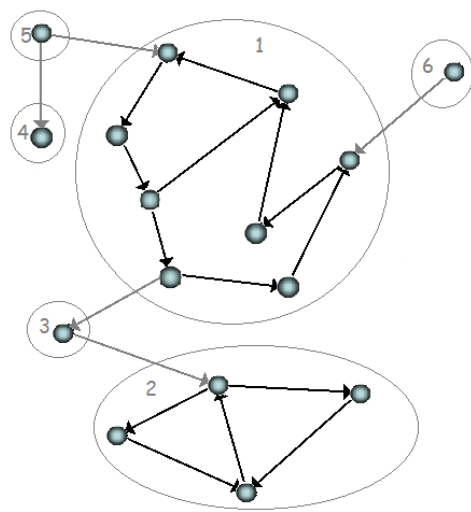

Figura 2.20 - Componentes conexos. Grafo com 6 componentes. Cada é um subgrafo conexo. 
Um grafo conexo que não possui ciclos é chamado de árvore, sendo os seus vértices de grau 1 denominado de folhas. Uma subárvore de um grafo $G$ é um subgrafo de $G$ que não contém ciclos. Uma árvore geradora de $G$ é uma subárvore que contém todos os vértices de G. A fig. 2.21 mostra um grafo, à esquerda, seguido de duas das onze árvores geradoras possíveis para esse grafo.

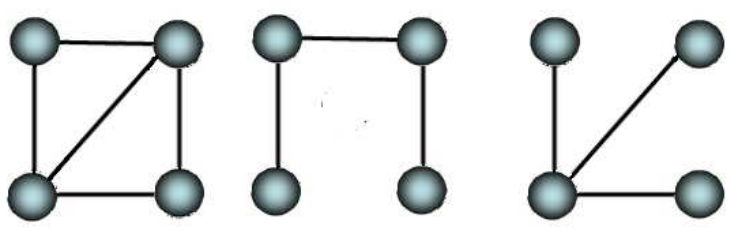

Figura 2.21 - Grafo e árvores geradoras.

A Teoria dos Grafos dispõe de diversas medidas para caracterizar a topologia de uma rede. Atualmente, devido ao avanço das pesquisas no campo de redes complexas, autores provenientes de diversas áreas contribuem com novas propostas de medidas e métricas a serem aplicadas nos modelos de redes. Tais medidas podem nos informar quão densa é uma rede, ou quais são os vértices mais importantes para um determinado modelo estudado. A seguir, veremos algumas das principais medidas.

Define-se a densidade de um grafo como sendo a razão entre o número de arestas existentes e o número máximo de arestas possível, sendo

$$
\rho=\frac{2 m}{n(n-1)}=\frac{\langle k\rangle}{n-1},
$$

para grafo, e

$$
\rho=\frac{m}{n(n-1)}
$$

para um digrafo. Esta medida mostra o quanto os vértices estão ligados entre si. Grandes redes podem ser suficientemente densas que podem ser aproximadas por $\rho=\frac{\langle k\rangle}{n}$.

Sendo $P(k)$ a probabilidade ou frequência de um grau $k$, definimos

$$
H=-\sum_{k=k_{\min }}^{k_{\max }} P(k) \log _{2} P(k),
$$

como a homogeneidade da distribuição da rede, ou entropia. Quanto mais homogênea a distribuição, menor o valor de $H$. Assim, em um grafo regular a entropia é 0 . Tal medida relaciona-se com a resistência de uma rede à falhas em seus vértices.

Se $A_{i k} A_{k j}=1$, então existe um caminho de $j$ para $i$, passando por $k$, passando pelas arestas $\{k, j\}$ e $\{i, k\}$, tendo um caminho de tamanho 2 . Assim, o número total de caminhos 
de tamanho 2 de $j$ para $i$, via outros vértices é

$$
N_{i j}^{(2)}=\sum_{k=1}^{n} A_{i k} A_{k j}=\left[A^{2}\right]_{i j} .
$$

Logo, para um caminho de tamanho $r$, temos

$$
N_{i j}^{(r)}=\left[A^{r}\right]_{i j}
$$

Ao caminho de menor tamanho entre um vértice $i$ e outro $j$ denota-se por distância geodésica $l_{i j}$. Ou seja, é o menor valor de $r$ tal que $N_{i j}^{(r)}>0$. Em grafo conexo, o maior valor possível de $r$ é $n-1$.

A excentricidade de um vértice $i$ é

$$
\epsilon_{i}=\max \left\{{ }_{j \in V} l_{i j}\right\}
$$

a distância geodésica de $i$ ao seu vizinho mais distante.

O raio de um grafo é definido como Um caminho hamiltoniano é um caminho que passa por todos os vértices de um grafo. Um grafo que possui um circuito que passe por todos os vértices do grafo é um grafo hamiltoniano.

Uma trilha fechada é uma trilha que começa e termina no mesmo vértice. Uma trilha que passa por todas arestas do grafo é uma trilha euleriana. Um circuito euleriano é uma trilha euleriana fechada. Um grafo que possui um circuito euleriano é um grafo euleriano (21). Um circuito euleriano não repete arestas, mas pode repetir vértices.

$$
R a=\min \left\{{ }_{i \in V} \epsilon_{i}\right\},
$$

a menor excentricidade de todos os vértices do grafo.

O diâmetro de um grafo é a maior distância geodésica entre qualquer par de vértices. Isto é,

$$
D m=\max \left\{{ }_{i, j \in V} l_{i j}\right\} .
$$

O coeficiente de correlação de Pearson mede grau de similaridade entre os vértices. Dada a matriz de adjacência $A$, o grau de similaridade entre os vértices $i$ e $j$ é dado por

$$
r_{i j}=\frac{\operatorname{cov}\left(A_{i}, A_{j}\right)}{\sigma_{i} \sigma_{j}} \text { sendo } k_{i}>1 \text {, }
$$

onde $A_{i}$ corresponde à linha $i$ da matriz de adjacências, e $\sigma_{i}$ é o desvio padrão da linha $i$. 
Centralidade de vértice visa medir qual é o vértice mais importante, o vértice mais central, aquele que se fosse eliminado causaria o maior dano a rede. Diferentes medidas são utilizados de acordo com os objetivos da análise.

A centralidade de autovetor serve para identificar o vértice que está ligado à maior parte dos nós de altos graus. Sendo $\lambda_{m} \circ$ maior autovalor da matriz de adjacências da rede e $v_{m}=\left(e_{m 1}, e_{m 2}, \ldots, e_{m i}, \ldots, e_{m n}\right)$ seu autovetor associado, o elemento $e_{m i}$ corresponde à centralidade de autovetor do vértice $i$ (20).

Coeficiente de agregação ou aglomeração ((Clustering coefficient) $C a_{i}$ de um vértice $i$ é definido como a razão entre o número de conexões $n b_{i}$ entre os vizinhos de $i$ e o número máximo de conexões possível. Sendo $k_{i}$ o grau do vértice, esse é também o número de vizinhos, $\log 0$

$$
C a_{i}=\frac{2 n b_{i}}{k_{i}\left(k_{i}-1\right)}
$$

Se todos os vizinhos tiverem conectados entre si, $C a_{i}=1$, e se nenhum deles estiverem conectados, $C a_{i}=0$. A ideia provem das redes sociais, onde espera-se os amigos de alguém sejam amigos entre si (20).

O coeficiente de agregação médio de uma rede é dado por:

$$
C a=\frac{1}{n} \sum_{i}^{n} C a_{i} .
$$

A centralidade de proximidade (closeness) $C p_{i}$ é a distância geodésica média entre seus vizinhos sendo:

$$
C p_{i}=\frac{n-1}{\sum_{j} l_{i j}}
$$

Se $C p_{i}$ é pequeno, mais centralizado está este vértice em relação ao número de arestas entre seus vizinhos. Portanto, seria o vértice que mais espalharia uma mensagem mais rapidamente pelos vértices da rede.

O grau de intermediação (betweeness) $B_{i}$ mostra a importância de um vértice $i$ como intermediário de contato entre dois vértices $j$ e $k$. Seja $n(j, i, k)=1$ se existe um caminho de $j$ para $k$, passando por $i$, ou 0 em caso contrário. Assim

$$
B_{i}=\sum_{j k} n(j, i, k)
$$

pode ser visto também como a probabilidade de uma mensagem passar por $i$. Se uma mensagem indo de $j$ para $k$ tem $g_{j k}$ caminhos geodésicos, então a probabilidade de passar pelo vértice é $\frac{g_{j k}}{n(j, i, k)}$. Obviamente, temos o grau de intermediação médio, representado pela 
média de todos os graus.

Provindo da teoria de difusão da física, temos a matriz laplaciana de um grafo (17). É uma matriz tal que:

$$
L_{i j}=\left\{\begin{array}{cc}
k_{i}, & \text { se } i=j \\
-1, & \text { se } i \neq j \text { e } j \text { incide em } i \\
0 &
\end{array}\right.
$$

Desta matriz laplaciana, obtém-se um conjunto de autovalores $\lambda_{0} \leq \lambda 1 \leq \ldots \leq \lambda_{n}$, sendo o $\lambda_{0}$ nulo. $O$ segundo menor autovalor $\lambda_{1}$ é denominado de conectividade algébrica. Quanto maior este valor, maior é a capacidade de espalhamento de uma informação na rede para todos os vértices.

Em um digrafo, a reciprocidade de um vértice $i$ é

$$
R(i)=\frac{\sum_{j \neq i} A_{j i} A_{i j}}{\sum_{j} A_{j i}},
$$

onde $R(i)=1$ se a quantidade de arestas que entram no vértice for igual às que saem.

A reciprocidade de um digrafo é definido como a correlação $R$ da matriz de adjacências do digrafo (22). Sendo

$$
R=\frac{\sum_{i \neq j}\left(A_{i j}-\bar{a}\right)\left(A_{j i}-\bar{a}\right)}{\sum_{i \neq j}\left(A_{i j}-\bar{a}\right)}
$$

e $\bar{a}=\frac{1}{n(n-1)} \sum_{i \neq j} A_{i j}$. Se $R>0$, dizemos que a rede é recíproca ou anti-recíproca em caso contrário.

\subsubsection{Modelos de Redes}

A seguir, abordaremos os três principais modelos de redes complexas mais estudadas. A saber, Redes Aleatórias, Pequeno Mundo, e Livres de Escala. Logo a seguir, veremos alguns exemplos de redes reais, envolvendo redes biológicas, de moléculas, de informação, e de aeroportos. 


\subsubsection{Redes aleatórias}

É um modelo onde as arestas são adicionadas de modo aleatório usando somente uma probabilidade $p$ de ligação. O modelo de grafos aleatórios mais difundido é o proposto por Paul Erdös e seu colaborador Alfred Rényi, em 1959, ficando conhecido como modelo ER (23). Neste modelo temos $\mathrm{n}$ vértices e para cada uma das arestas temos uma probabilidade $p$ de ligação e obviamente $1-p$ de não ligação. Se tivéssemos um grafo completo $(p=1)$, o número total de arestas seria $\frac{n(n-1)}{2}$. Portanto, o número esperado de arestas para este modelo é $p \frac{n(n-1)}{2}$. O grau médio é $\langle k\rangle=p(n-1)$, sendo que para uma rede com uma grande quantidade de vértices este grau médio aproxima-se de $p n$.

Redes deste tipo apresentam uma distribuição correspondente à distribuição de Poisson definido como

$$
P(k)=\frac{\langle k\rangle^{k}}{k !} e^{-\langle k\rangle}
$$

onde a maioria dos vértices apresentam grau médio $\langle k\rangle$. Na fórmula acima vê-se que a probabilidade de um vértice estar conectado a vértices de graus altos diminui exponencialmente. $\mathrm{Na}$ fig. 2.22.(a) temos o grafo correspondente a uma rede de 100 vértices e probabilidade de ligação 0,2 . Ao lado na fig. 2.22.(b), temos a distribuição de seus graus.

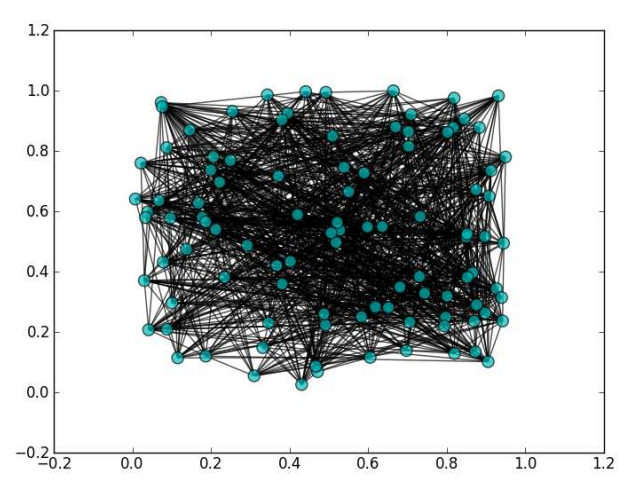

(a) Rede ER.

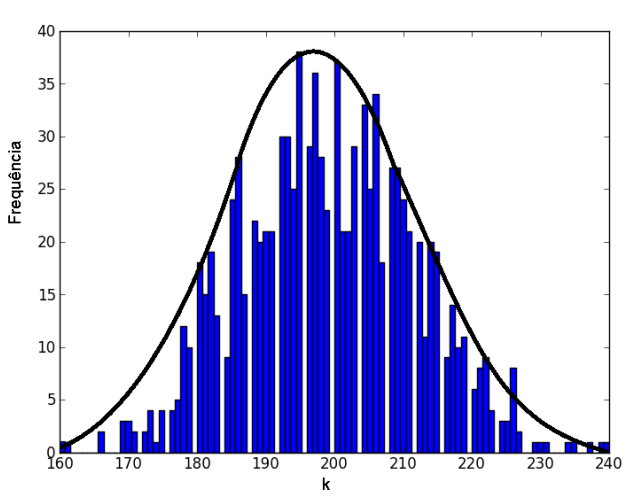

(b) Distribuição dos graus da rede ER.

Figura 2.22 - Um um grafo representando uma rede ER de 100 vértices com grau e probabilidade de conexão 0.2 (a) seguida da distribuição dos seus graus em (b).

Neste modelo, Erdõs e Reinyi verificaram um comportamento interessante e comum em vários fenômenos da natureza. Tendo uma rede com uma grande quantidade de vértices, se 
tivéssemos apenas uma aresta, o maior componente conexo teria tamanho dois e uma densidade de $\frac{2}{n}$. À medida que arestas são adicionadas a densidade do maior componente aumenta, tendo ainda outros componentes menores espalhados pelo grafo. Quando adicionamos arestas o bastante para que cada vértice tenha na média grau 1, a fração do maior componente salta subitamente para cerca de 1, espalhando-se por todo o grafo, conforme mostra a fig. 2.23.

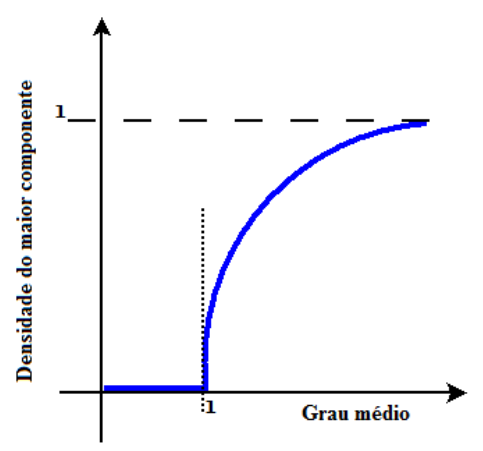

Figura 2.23 - Formação de componente gigante em um grafo aleatório. A densidade do maior componente muda bruscamente quando o grau médio se aproxima de 1 .

Este é um fenômeno conhecido na física como transição de fase e o ponto divisório dessa transição é chamado de ponto crítico(24). Este fenômeno conecta vários componentes menores, formando um componente gigante espalhando-se por todo o grafo. Em 1959, Erdös e Rénnyi, mostraram que quando $p>\frac{1}{n}$ existe um componente gigante, com pouquíssimos pequenos componentes isolados e quando $p>\frac{\ln (n)}{n}$ todos os vértices estão conectados (20). Na natureza, vários fenômenos físicos ocorrem bruscamente, tendo alguns pontos críticos como a temperatura de fervura da água, de congelamento e de gelificação do ovo. Outros materiais apresentam pontos de fusão ou solidificação que variam conforme a característica de ligação entre suas moléculas, que também podem ser representadas como um modelo de redes.

Verificou-se que o modelo ER não é a melhor proposta para redes reais. Nas redes do mundo real as ligações não ocorrem de modo uniformemente aleatório. Caso contrário, a escolha de uma pessoa por amizades com alguém de seu bairro seria menos provável do que escolher amizade com alguém da China, com mais de 2 bilhões de habitantes. Ligações de longas distâncias podem ocorrer na natureza, mas, de modo geral, as ligações surgem entre comunidades, composta de vértices altamente conectados com seus vértices mais próximos, havendo uma quantidade menor de ligações entre comunidades. Ou seja, a natureza tem 
características de aleatoriedade, mas não é uniformemente aleatória.

\subsubsection{Redes pequeno mundo}

Nas redes sociais, graus de separação é a distância geodésica entre dois vértices. Neste conceito, se uma pessoa $A$ conhece uma pessoa $B$ que conhece uma pessoa $C$ que conhece uma pessoa D que conhece o Dalai Lama, então o grau de separação de A com o Dalai Lama é 4. Baseando em algumas especulações de qual era o grau de separação médio entre duas pessoas, Jonh Milgram realizou uma experiência (25). Selecionou voluntários das cidades do Nebraska e Boston que tinham que entregar uma carta para uma única pessoa da cidade. A carta deveria ser entregue via correio caso não a pessoa não fosse conhecida, pessoalmente caso fosse conhecida ou para alguém que poderia conhecer essa pessoa. O número médio de intermediações foi de 5,2 , o que sugere que todas as pessoas da terra estão conectadas na média por 6 arestas. Redes como essas características são conhecidas como redes mundo pequeno, pois bastam poucas arestas ligando as comunidades para que as conexões entre grupos inteiros sejam estabelecidas. Tais redes também se caracterizam por alto coeficiente de agregação.

Watts e Strogatz propuseram um algoritmo para representar esse tipo de rede, conhecido como rede WS. Partindo de um grafo $k$-regular de $n$ vértices, cada vértice era religado a outro vértice com probabilidade $p$. Deste modo, a o grau de separação entre alguns vértices caia

bruscamente para 1 . Nesse modelo, o número de vértices a ser reconectado é igual a $p n \frac{k}{2}$. Se $p=0$, a rede permanece regular e quando $p=1$ a rede é aleatória.

Posteriormente, em 1999, um outro modelo, foi proposto por Newman e Watts, com a diferença que não removia as conexões anteriores (20). Tal modelo evitava a formação de componentes desconexos como o algoritmo anterior.

Estes dois modelos apresentam uma distância média pequena e um coeficiente de agregação próximo de 0.5. A distribuição destes graus assemelha-se ao modelo de $E R$, mas apresentam um alto coeficiente de agregação (26). Abaixo, temos grafos representando o algoritmo de formação de WS com 10 vértices e grau 4 (fig. 2.24). No primeiro grafo, a probabilidade é 0 , sendo portanto regular, e na segunda, a probabilidade é 0.2 , tendo características aleatórias. 


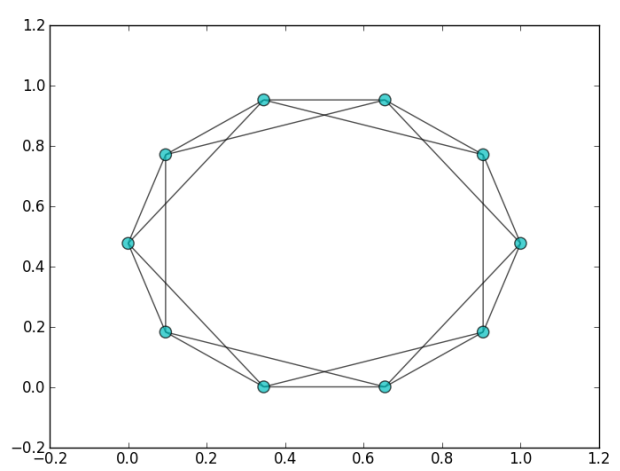

(a) WS com probabilidade 0

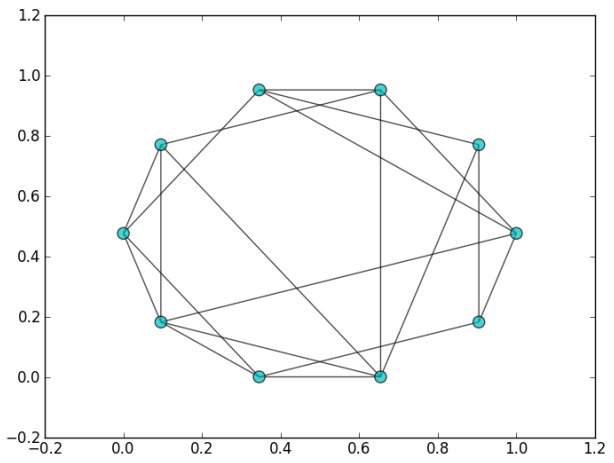

(b) Rede com probabilidade 0.2.

Figura 2.24 - Redes WS com 10 vértices e grau inicial 4. Em (a), com $p=0$ temos uma rede regular, já em (a), com $p=0.2$ temos um comportamento aleatório. Se $p=1$ a rede seria completamente aleatória.

\subsubsection{Redes livres de escala}

Em 1998, Barabási e Albert (27), ao mapear as redes da internet descobriram que $80 \%$ das páginas possuíam menos de 4 ligações, e aproximadamente $0,01 \%$ das páginas tinham graus maiores que 1000. Ao fazer a contagem desses vértices descobriram que a probabilidade de um nó com grau $k$ era proporcional a $k^{-\alpha}$, obedecendo a uma lei de potência. Sendo $P_{k}=a k^{-\alpha}$, se $a=0.3, \alpha=2$ e $k=2$, teríamos a probabilidade $P_{2}=\frac{0.3}{4}$, enquanto para $k=4$, teríamos $P_{4}=\frac{0.3}{16}$. Ou seja, temos muitos graus baixos e poucos graus altos. A razão para o termo livre de escala é que se multiplicarmos $k$, por uma constante $c$, teríamos $P_{c k}=a(c k)^{-\alpha}=\left(a c^{-\alpha}\right) k^{-\alpha}$. Como $a c^{-\alpha}$ é uma constante,a probabilidade ainda depende do valor de $k$, e não do escalar $a c^{-\alpha}$. Diversas redes reais apresentam características de livres de escala, onde, conforme já mencionado, apresentam alguns poucos vértices com graus altíssimos. Estes vértices são chamados de hubs ou concentradores.

Nos modelos de rede anteriores, o número de vértices é fixo, havendo variações nas suas conexões de acordo com a probabilidade. O modelo de rede proposto por Barabási (BA) apresenta uma característica dinâmica de crescimento de vértices. A dinâmica começa em $t=0$, com $n_{0}=n(t)$ vértices e $a_{0}=a(t)$ arestas ligados aleatoriamente com esses vértices. A seguir, adiciona-se um novo vértice criando $m \leq a_{0}$ ligações com os vértices anteriores. A ligação do novo vértice com um vértice $i$ obedece uma regra de conexão preferencial, onde os vértices mais conectados tem a preferência de conexão. Esta regra de conexão preferencial é 
definida por Barabási e Albert (20) como

$$
c p\left(k_{i}^{t}\right)=\frac{k_{i}^{t}}{\sum_{j=1}^{n(t)} k_{j}^{t}},
$$

sendo $k_{i}^{t}$ o grau do vértice $i$ no tempo $t$. O novo vértice é adicionado no tempo $t+1$ e as $m$ conexões ocorrem de acordo com a probabilidade $c p\left(k_{i}^{t}\right)$. No decorrer de um tempo $t$, teremos $n(t)=n_{0}+t$ e $a(t)=a_{0}+m t$.

A fig. 2.25(a) mostra um grafo de rede BA com $n=100, m=5$ e sua distribuição de graus (fig. 2.25(b)). Vê-se que o valor $P_{k}$ decresce, não apresentando um pico como na distribuição de Poisson. Portanto, o grau médio não é seu grau característico.

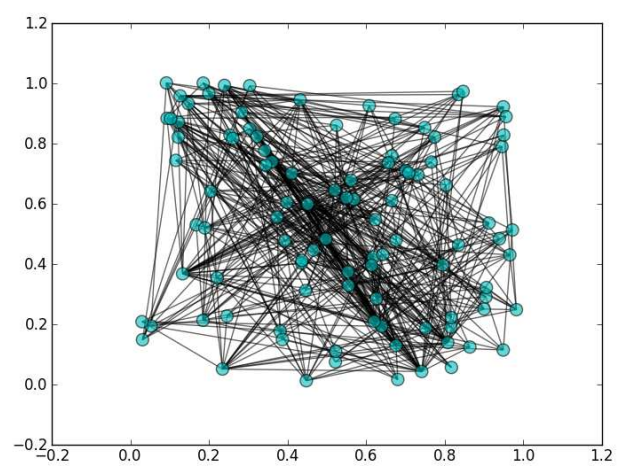

(a) Rede

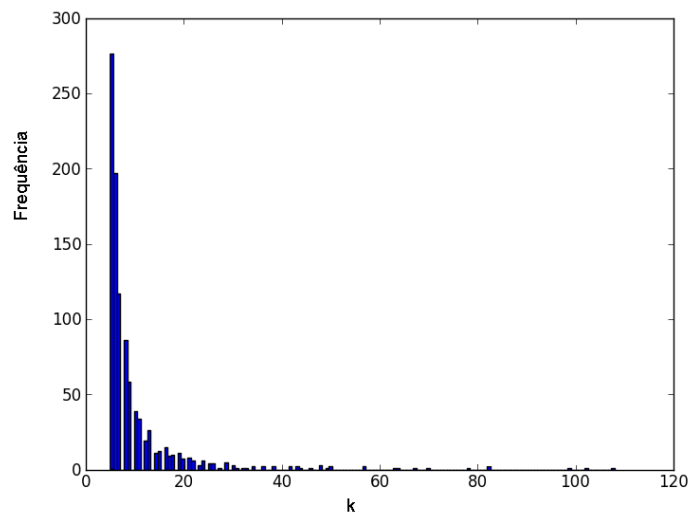

(b) Histograma

Figura 2.25 - Redes BA com $n=100$ e $m=5$.

Ao aplicarmos propriedade de logaritmos na distribuição $P_{k}$, temos

$$
\log \left(P_{k}\right)=\log (a)-\alpha \log (k)
$$

uma função linear, conforme mostra uma aproximação do gráfico de distribuição da fig. 2.26.

Embora estas redes sejam resistentes a ataques, Moreno e colaboradores (28) constaram ainda que independente do valor de $\alpha$, redes livres de escala favorecem a persistência de doenças. 


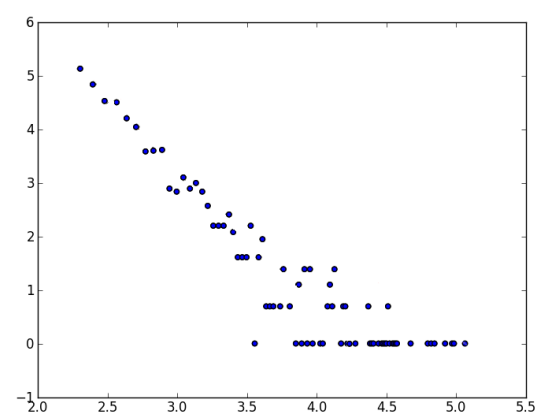

Figura 2.26 - Distribuição BA em escala logarítmica

\subsubsection{Redes espaciais ou geográficas}

Redes espaciais ou geográficas são redes onde a possibilidade de conexão dos vértices estão restringidas pela posição no espaço, onde o custo de conexão depende da distância, da dificuldade de acesso ou tempo de latência (29). Redes de estradas, aeroportos, trilhos, internet e neurônios são exemplos de redes espaciais. São redes em que ocorrem restrições de acesso devido à alguma geometria. Algumas destas restrições podem ser devido características morfológicas e espaciais como no caso de redes neuronais (30), de custo, como no transporte de cargas ou de distribuição não uniforme dos graus dos vértices e distância, como no caso de aeroportos. Em todas estes exemplos a distância é relevante.

Um modelo de rede espacial é o grafo de Waxman, onde dois vértices $i$ e $j$ são ligados com probabilidade $p(i, j)=\alpha \exp \left(\frac{-d}{\beta L}\right)$, sendo $d$ a distância euclidiana entre os vértices, $L$ o tamanho máximo das ligações e $\beta$ um parâmetro de controle da densidade das ligações. Apesar de ser um modelo simples, ajuda a entender a importância do espaço nas conexões (29).

A fig. 2.27(a) ilustra uma rede de Waxman e seu gráfico de probabilidade de conexão conforme a distância.

\subsubsection{Redes Biológicas}

Identificamos redes complexas em vários exemplos da natureza. A formação de vasos sanguíneos no organismo, obedece regras de crescimento topológico e dinâmico, adaptando-se 


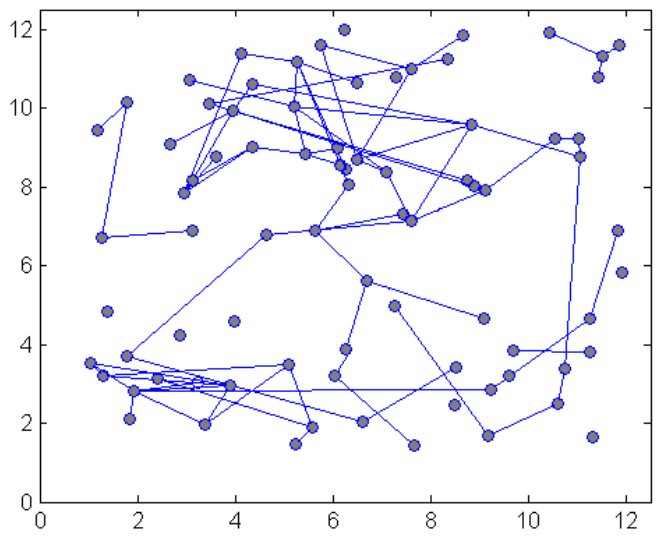

(a) Rede.

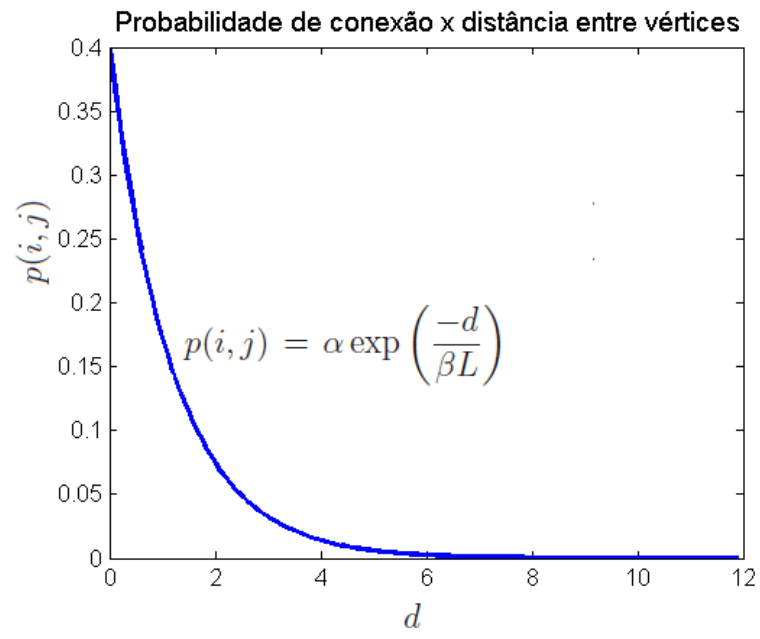

(b) Probabilidade de conexão $\times$ distância euclidiana.

Figura 2.27 - Rede Waxman distribuída num retângulo $20 x 20$, com 80 vértices, $\beta=0.8$ e $L=11$.

conforme as deficiências encontradas, como no entupimento de uma veia. A disseminação de uma doença como o câncer através do espalhamento de células neoplásicas no organismo (19). No modelo de rede equivalente os tumores são os vértices e as ligações são entre os tumores e neoplasias seguintes. O surgimento de neuroblastos em organismo adulto após uma isquemia, atraídos por proteínas como a betacelulina (31) permitindo a recuperação parcial ou total da injúria. Os neurônios são os vértices e as ligações representam as sinapses.

O espalhamento de sementes de uma árvore também pode ser visto como uma rede complexa, onde os vetores de espalhamento podem ser pássaros, mamíferos ou insetos. Neste caso, o tipo de animal pode ser uma característica para a força de espalhamento de novas árvores na floresta.

Na relação entre espécies, o modelo de redes presa-predador pode ser representado por uma rede do tipo digrafo, onde de um lado temos os vértices predadores e de outro os vértices 
presa. Há uma quantidade imensa de redes biológicas onde podemos usar diferentes estruturas de redes. Explanaremos abaixo três tipos de rede: neuronais, proteicas e metabólicas.

2.5.2.5.1 Redes neuronais A complexidade neuronal sempre dispertou interesse da comunidade científica. Como exemplo temos as células piramidais que possibilitam o envio de sinais desde as camadas mais profundas do córtex até outras áreas mais distantes. As redes neuronais possuem tanto características de pequeno mundo como livre de escala, pois em determinadas regiões ocorrem uma densidade de neurônios com uma complexidade de conexões diferenciadas de outras regiões. A ativação neuronal durante uma aprendizagem, onde diversos neurônios tentam adaptar-se para execução do exercício, para no decorrer do tempo as células de determinados locais concentram-se especificamente em detrimento de outras é um exemplo de dinâmica neuronal.

A estrutura neuronal do C. elegans com cerca de 282 neurônios formando uma rede direcionada com distribuições de conectividade exponencias. Justamente pela pouca quantidade de neurônios, é uma das redes neuronais mais estudadas até o momento. Mesmo com essa quantidade pequena de neurônios, esta rede apresenta características de pequeno mundo (32, 33), diferentemente de uma rede aleatória.

2.5.2.5.2 Redes de proteínas Proteínas interagem entre si e entre outras biomoléculas. Reagem quimicamente com um grupo de moléculas formando pequenos grupos de reações químicas, como no caso das reações enzimáticas. Nesse modelo, as proteínas seriam os vértices com ligações não direcionadas representando as interações químicas resultantes (17).

2.5.2.5.3 Redes metabólicas Metabolizar significa separar e remontar as moléculas dos nutrientes em moléculas apropriadas para fornecer energia química para as células. Isso envolve uma cadeia de reações químicas processam as entradas brutas (alimentos) em substâncias utilizáveis pelo organismo em uma série de passos. O caminho completo de todas essa reações químicas formam uma rede metabólica (17). Os vértices nessa rede seriam as substâncias químicas produzidas e consumidas através das reações. Essas substâncias são conhecidas como metabólitos. Uma rede de proteínas pode ser representada como uma rede bipartida com vértices específicos representando as substâncias e outros para representar as reações entre estas. O caminho destas reações começa com dois vértices de substâncias cujas arestas direcionadas apontam para um vértice de reação. Este por sua vez produz dois vértices de saídas apontando para as novas substâncias metabolizadas. O processo segue por até que não haja mais moléculas para serem quebradas e transformadas. 


\subsubsection{Redes de Informação}

Um exemplo de rede de informação é a rede de citações bibliográficas onde diversos artigos citam alguns poucos. Sendo uma rede direcionada, sua estrutura reflete a informação relacionada em seus vértices. Um outro tipo de rede deste tipo é a World Wide Web, com seus repositórios de dados (17).

\subsubsection{Outras redes}

A natureza é composta de diversas redes. Entender a sua dinâmica e suas características estruturais é um dos desafios da ciência deste século. Embora muitas redes da natureza comportem-se como livre de escala, algumas redes não comportam essas características, tais como a rede elétrica. Redes sociais tem características de redes de livre de escala, assim como rede de aeroporto parecem ser uma mescla de mundo pequeno e livre de escala (18).

\subsection{Crescimento e percolação de redes morfológicas artificiais e reais}

“Percolação significa a passagem de um fluído através de um meio poroso. Existe uma diferença básica entre percolação e difusão. Na difusão um fluído aleatório propaga-se num meio determinístico enquanto na percolação um fluído determinístico propaga-se num meio aleatório" (34). O espalhamento de uma gota de tinta em uma piscina é difusão, enquanto que a água passando pelo pó de café uma pedra porosa é percolação.

Para explicar percolação, vamos usar um modelo para representar uma floresta de árvores, situadas em uma área retangular. O modelo usado é composto de subáreas ou sítios onde cada sítio pode ter ou não uma árvore (fig. 2.28 (a)). Cada sítio $s(x, y)$ tem probabilidade $p$ de ter uma árvore (representada pelo sítio na cor cinza), e $(1-p)$ de estar vazio. Consideramos como vizinhos de $s(x, y)$ os sítios $s(x-1, y), s(x, y-1), s(x+1, y)$ e $s(x, y+1)$, que é conhecido como 4-vizinhança. Nessa floresta, o fluído será o fogo. Vamos supor que todas as árvores da primeira linha do retângulo comece a queimar, de acordo com o gráfico da fig. 2.28(b), e após consumir as árvores da primeira linha o fogo se propaga para seus vizinhos( 
2.28(c)), continuando posteriormente até a última linha (fig. 2.28(d)).

Devido ao tipo de vizinhança considerada, nem todos os sítios com árvores foram queimados. Isso acontece por que a probabilidade de ocupação não foi alta o suficiente para povoar mais sítios da floresta com árvores. Mesmo assim, o fluído espalhou-se da primeira linha até a última. Representando estes sítios com árvores como vértices de um grafo, as áreas queimadas corresponderiam a um componente fortemente conexo (cluster), que se estende da primeira até a última linha. Quando um fluído passa de um extremo a outro de um meio aleatório, diz se que este fluído percola o meio. Ou seja, o fogo percolou a floresta.

Na teoria da percolação, um componente dominante é o componente conexo de maior tamanho entre os demais. Um componente infinito ou componente percolante é o componente que se espalha por toda a rede (24). Na fig. 2.29, temos um momento antes de ocorrer a percolação e o momento da percolação, o componente percolante em vermelho espalhando-se por todo o sistema. A parte vermelha indica o componente percolante. A teoria da percolação utiliza uma série de medidas e métricas para caracterizar sistemas quanto a possibilidade de ter um componente percolante.

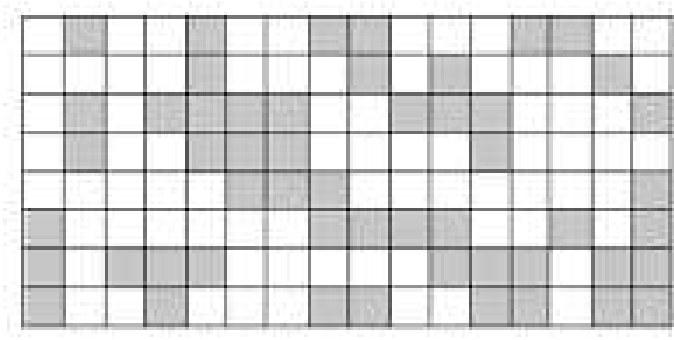

(a) Momento antes da ianiçัง

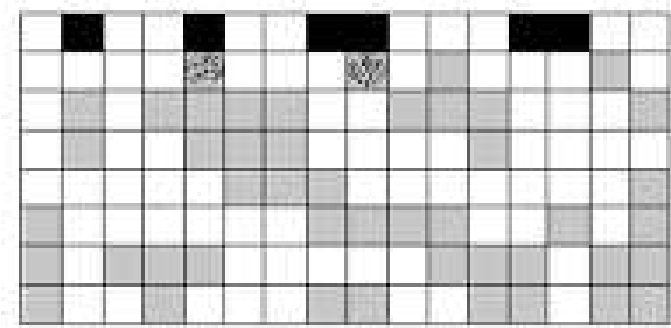

(c) Queima e propagagào para a segunda linha

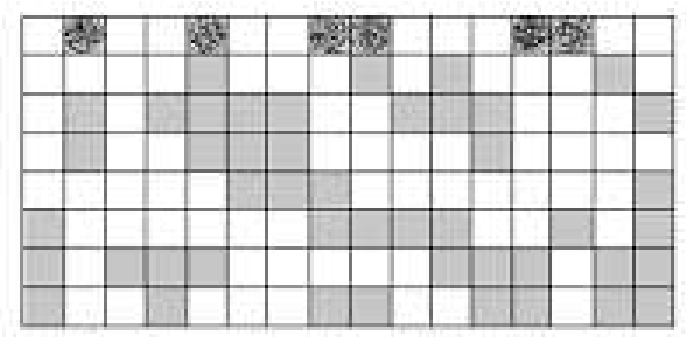

(b) Inioio da ignigào

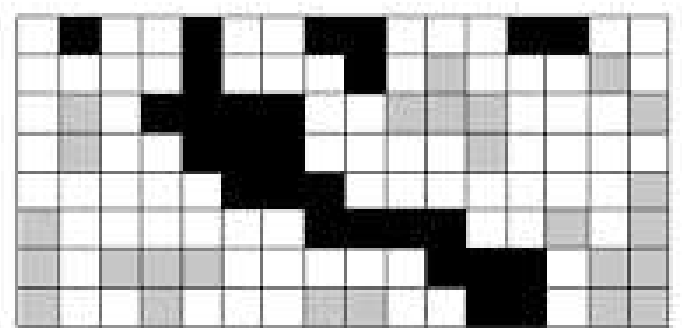

(d) Fim da queims

Figura 2.28 - Exemplo de percolação. No primeiro momento, nenhum sítio entrou em ignação (a), a seguir ocorre a iginição na primeir fileira de 'árvores' do sítio (b), espalhando-se para a segunda fileira. A queima termina quando o fogo atinge a última linha da área retangular, não havendo mais nenhum vizinho para espalhar o fogo.

Algumas medidas são convencionais para a teoria da percolação. A seguir mostramos as 


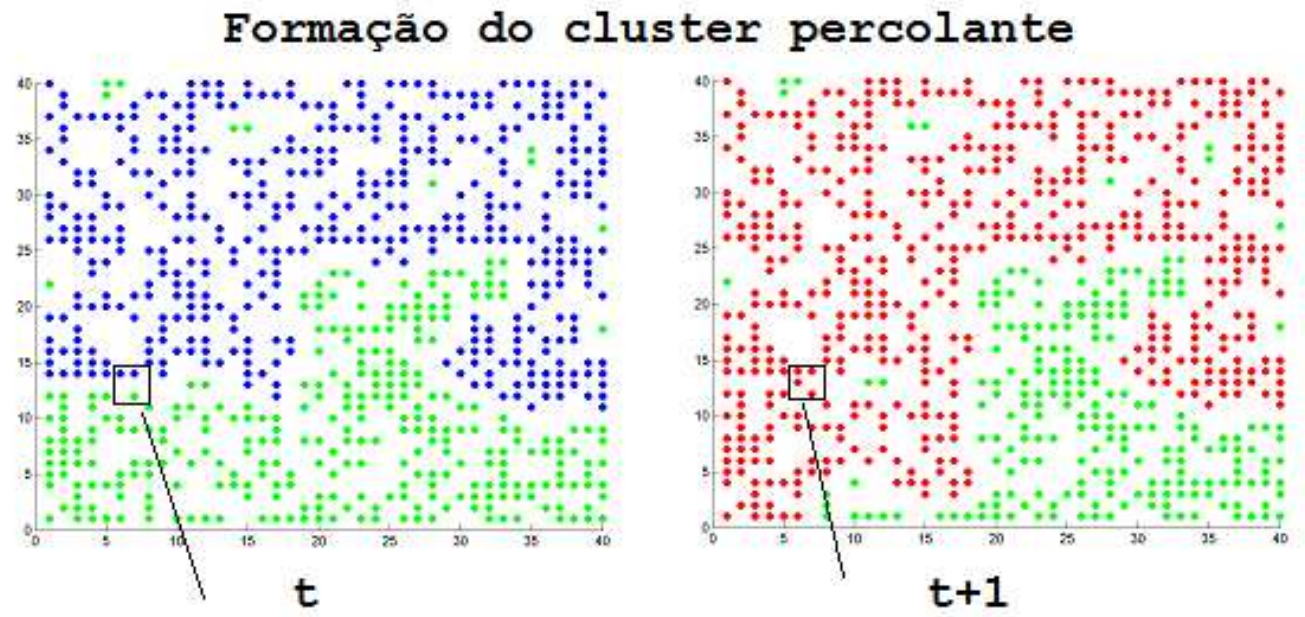

Figura 2.29 - Momento da percolação. O sistema num tempo $t$ antes de percolar em todas as bordas e o sistema num tempo $t+1$, o momento de percolação.

mais utilizadas:

- $N$ : número total de sítios da rede

- $n$ : número de sítios ocupados

- $p$ : probabilidade de ocupação

- $\langle n\rangle$ : número médio de sítios ocupados,

- $p_{c}$ : limiar de percolação, densidade a partir da qual aparece o componentes percolante (24). Para que ocorra percolação, $p>p_{c}$

- $n_{s p}$ : número de sítios no componente percolante,

- $P$ : probabilidade de percolação, esta função só é valida quando $p>p_{c}$, onde

- $n_{c}$ : número de componentes existentes

- $n_{s}$ : número de componentes de tamanho $s$

- $\langle s\rangle$ : tamanho médio dos componentes, ou seja, $\langle s\rangle=\frac{1}{n} \sum_{i} s_{i}$. Este valor diminui quando $p>p_{c}$, pois não incluímos o componente percolante.

Destas medidas, as mais convencionais são $\langle n\rangle, n_{s}, p, p_{c}, P$, e $\langle s\rangle$. Se incrementarmos $p$ iterativamente observaremos que o tamanho do componente dominante cresce abruptamente quando $p>p_{c}$. Neste momento ocorre uma transição de fase, onde o componente dominante passa a ser percolante, conforme ilustra a fig. 2.30. Esse fenômeno é também conhecido 
como fenômeno crítico (24). Nesta tese, faremos uma analogia com o fenômeno de percolação aplicado a redes neuronais direcionadas, o que difere dos muitos estudos que tratam de redes não direcionadas. A fig. 2.31 mostra uma rede neuronal não regular e direcionada com a formação de um componente conexo forte ou componente percolante.
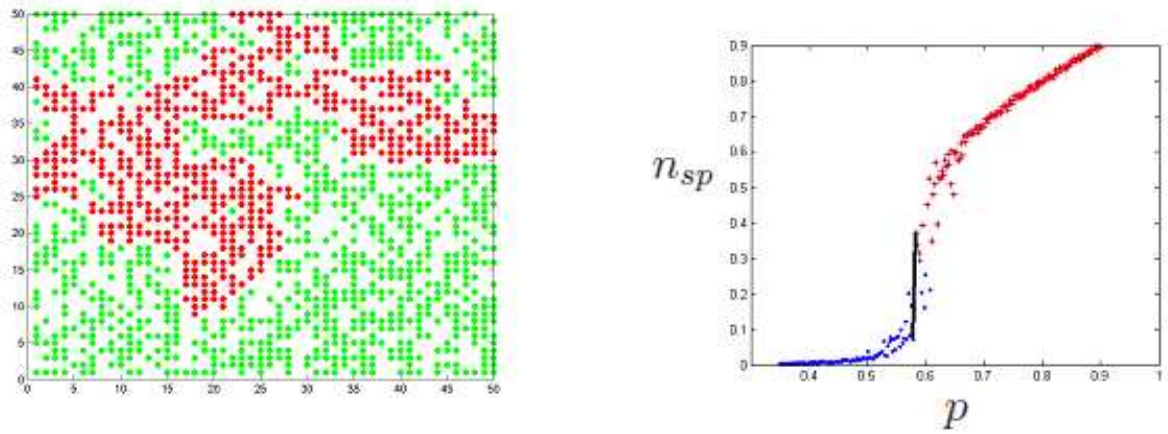

Figura 2.30 - Ponto critico. Uma grade regular no momento que ocorreu uma percolação horizontal e o gráfico de densidade do componente. A reta mostra o momentoo momento da transição de fase.

\subsection{Dinâmica em redes}

Quanto a caracterização de dinâmicas podemos dividi-las em dois tipos: dinâmica de topologia e dinâmica de ativação.

A dinâmica de topologia utiliza medidas para caracterizar as mudanças topológicas que ocorrem na estrutura da rede no decorrer de cada época. A inoperância de um $h u b$, devido a falha ou ataque, numa rede de servidores causam alterações na topologia da rede.

A dinâmica de ativação analisa as mudanças relacionadas aos estados dos vértices da rede no decorrer do tempo em uma mesma época $E$. Para uma rede neuronal, a diferença de potencial acumulada no soma são os estados assumidos pelo vértice. $O$ número de vezes que um neurônio tornou-se ativo conforme o crescimento da rede é uma medida de dinâmica de ativação. Este tipo de dinâmica pode ser usado para simular a disseminação de doenças em plantas (35) ou em comunidades, caracterizar medidas no processo de envio de potenciais de ativação de redes conforme diversas topologias (32), relacionar estrutura e dinâmica em redes complexas $(36,37)$, entre outros.

Na seção 2.7.1, analisaremos um modelo que será utilizado para caracterizar dinâmica de ativação, finalizando na seção 2.7 .3 com alguns trabalhos relacionados com medidas de dinâmica e medidas topológicas em redes. 


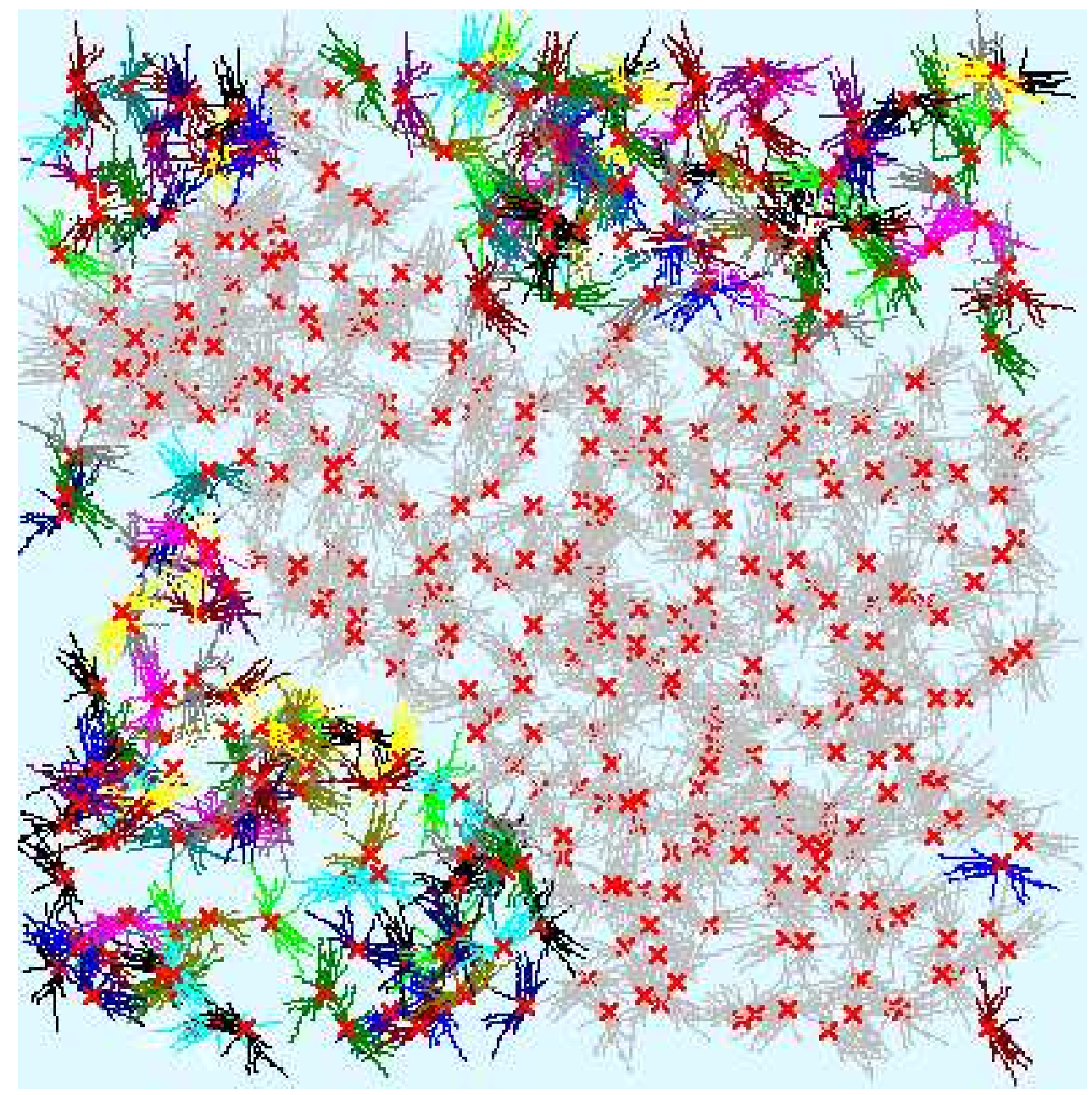

Figura 2.31 - Formação do componente gigante em redes neuronais em uma rede de neurônios piramidais do córtex de macaco (macaco Rhesus). Na cor cinza, as células que fazem parte do componente gigante. As marcas em ' $x$ ' correspondem ao centro do soma. 


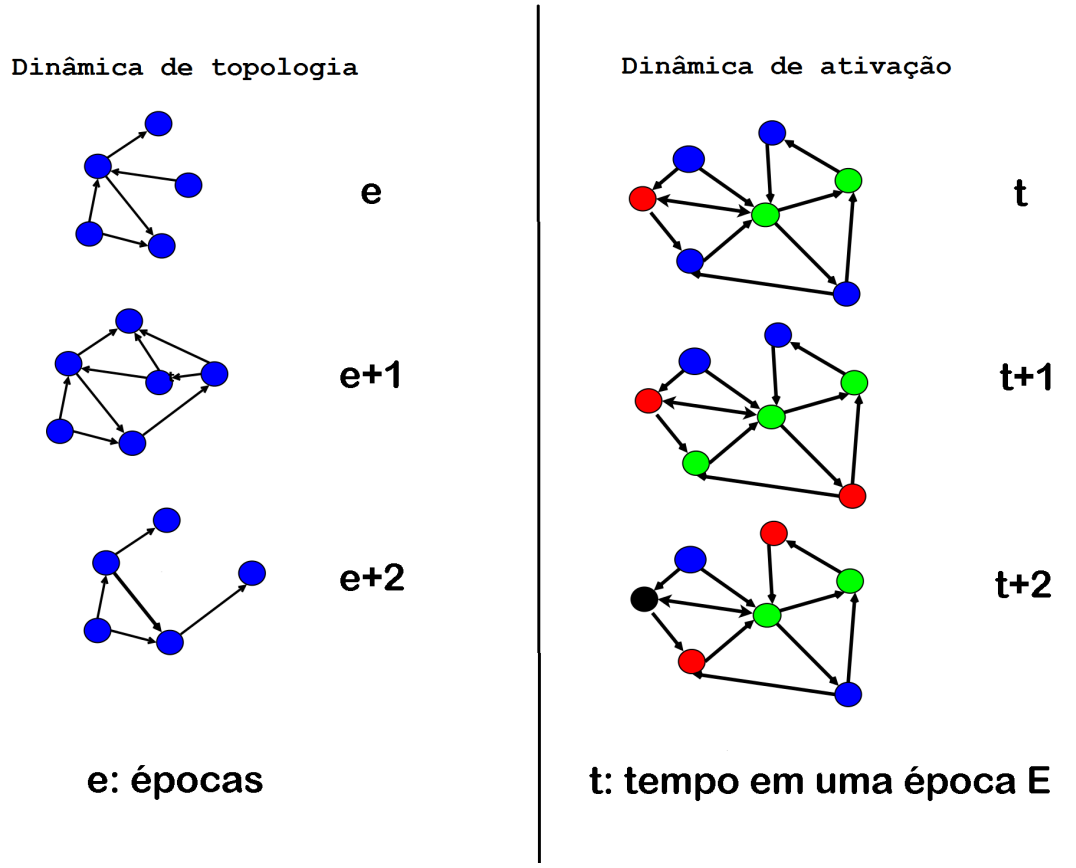

Figura 2.32 - Tipos de dinâmica em rede. A dinâmica de topologia pode alterar a estrutura da rede no decorrer do tempo, enquanto a dinâmica de ativação altera os estados dos vértices.

\subsubsection{Modelo integra e dispara}

A fig. 2.33 ilustra um neurônio $i$ recebendo sinapses dos neurônios $j=1$ e $j=2$. 0 instante de disparo de um neurônio $j$ é denotado por $t_{j}^{(f)}$. Um trem de pulsos do neurônio $j$ seria representado pelo conjunto de instantes de disparos $\left\{t_{j}^{(1)}, t_{j}^{(2)}, \ldots, t_{j}^{(N)}\right\}$. A fig. 2.33 mostra dois instantes de disparos para cada neurônio $j$. Após os dois disparos de cada neurônio, o potencial da membrana $i$ atinge o limiar mudando abruptamente para o potencial de ativação (spike).
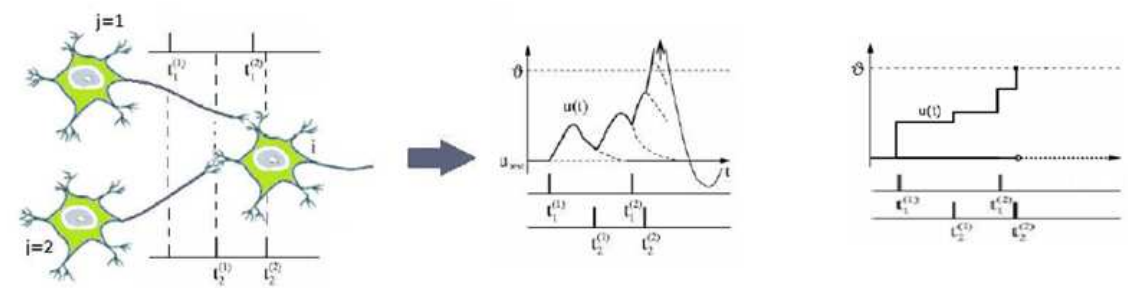

Figura 2.33 - Ativação por limiar. Os sinais pré-sinápticos dos neurônios da esquerda são enviados até que o limiar seja atingido, causando uma mudança abrupta no potencial da membrana.

Para estudar dinâmica de redes, temos que definir qual o modelo mais adequado que desejamos dada as características da rede a ser investigada. Os modelos de disparo por limiar são baseados na soma de todas contribuições pré-sinápticas recebidas pela membrana. Quando 
essa soma ultrapassa um limiar este neurônio dispara. O modelo Integra e dispara (integrate and fire) é um modelo de dinâmica neuronal simplificado, o qual supõe uma rede de neurônios conectados com conexões distintas e potenciais de ativação dados por deltas de Dirac (10). Outros modelos como o de Hodgkin-Huxley (38), Hindmarsh-Rose (39) são mais interessantes quando se deseja estudar o comportamento mais aprofundado dos processos sinápticos entre neurônios (40).

No modelo Integra e Dispara, o potencial da membrana de cada neurônio é dada por

$$
\tau_{m} \frac{d V_{i}}{d t}=-V_{i}+R I_{i}^{e x t(t)}+\sum_{j=1}^{N} \sum_{f} g_{j i} \delta\left(t-t_{j}^{(f)}\right),
$$

sendo

- $V_{i}$ : potencial da membrana;

- $I_{i}^{\text {ext }}$ : a corrente de entrada;

- $R$ : resistência da membrana

- $g_{i j}$ : uma matriz de custos, sendo $g_{i j}=\frac{1}{k_{i}}$, no modelo conservativo, ou 1 em caso contrário,

- $\tau_{m}=R C$, sendo $C$ a capacitância.

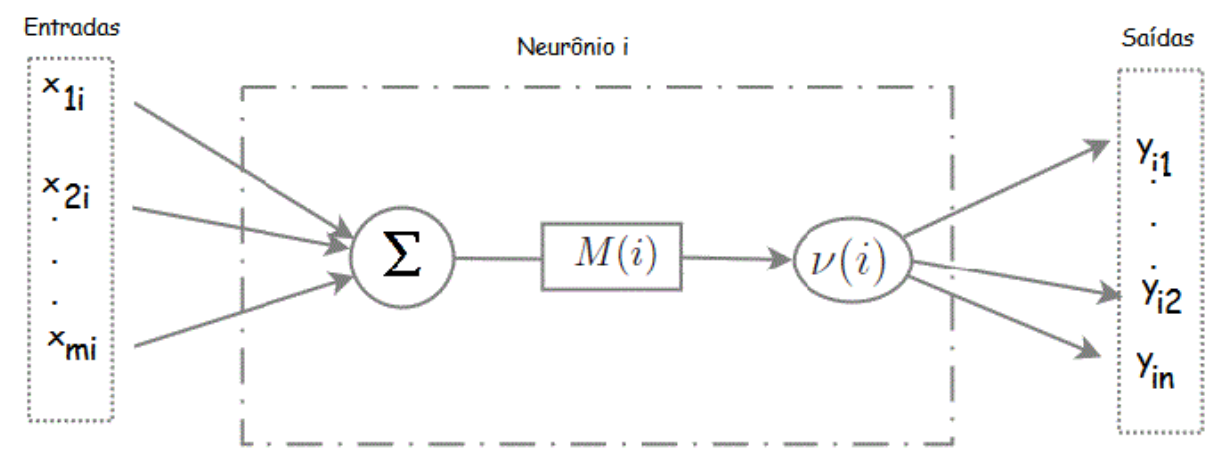

Figura 2.34 - Modelo Integra e dispara.

Dada uma rede de neurônios, adaptamos o modelo acima e representamos conforme a fig. 2.34. O neurônio $i$ recebe potenciais provindos das entradas $x_{1 i}, x_{2 i}, \ldots x_{N i}$, sendo $1,2, \ldots, N$ os neurônios pré-sinápticos de $i$ que modificam o estado de ativação ou diferença de potencial da membrana plasmática $M(i)$. $\Sigma$ é um integrador, que recebe as entradas do $m$ neurônios. 
A membrana recebe um trem de impulsos provindos das entradas em diferentes momentos. Considerando $t+1$ como o momento em a membrana recebeu um impulso a sua equação de atualização da membrana $M(i)$ é dada por

$$
M(i)^{(t+1)}=M(i)^{(t)}+\sum_{j=1}^{N} x_{i j}^{(t+1)},
$$

sendo que em alguns modelos utiliza-se ainda um decaimento de potencial $\alpha$ ficando então a equacão mudada para

$$
M(i)^{(t+1)}=\alpha M(i)^{(t)}+\sum_{j=1}^{N} x_{i j}^{(t+1)}
$$

sendo que quando $\alpha=1$, não houve decaimento. Na fig. 2.34, $\nu(i)$ é uma função que verifica se $M(i)$ atingiu um potencial maior ou igual a um limiar $T h$. No momento que esse limiar é atingido, $M(i)$ torna-se ativo e o neurônio $i$ dispara (transmite) potenciais pós sinápticos a todos os seus $n$ neurônios pós-sinápticos.

Após a transmissão, $M(i)=0$, entrando em estado de repouso. No próximo passo processo recomeça com todos os outros neurônios que atingiram o limiar, continuando sucessivamente.

Estes modelos podem ser conservativos, quando cada $y_{i k}$ recebe $\frac{M(i)}{N}$, ou seja, a diferença de potencial conserva-se no sistema. De outra forma, pode-se adotar o modelo não conservativo, onde um potencial único é disparado para cada um dos $N$ neurônios independente da quantidade de vizinhos.

Considerando que inicialmente no tempo $t=0$ todos os $M(i)$ tem potencial zero, a ativação inicial do modelo pode ser feito de vários modos. Abaixo, formas de ativação mais utilizadas:

1. Escolhemos arbitrariamente alguns vértices sementes e de acordo com uma regra estabelecida, ativamos estes vértices com uma diferença de potencial Th. Por exemplo, podemos ativar todos os vértices que tiverem grau de saída maior que o grau médio;

2. Escolhemos aleatoriamente uma certa quantidade de vértices e o ativamos;

3. Adicionamos a todos os vértices potenciais aleatórios $v_{i}$ entre $[0, t h]$.

Nos dois primeiros itens, os neurônios sementes (com fonte) podem ser recarregados ou não (sem fonte). Em ambos os casos ocorre uma dinâmica de mudança de estados dos vértices no decorrer do tempo. Nos casos sem fonte, a escolha do valor do limiar é importante, estando 
relacionado com o grau médio da rede. Com limiares muito acima do grau médio, a rede tende a perder estabilidade e o número de neurônios ativos tende a zero. Com limiares próximos ao grau médio, a curva média de várias redes de neurônios ativos é pequena inicialmente formando uma curva crescente até estabilizar-se em um patamar com pequenas oscilações. A fig. 2.35 mostra a curva de disparos para algumas redes formada por neurônios piramidais do hipocampo. As curvas do gráfico mostram que após um período a rede estabiliza o número de disparos.

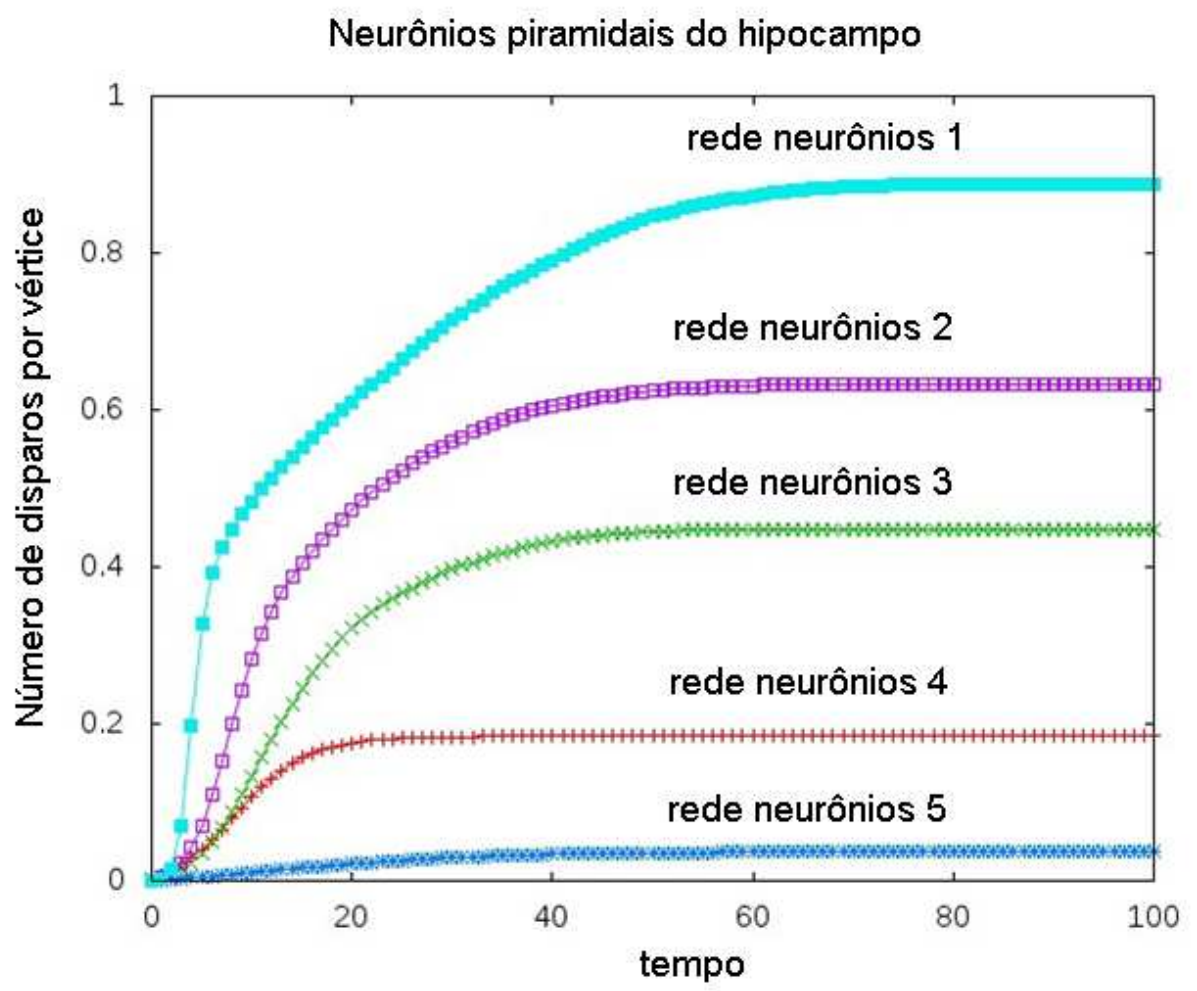

Figura 2.35 - Número de disparos para redes formadas por neurônios do hipocampo.

\subsubsection{Medidas de dinâmica do integra e dispara}

Para simular a dinâmica, necessitamos de um vetor de cargas com os potenciais iniciais, e um vetor auxiliar com valores zero, que servirá como integrador nos próximos passos. Para todos aqueles vértices que atingiram o limiar disparamos potenciais aos seus vizinhos póssinápticos. Após os disparos, os vértices que atingiram o limiar ficam com valor zero, simulando o estado de repouso do neurônio. Os sinais recebidos pelos vértices pós-sinápticos serão 1 no modelo não conservativo, ou $1 / k_{i}$ para o modelo conservativo. Para cada vértice $i$ adicionamos os potenciais recebidos de vizinhos pré-sinápticos, adicionando posteriormente 
este vetor integrador ao vetor de cargas. A seguir, zeramos o vetor integrador. Voltamos então para o vetor de cargas e repetimos as operações por uma quantidade de períodos $T_{\max }$. Para representar os períodos de ativação dos neurônios (spykegram), usamos uma matriz binária

$$
S=\left[\begin{array}{cccc}
S_{11} & S_{12} & \ldots & S_{1 n} \\
S_{21} & \ddots & & \vdots \\
\vdots & & \ddots & \\
S_{T_{\max 1}} & S_{T_{\max } 2} & \ldots & S_{T_{\max } n}
\end{array}\right],
$$

sendo $T_{\max }$ o tempo máximo observado e $n$ o número de neurônios. $S_{t j}=1$, se o neurônio $j$ disparou no tempo $t$. A seguir, temos algumas medidas:

- A taxa de disparos de cada neurônio i:

$$
\operatorname{tau}_{i}=\frac{1}{T_{\max }} \sum_{t=0}^{T_{\max }} S_{t i}
$$

- O número de disparos ou de neurônios ativos em cada tempo $t: \beta_{t}=\sum_{j} S_{t i}$;

- A média de disparos na rede: $\gamma=\sum_{t=0}^{T_{\max }}$

- O intervalo médio entre disparos de um neurônio $i$ : $\left\langle\delta_{i}\right\rangle=\frac{1}{k} \sum_{j=1}^{k} \delta_{i j}$, onde $\delta_{i 1}, \delta_{i 2}, \ldots, \delta_{i k}$ são os intervalos entre dois disparos consecutivos.

- O desvio padrão do intervalo de disparos : $\sigma_{\delta_{i}}=\sqrt{\frac{1}{k} \sum_{j=1}^{k}\left(\delta_{i j}-\left\langle\delta_{i}\right\rangle\right)^{2}}$

Nesta tese, usaremos redes compostas por neurônios reais aplicando a dinâmica integra e dispara, onde a estrutura da rede depende das características morfológicas do tipo de neurônio utilizado. Escolhemos o modelo não conservativo, por ser o mais próximo da propagação natural de sinais entre neurônios. Com essa dinâmica, relacionaremos as medidas topológicas entre si e com as medidas de dinâmica.

\subsubsection{Estrutura e dinâmica em redes morfológicas: trabalho rela- cionados}

Vários trabalhos do Grupo de Pesquisa em Visão Cibernética estão relacionados com redes neuronais tendo por investigação as relações entre estrutura e dinâmica. Em 2008, Luciano Costa publicou um trabalho utilizando redes neuronais aplicando a dinâmica de integra e 
dispara para investigar padrões de ativação em comunidades neuronais (41). Relacionando várias situações reais, uma das estimativas percebidas foi que a a estabilização do número de disparos na rede (avalanches) (32) está relacionada com o número de vértices em cada nível hierárquico. A seguir, em 2009, Anhnert, Travençolo e Costa (30) investigaram a dinâmica e a conectividade de redes neuronais bidimensionais e sua relação com a forma. Usaram um modelo simplificado de neurônios, sendo seus dendritos representados por retas e o soma por círculos, conforme ilustra a fig. 2.36. No modelo, ocorria conexão pré-sináptica de um neurônio $A$ em um neurônio $B$ se o dendrito de $B$ estivesse sobreposto ou tocasse o círculo de $A$. Variando a quantidade de dendritos na rede e utilizando o modelo integra e dispara, constatou-se que a variabilidade de dendritos é proporcional à densidade de neurônios ativos e conectados entre si após um determinado período.

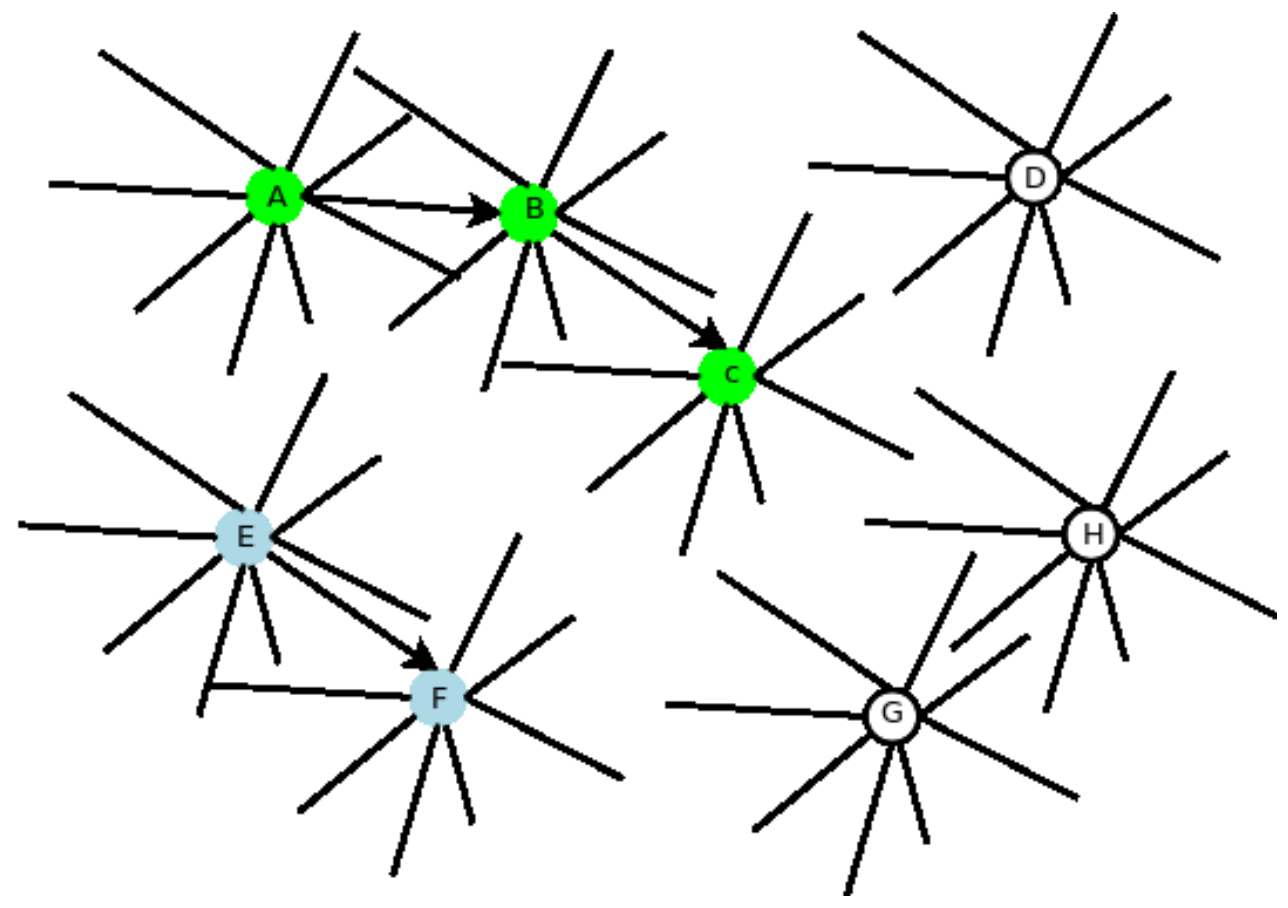

Figura 2.36 - Um modelo de rede morfológica. Um modelo simplificado, conforme definido em (30). O soma, ao tocar um dendrito, emite um sinal pré sináptico para o dendrito.Assim, os sinais de sinapses são emitidos de $A$, para $B$ e de $B$ para $C$, sendo a direção da sinapse indicado pela seta que aponta para o neurônio que possui o dendrito. $O$ mesmo acontece entre os neurônios $E$ e $F$, ficando os demais sem conexão.

Outros artigos mais atuais tratam de outras investigações relacionadas a dinâmica e topologia, tais como (36), (37) e (42). Esta tese investiga as relações entre dinâmica e topologia por meio de um outro perfil: a investigação da evolução da rede por épocas utilizando neurônios tridimensionais e suas relações entre topologia e dinâmica em cada época, especialmente quanto à caracterização das redes em termos das suas medidas topológicas ao longo das épocas de desenvolvimento e pela variação da correlação de Pearson entre a dinâmica de ativação e topologia durante o desenvolvimento das redes. 


\section{Desenvolvimentos e Resultados}

Neste capítulo descreveremos o desenvolvimentos desta pesquisa. Inicialmente a motivação e objetivos gerais do trabalho realizado, seguido dos materiais utilizados e procedimentos para análise dos resultados. Os resultados obtidos são então apresentados e discutidos.

\subsection{Metodologia}

Durante o período pré-natal os neurônios nascem e crescem em várias regiões do cérebro, continuando após o nascimento do animal, embora de modo mais discreto. Na formação inicial de uma rede de neurônios desde o período pré-natal, células neuronais primordiais (neuroblastos) diferenciam-se e migram para determinadas regiões do cérebro em diferentes momentos. À medida que crescem, vão ramificando-se e conectando-se com seus vizinhos, formando uma rede neuronal complexa que depende da genética do indivíduo e dos estímulos recebidos do ambiente. Em cada região temos células com diferentes formas apropriadas para execução de determinadas funções.

Pretendemos simular a evolução da conectividade distribuindo neurônios tridimensionais ao longo de uma região plana, compatível com a organização do córtex dos primatas, conforme ilustrado na fig. 3.1. Os neurônios são distribuídos célula por célula formando, na aleatoriedade da distribuição espacial, grupos que se conectam entre si formando componentes fortemente conexos. A classe de neurônios escolhida é a das células piramidais, que são bastante frequentes no córtex dos mamíferos e também possuem uma maior quantidade de amostras na base neuromorpho. De forma a refletir a organização espacial destas células no córtex, no modelo aqui desenvolvido elas são distribuídas com rotação livre, ou seja, de forma a melhor refletir a organização uniformemente aleatória. Por simplicidade, o axônio é representado por um cilindro, com o respectivo raio de alcance. Tal simplificação também se deve a termos poucas células na base neuromorpho com informações confiáveis sobre os axônios.

O foco desse trabalho é a conexão de curto alcance, de forma que células mais próximas terão maior probabilidade de conexão. Não incluiremos conexões de longo alcance para evitar 


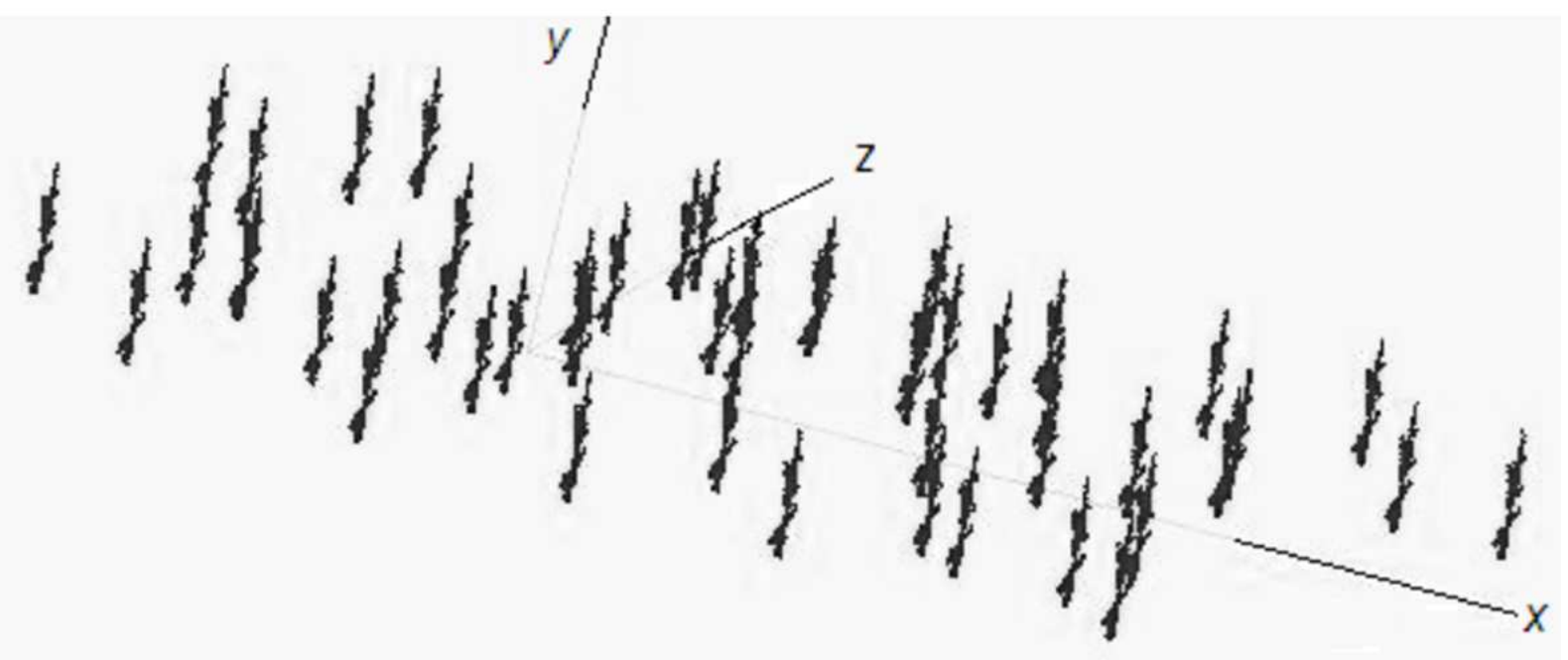

Figura 3.1 - Ilustração da organização das redes simuladas ao longo de um plano-xz. O eixo principal das células é orientado ao longo do eixo y.

acréscimo de parâmetros nas simulações e permitir uma análise mais focada na adjacência espacial dos neurônios formando uma rede geográfica.

A estrutura topológica utilizada para representar estas redes neuronais é uma rede direcionada, sendo a origem da ligação o vértice correspondente ao neurônio pré-sináptico. Investigamos então as medidas topológicas e dinâmicas destas redes ao longo das épocas. Para cada época, de cada rede, simula-se o modelo integra-e-dispara sem conservação, de forma a que possamos relacionar as medidas de topologia com as medidas de dinâmica.

Utilizando os dados digitais da base neuromorpho, inicialmente alinhamos a maior variação das 3 medidas (comprimento, largura e altura) do neurônio ao eixo-y do conjunto de coordenadas 3D, utilizando a transformada Karhunen-Loève (43), conforme ilustra a fig. 3.2. Após essa operação, normalizamos as dimensões da célula de tal modo que todos tivessem uma mesma largura de projeção de seus dendritos basais no plano- $x z$, Isto evita os efeitos de alcance de conexão em distâncias diferentes, uma vez que queremos estudar as características relacionadas à forma (fig. 3.3).
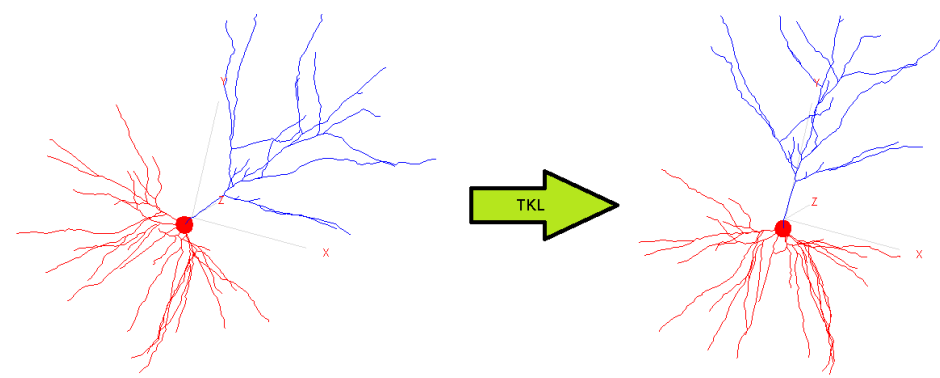

Figura 3.2 - Transformada Karhunen-Loève (TKL). A transformada possibilita alinhar os eixos na ordem que desejar. 


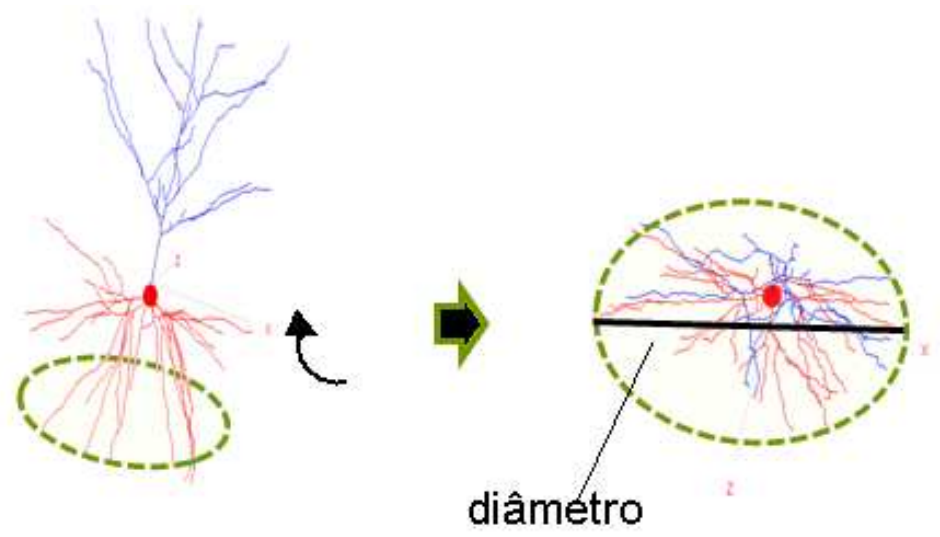

Figura 3.3 - Normalização na projeção do plano-xz. Tomando o a projeção do plano-xz, a normalização da célula é feita pela divisão de todos os pontos pelo diâmetro dos dendritos basais (vermelho).

A fig. 3.4.(a) ilustra o crescimento de uma rede neuronal ao longo de 4 épocas. Definese como época o estágio de desenvolvimento da rede, relativo à quantidade de neurônios adicionados ao longo do tempo. A dinâmica começa com a colocação de uma célula piramidal em uma posição do plano. Esta posição é escolhida aleatoriamente e a célula é rotacionada em um ângulo uniformemente aleatório. Esta é a época 1 da rede a ser formada. A seguir, na época 2 , fazemos uma nova adição da mesma célula sorteando uma nova rotação e posição no plano. Observamos então a possibilidade de sinapse dendrito-axônio desta célula com a célula anterior, e vice-versa. Uma conexão sináptica é assim obtida sempre que houver uma sobreposição entre um axônio de uma célula com um dendrito de outra. O processo se repete até uma certa quantidade de épocas $E$, que fixaremos em 500 . Este número de épocas é suficiente para que possa ser investigado o fenômeno de percolação na rede. Então, cada rede é obtida respectivamente a um determinado neurônio.

As conexões entre as células dependem da distribuição espacial do dendritos basais, cuja possibilidade de receber a conexão de um axônio pré-sináptico depende de uma distância considerada suficiente para passagem de elementos químicos para os dendritos pós-sinápticos. Definimos como raio de alcance a distância máxima para conexão entre um axônio pré-sináptico e um dendrito pós-sináptico. Ou seja, não há conexão se a menor distância entre uma axônio e um dendrito for superior ao raio de alcance. O valor do raio de alcance neste trabalho foi 5. Simplificadamente, seria como se o axônio pré-sináptico fosse um cilindro de raio igual a 5, cuja sinapse só ocorreria se o axônio tocasse o dendrito pós-sináptico. A formação dos fenômenos referentes a percolação é aproximado à esferas de percolação (44). No artigo de (44), usando simulações de Monte Carlo, foram utilizadas esferas aleatoriamente distribuídas e analisado o limiar de percolação no espaço 3D. Na construção das redes nesta tese, cada 
vértice seria uma esfera de tamanho diferente, e distribuídas em um plano.

A fig. 3.4.(b) ilustra o gráfico normalizado do tamanho do maior componente conexo fraco e forte. A formação do componente forte é representado em verde na fig.3.4.(a). Inicialmente, temos a formação de vários componentes fortes, representados pela mesma cor. A seguir, com o surgimento de novos neurônios na região, as conexões destas células com as demais permitem o crescimento deste componentes mediante a ligação de um componente com outro. O componente conexo dominante aumenta com a união de outros componentes menores variando gradualmente de tamanho até sofrer uma variação abrupta, momento este em que o componente se espalha por todo o sistema, formando o componente percolante (24). A indicação desta variação são os picos, na base do gráfico, correspondendo às derivadas do tamanho dos maiores componentes fortes e fracos. Observa-se, na fig. 3.4 que por volta de 400 neurônios ocorre uma variação abrupta, momento em que o maior componente conexo percola o sistema.

Para a caracterização topológica escolhemos como medidas individuais dos vértices: o grau de entrada, grau de saída, coeficiente de agregação e reciprocidade. Para caracterizar a dinâmica integra e dispara utilizaremos a taxa média de disparos e a média e o desvio padrão dos tempos entre disparos.

A fig.3.4.(c), ilustra o grau médio para o exemplo respectivo. Percebe-se que esta medida está fortemente relacionada com o tamanho do maior componente conexo.

A fig.3.4.(d) mostra uma medida de dinâmica integra e dispara, ou seja, o número final de sinais sinápticos (disparos) sendo emitidos para época final daquele estágio de simulação. E finalmente, na fig. 3.4.(e), ilustramos a evolução dos disparos (obtida da matriz binária de disparos), sendo as linhas correspondentes aos instantes e as colunas correspondentes aos neurônios. A cor vermelha identifica os neurônios que estão em estado de ativação naquele instante. Portanto, quanto maior o tamanho do componente fortemente conexo, maior a quantidade de neurônios disparando para seus vizinhos, podendo um sinal ser propagado por longas distâncias no sistema.

Na fig. 3.5 temos, em tamanho maior, a matriz de disparos para época 500. Percebe-se que alguns vértices nunca disparam (cor azul). São aqueles que não pertencem ao maior componente conexo forte. Incialmente a rede possui alguns vértices ativos, aumentando com o decorrer do tempo até atingir um patamar de ativação semelhante a fig. 2.35.

Para verificar como a forma está influenciando na evolução topológica escolhemos três tipos de neurônios piramidais escolhemos três tipos de neurônios piramidais, do córtex occipital e pré-frontal de humanos e do córtex de macao. Escolhemos aleatoriamente 15 neurônios de 


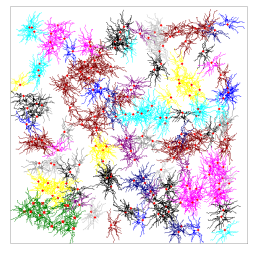

$$
E=200
$$
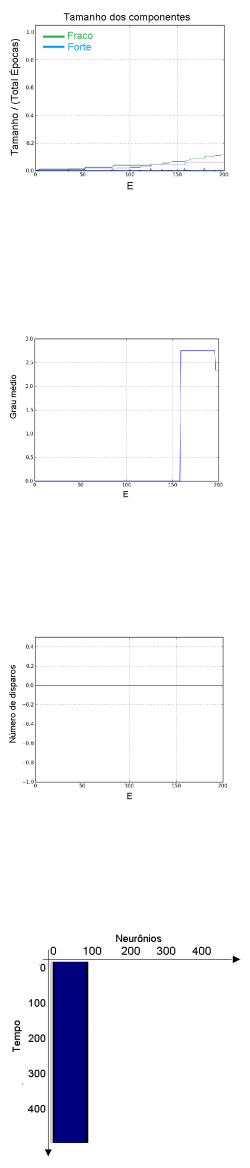
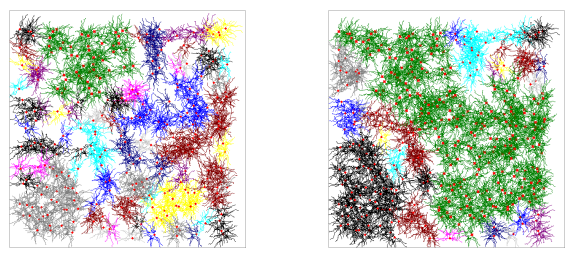

$E=300$

$E=400$

$E=500$

Evolução da rede.

(a)
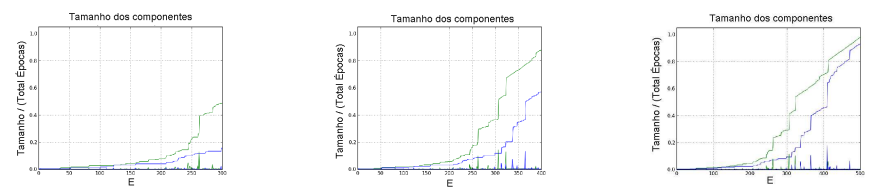

Componentes fraco e forte (cor azul).

(b)
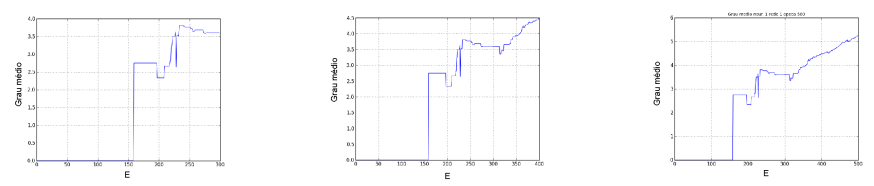

\section{Grau médio}

(c)
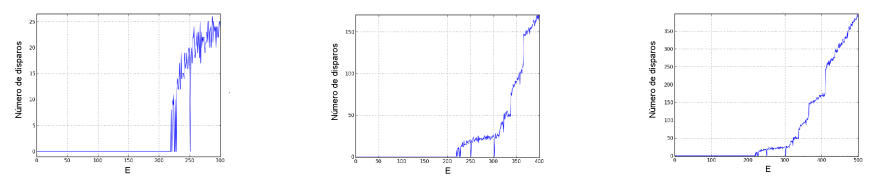

Número de disparos emitidos.

(d)
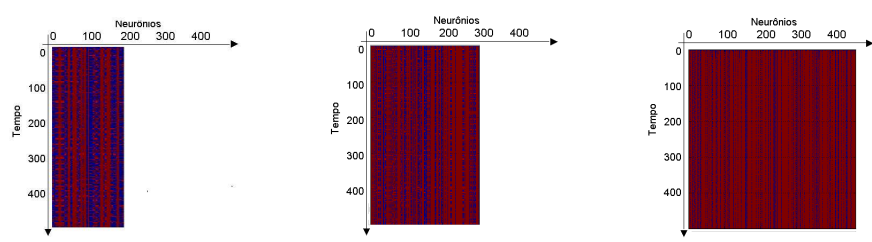

Matriz de disparos (spikegram).

(e)

Figura 3.4 - Exemplo de dinâmica neuronal. Uma mesma rede sendo formada ao longo de épocas quando a rede está com 200, 300, 400 e finalmente 500 neurônios (a), as cores idênticas indicam componentes fortemente conexos sendo formados conforme o crescimento da rede, sendo a cor verde o maior componente conexo. Gráficos com o tamanho normalizado (b) do componentes forte (azul) e fraco (verde), de acordo a dinâmica da rede. 


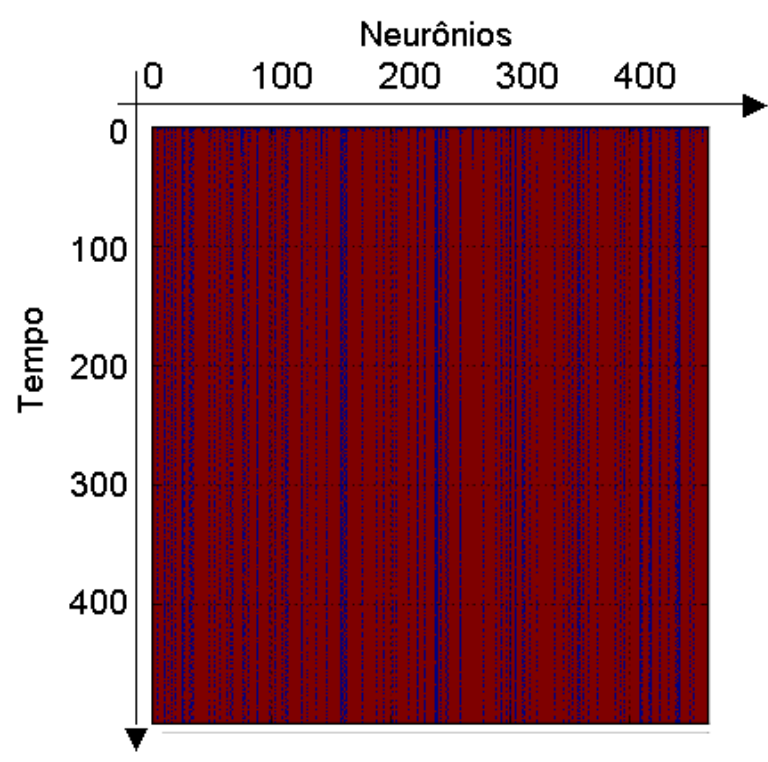

Figura 3.5 - Matriz de disparos (spikegram) para época 500.

cada um destes tipos. Alguns destes neurônios são ilustrados nas fig. 3.6, 3.7 e 3.8.

O desenvolvimento deste arcabouço experimental permite várias investigações relacionando a morfologia individual dos neurônios, as propriedades topológicas das redes respectivamente obtidas e a dinâmica de ativação segundo o modelo integra-e-dispara. Em particular, estamos interessados em dois principais aspectos descritos a seguir.

Primeiro, pretendemos estudar como medidas topológicas obtidas ao longo das épocas podem contribuir para a diferenciação das células neuronais, comparativamente à caracterização mais tradicional por medidas diretas da forma do neurônio. Assim, primeiramente caracterizaremos as propriedades morfológicas dos neurônios utilizados em termos de 21 medidas representadas como histogramas, assim como através da respectiva projeção por análise de componentes principais. Em seguida, utilizaremos como atributos a sequência de valores de certas medidas topológicas (mais especificamente grau de entrada, grau de saída, coeficiente de agregação e reciprocidade) tomadas ao longo das épocas como vetores de atributos, o que permitirá a comparação com os grupos obtidos utilizando-se apenas as medidas morfológicas de cada neurônio.

O segundo ponto de interesse especial desta tese é a investigação do relacionamento entre função (dinâmica integra-e-dispara) e a topologia da rede ao longo das épocas de desenvolvimento. Este relacionamento será quantificado através da correlação de Pearson entre cada uma de várias medidas de topologia (isto é, grau de entrada, grau de saída, coeficiente de agregação e reciprocidade) e cada uma de várias medidas dinâmicas (isto é, taxa de disparo, média e desvio padrão do intervalo de disparos). Um alto valor de correlação portanto indicará 
que a propriedade dinâmica pode ser estimada com boa precisão a partir da medida topológica, e vice-versa. Questões de particular interesse incluem:

(A) Como essas correlações variam ao longo do crescimento da rede, em particular antes e após o fenômeno crítico de percolação?

(B) Como essas correlações dependem das propriedades topológicas das redes e também das propriedades morfológicas das células neuronais respectivas?

(C) Até que ponto as correlações podem ser utilizadas para discriminação entre as células neuronais utilizadas na construção das redes?

(D) Como as correlações se modificam quando mudamos a distância máxima de conexão de alcance da região axonal?

As seções seguintes tratam dos recursos computacionais utilizados, descrevem os resultados obtidos e suas respectivas discussões.

\subsection{Recursos computacionais}

Para cada neurônio foram obtidas 50 evoluções de rede e para cada época dessas redes foram realizadas 500 simulações da dinâmica. A linguagem Delphi foi usada para construir a rede ao longo das épocas, visualizar os neurônios e rede em três dimensões. Os scripts em Python e Scilab foram usados para geração de gráficos e extração de medidas. Usamos a biblioteca livre Igraph e script Scilab para análise de dados utilizando Análise de Componentes Principais (PCA) e Análise Canônica (45). Para geração das redes utilizou-se o sistema operacional Windows e extrações medidas foram feitas num cluster GNU Linux.

\subsection{Caracterização dos neurônios através de Medidas Morfológicas}

Nas fig.3.6, fig.3.7 e fig.3.8, temos alguns neurônios cujas coordenadas foram retiradas do repositório neuromorpho e visualizadas através de um programa desenvolvido durante a pesquisa para este propósito.

Para caracterizar a morfologia das classes neuronais, extraímos a principais medidas utili- 


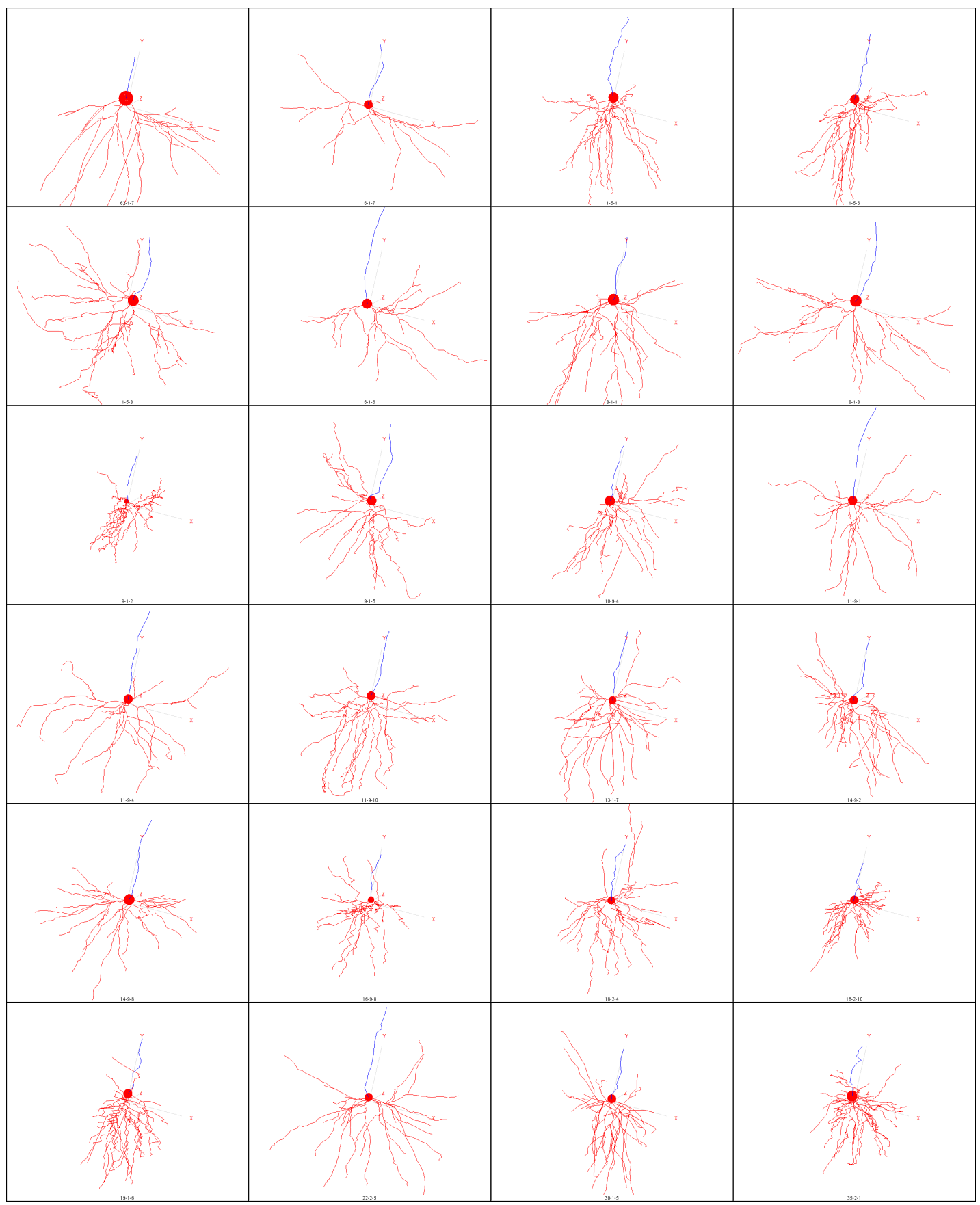

Figura 3.6 - Neurônios piramidais occipitais. 


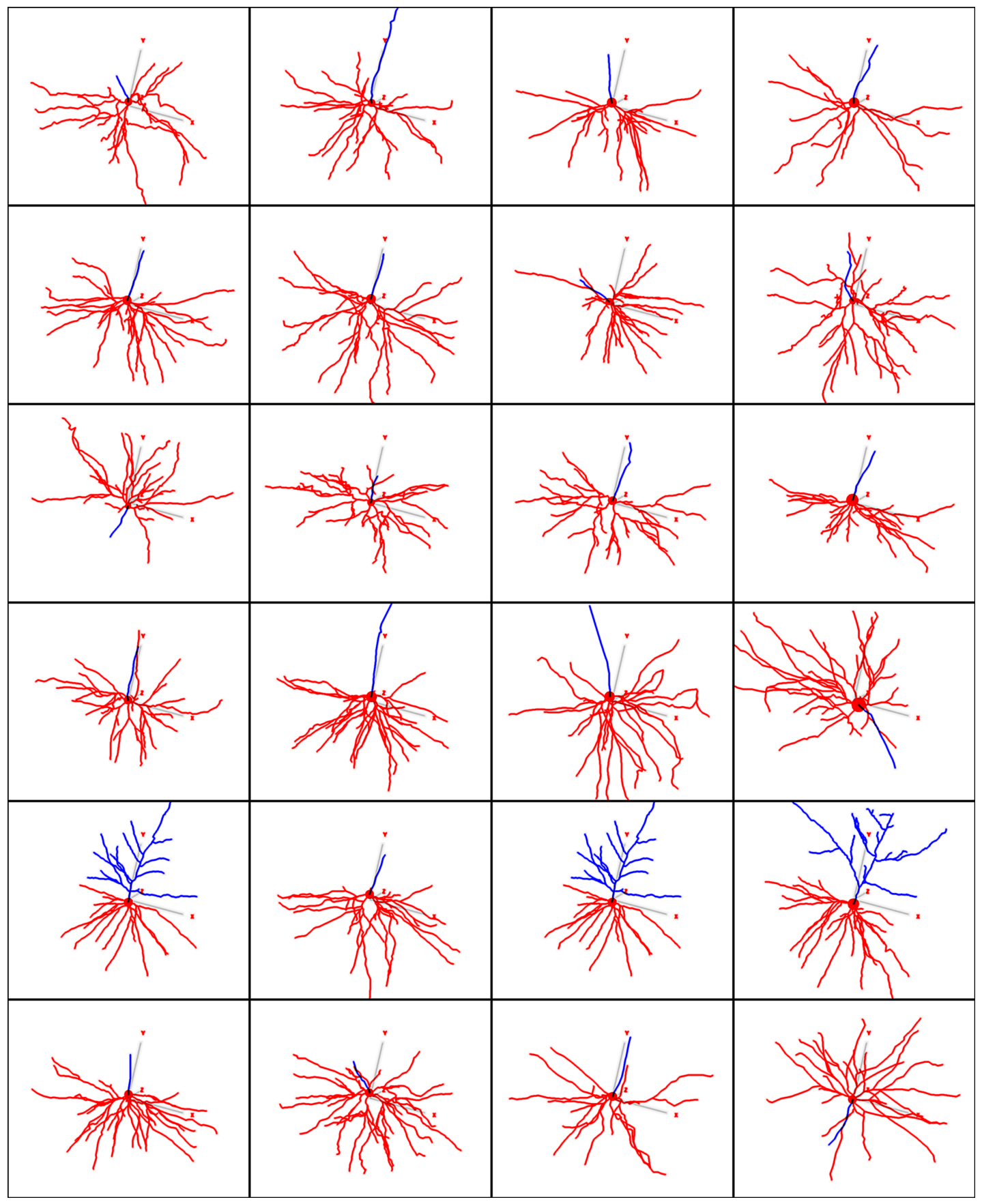

Figura 3.7 - Neurônios piramidais pré-frontais. 


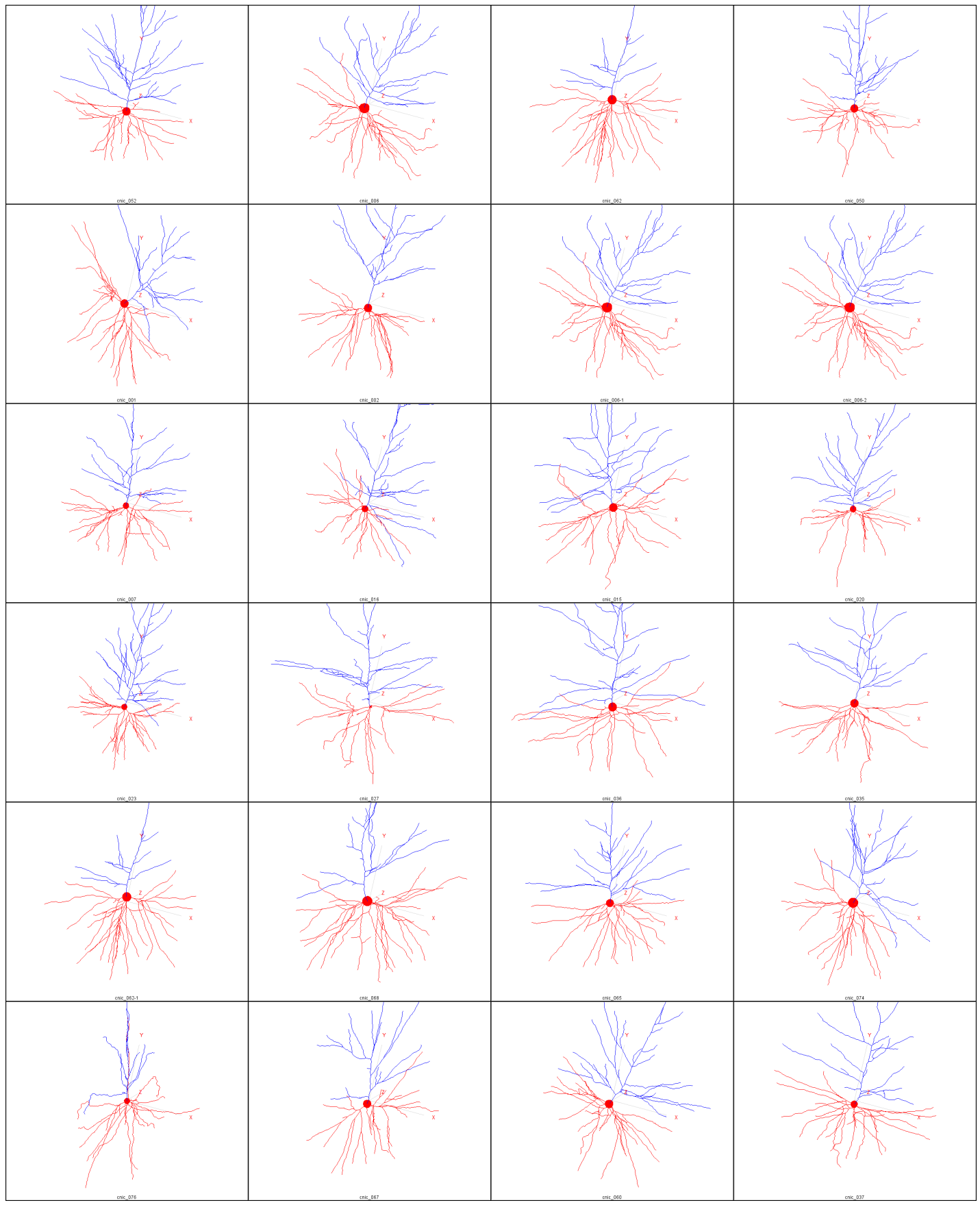

Figura 3.8 - Neurônios piramidais córtex macaco. 
zadas, através do programa gratuito L-Measure, disponível no repositório neuromorpho. Extraímos as medidas e disponibilizamos visualmente as características destas células através de vários histogramas conforme a fig. 3.9. Com estas medidas podemos classificar com distinção os neurônios do córtex do primata, enquanto os neurônios do córtex humano apresentam características morfológicas semelhantes. Isto fica claro na separação entre a curva verde (macaco) e as outras duas curvas, especialmente para as medidas números de bifurcações, profundidade, diâmetro médio, ordem do ramo, contração média, fragmentação, taxa média de Rall, média do ângulo de bifurcação local e média da dimensão fractal.
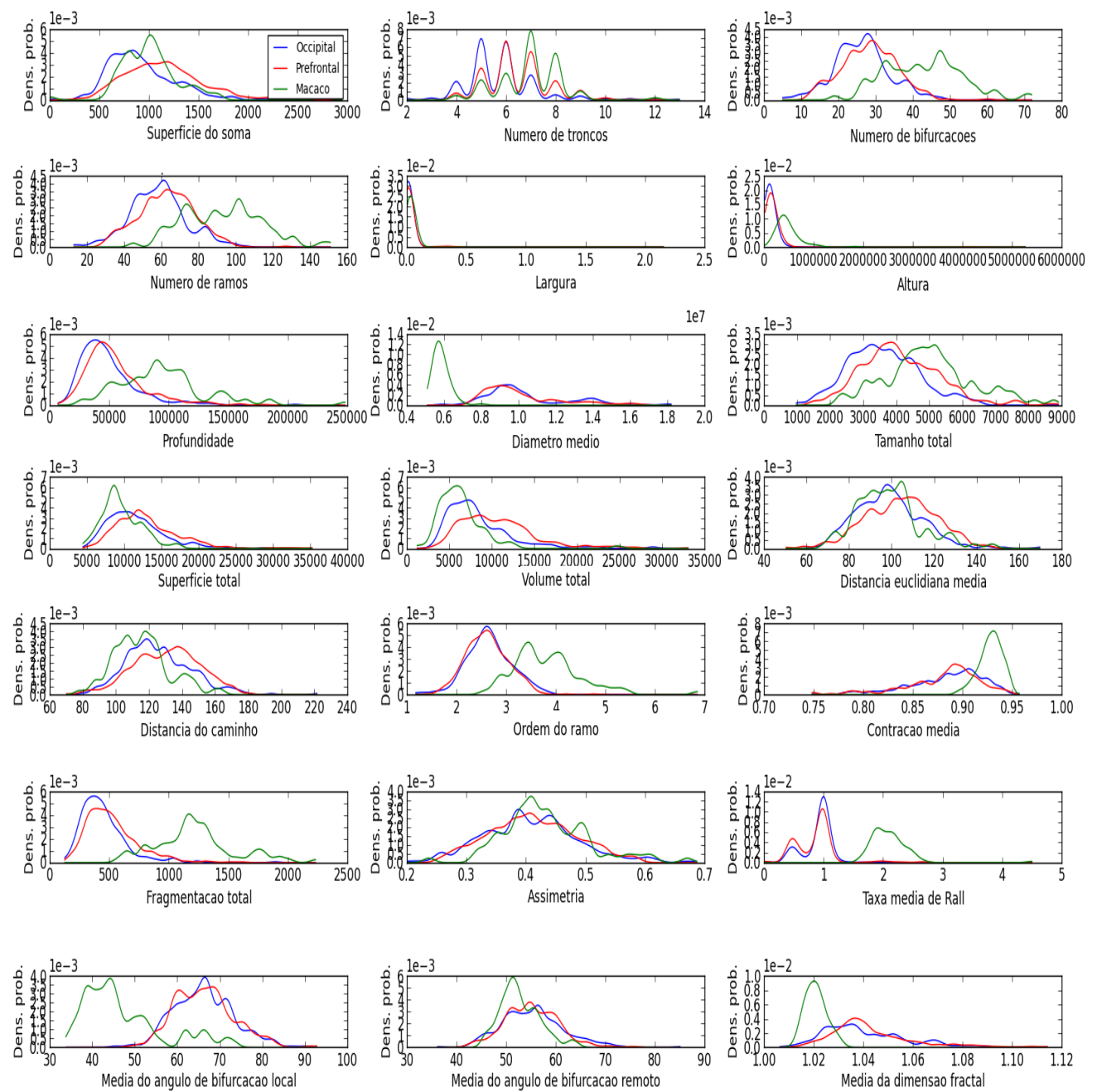

Figura 3.9 - Histograma de medidas neuromorpho. Medidas relacionadas aos neurônios humanos occipital e prefontal, e neurônios do córtex de macaco.

Utilizando a técnica PCA (45) reduzimos as dimensões de características para somente duas, podendo ver conforme a fig. 3.10 que há uma distinção entre estas classes de neurônios piramidais de humanos e primatas. Um pouco mais além, podemos visualizar com mais 


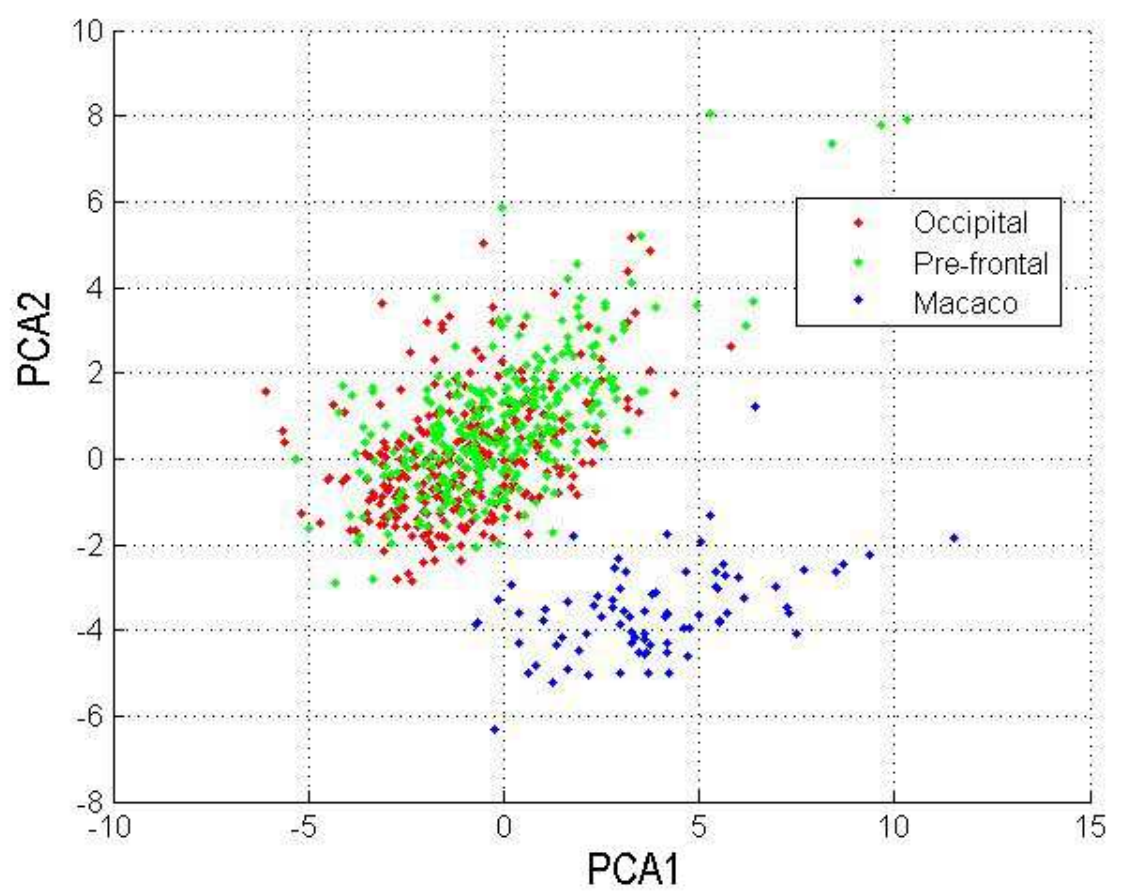

Figura 3.10 - PCA para medidas das três classes neuronais, occipital, pré-frontal e córtex de macaco.

conforto esta separação através do discriminante linear de Fisher ou discriminante canônico. Este discriminante, através de duas combinações das medidas extraídas conseguiu discriminar um pouco mais as informações correspondentes aos neurônios do símio, mas não aos neurônios de humanos.

\subsection{Correlações dinâmica $x$ topologia em relação ao crescimento das redes: redes individuais}

As figs. 3.12, 3.13, 3.14 mostram vários aspectos de redes obtidas respectivamente para neurônios do macaco, occipitais humanos e pré-frontais humanos. A evolução do tamanho do maior componente (primeira linha das figuras) é semelhante nos três casos, com a percolação por componente fraco acontecendo antes do componente forte, como poderia ser esperado. $\mathrm{O}$ ponto de percolação forte lado-a-lado, marcado com uma linha vertical em todas essas figuras, tende a corresponder à variação abrupta do tamanho do maior componente e a acontecer proximamente na época 400. Essas figuras mostram também a derivada do tamanho desses componentes.

O número de neurônios ativos (segunda linha das figuras) tende a acompanhar proxi- 


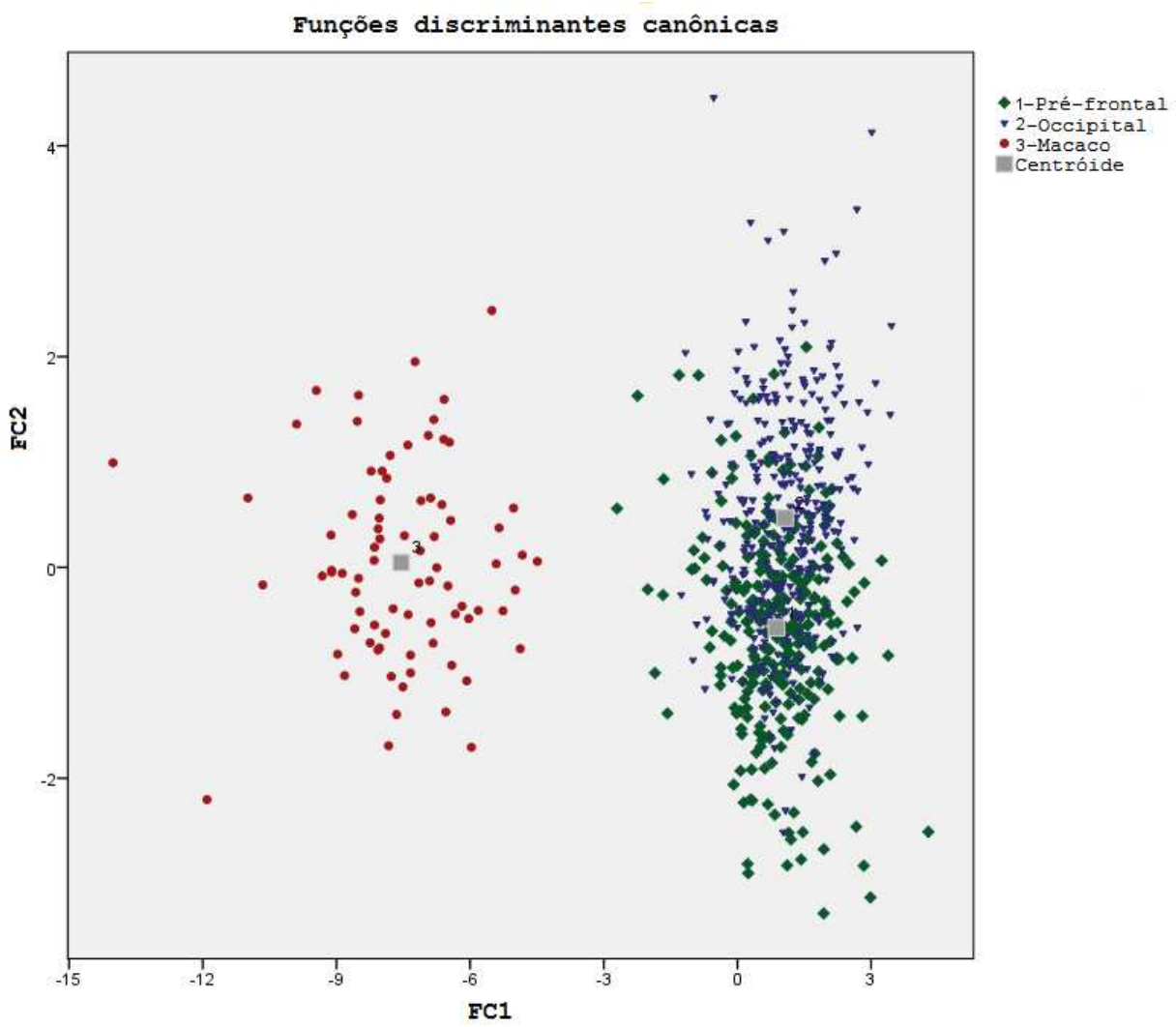

Figura 3.11 - Função discriminante canônica para medidas das três classes neuronais, occipital, préfrontal e córtex de macaco.

mamente o tamanho do maior componente forte, apresentando uma variação abrupta na percolação. Quando normalizado pelo tamanho do maior componente, o número de neurônios ativos (terceira linha) apresenta grande variação num intervalo de épocas próximo à percolação do componente fraco, seguida de uma evolução mais suave, que tende para $100 \%$. Comportamento semelhante é observado para os três neurônios.

A reciprocidade da rede (quarta linha) converge rapidamente para um valor pouco superior a 0.5 , apresentando pouca variação ao longo das épocas mesmo por ocasião da percolação do componente fraco e forte.

As quintas linhas das figuras mostram a evolução da correlação de Pearson entre o grau de saída e a taxa média de disparos dos neurônios. Observa-se grande variação num intervalo de épocas que precede a percolação do componente fraco, seguida de uma convergência suave para um valor ligeiramente acima de 0.5 , que tende depois a retornar a este valor (próximo à época 500).

Estas variações anteriores à epoca da percolação do componente conexo fraco, ocorre porque o maior componente fortemente conectado alterna entre os grupos conectados (fig. 3.4 (a), para $E=200$ e $E=300$ ). Os componentes conexos fortes que surgem oscilam no 
MEDIDAS TOPOLÓGICAS E DINÂMICAS REDE DE NEURÔNIOS CÓRTEX DE MACACO
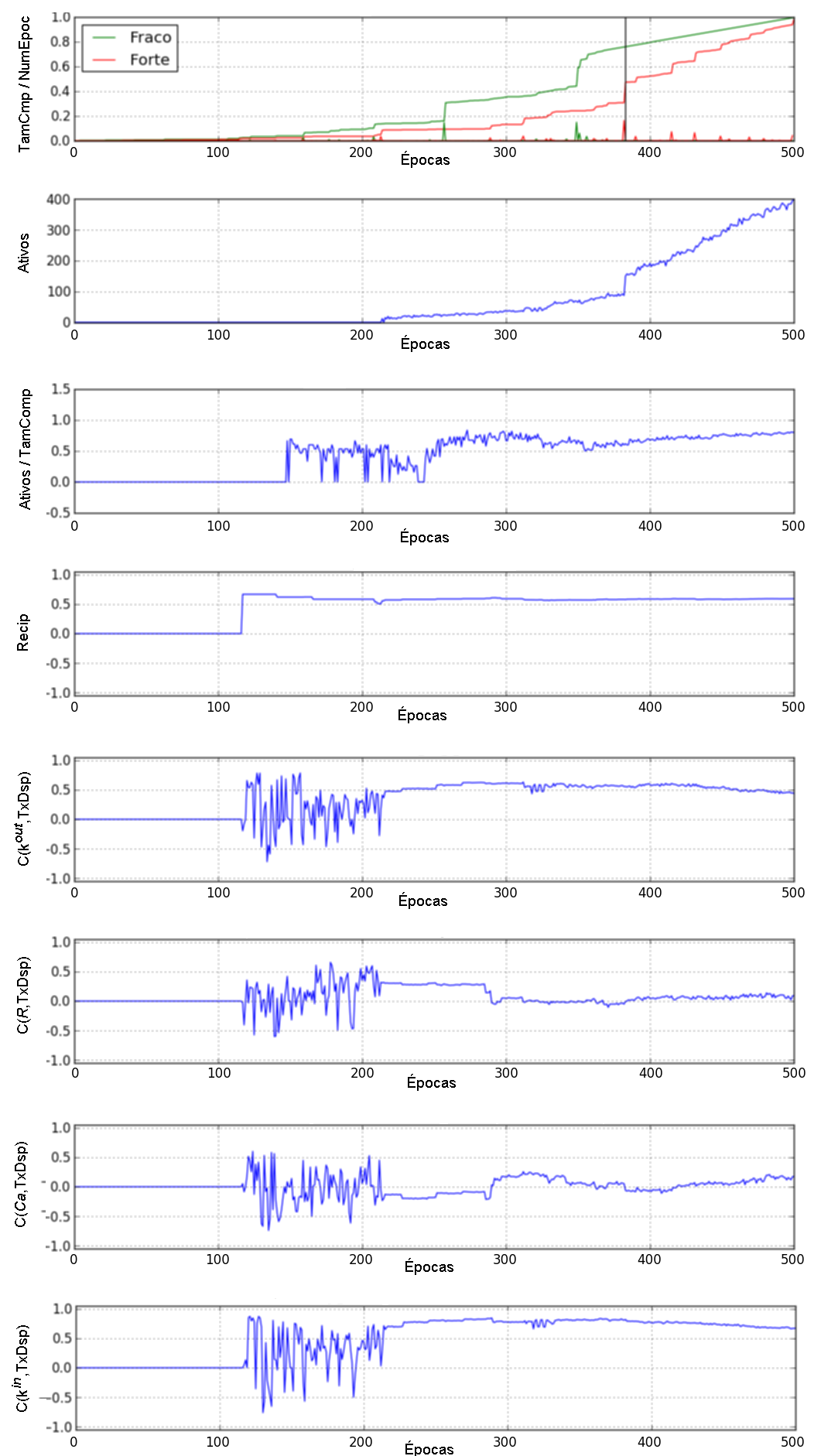

Figura 3.12 - Medidas de topologia e dinâmica para redes de neurônios do cortex do macaco ao longo das épocas. De cima para baixo, tamanho dos componentes conexos, número de neurônios ativos, neurônios ativos por tamanho de componente, reciprocidade da rede, correlações entre grau de saída $x$ taxa de ativação, reciprocidade $x$ taxa de ativação, coeficiente de agregação $\times$ taxa de ativação e grau de entrada $\times$ taxa de ativação. 
MEDIDAS TOPOLÓGICAS E DINÂMICAS REDE DE NEURÔNIOS CÓRTEX OCCIPITAL HUMANO
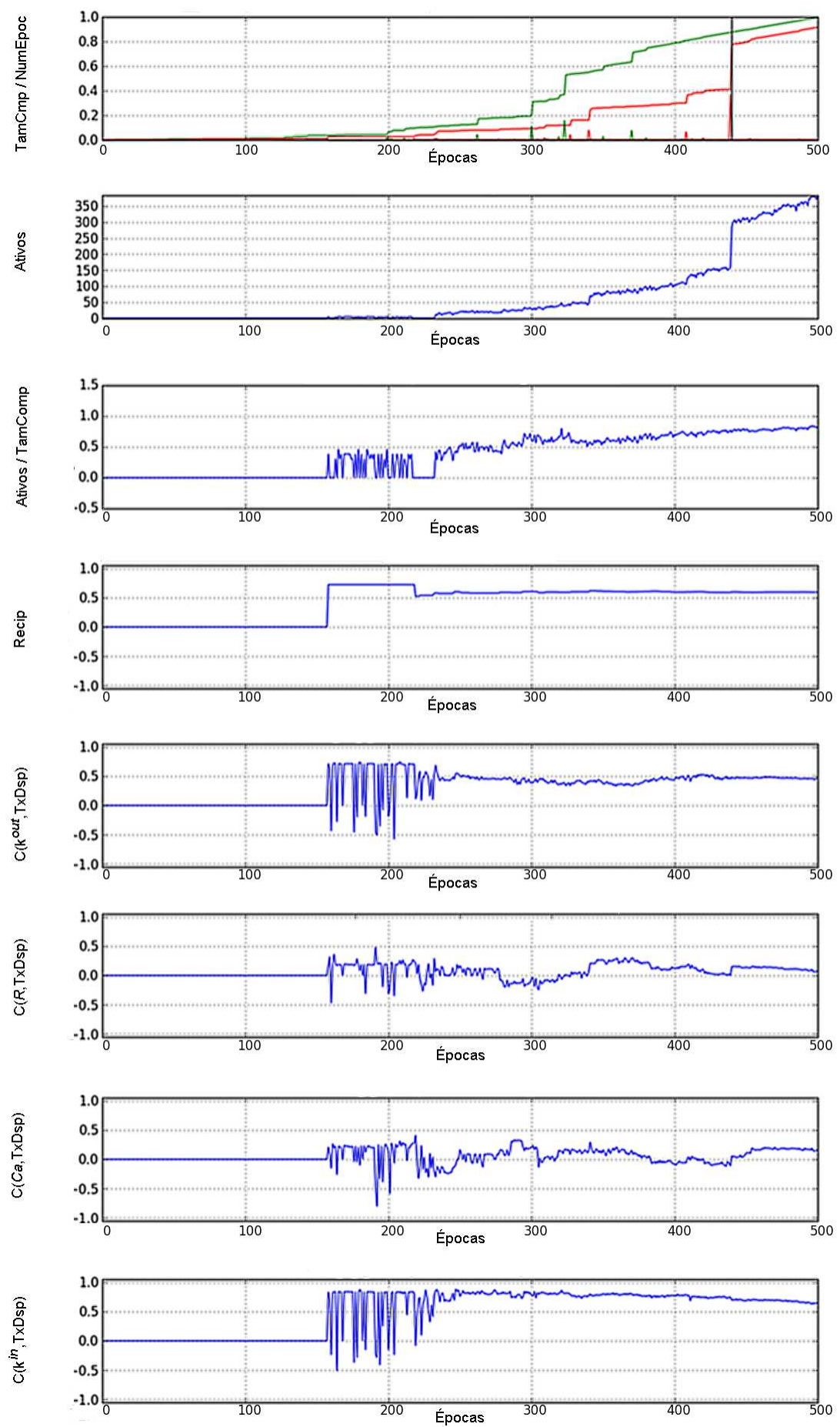

Figura 3.13 - Medidas de topologia e dinâmica para rede de neurônios occipitais ao longo das épocas. De cima para baixo, tamanho dos componentes conexos, número de neurônios ativos, neurônios ativos por tamanho de componente, reciprocidade da rede, correlações entre grau de saída $x$ taxa de ativação, reciprocidade $x$ taxa de ativação, coeficiente de agregação $x$ taxa de ativação e grau de entrada por taxa de ativação. 
MEDIDAS TOPOLÓGICAS E DINÂMICAS REDE DE NEURÔNIOS CÓRTEX DE PRÉ-FRONTAL HUMANO
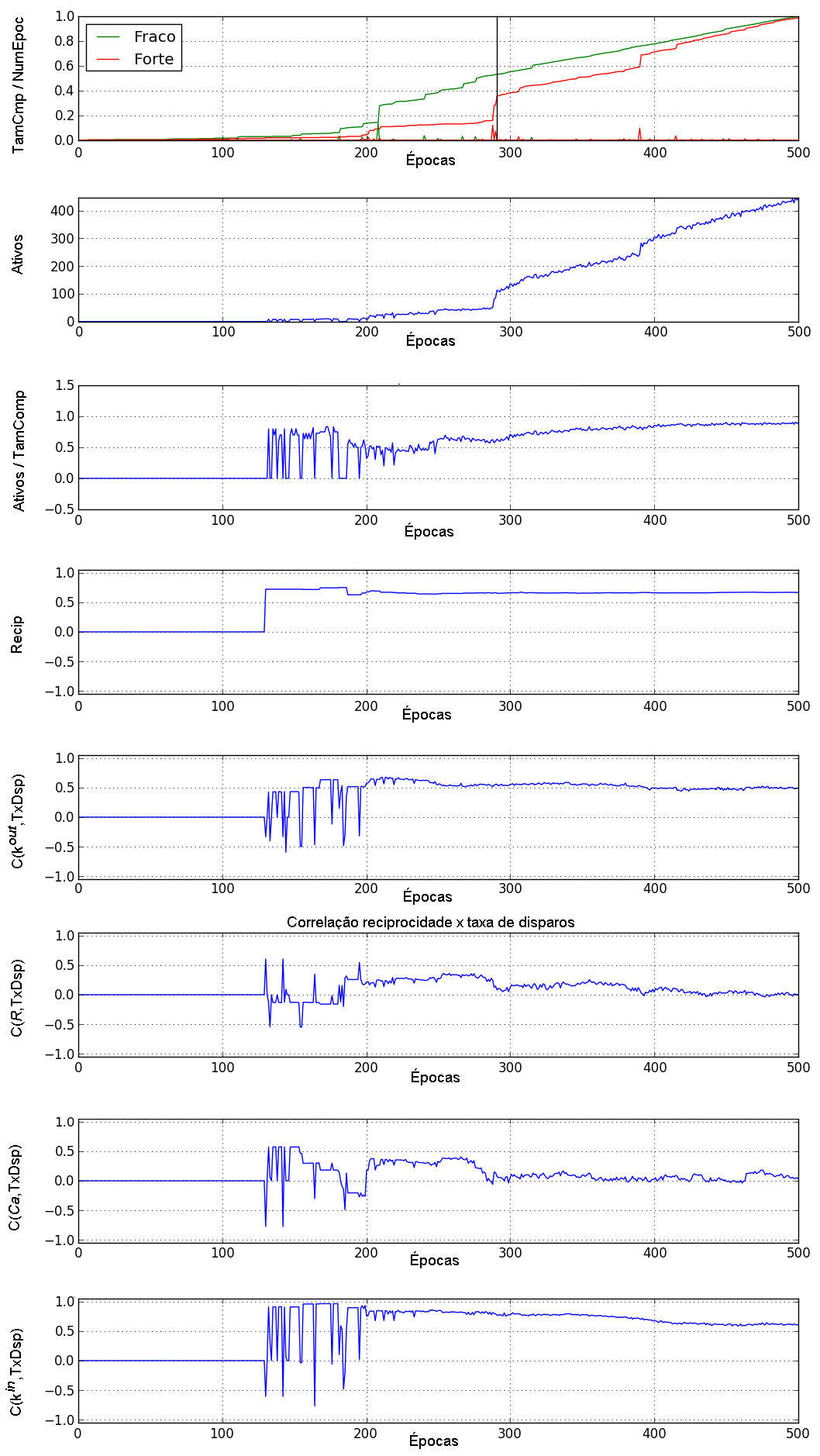

Figura 3.14 - Medidas de topologia e dinâmica para rede de neurônios occipitais ao longo das épocas. De cima para baixo, tamanho dos componentes conexos, número de neurônios ativos, neurônios ativos por tamanho de componente, reciprocidade da rede, correlações entre grau de saída $x$ taxa de ativação, reciprocidade $x$ taxa de ativação, coeficiente de agregação $x$ taxa de ativação e grau de entrada por taxa de ativação. 
domínio do maior tamanho de uma época para outra.

O comportamento da correlação entre o grau de entrada e a taxa média de disparos, ilustrado nas sextas linhas das figuras, apresenta comportamento semelhante, a menos do fato de que a convergência se dá para um valor superior a 0.5 nos três casos. Estes valores de correlações, superiores ou próximos de 0.5 , são significativos e indicam um relacionamento entre a taxa média de disparos e os graus de entrada e saída médios nas redes obtidas para os 3 tipos de neurônios. De fato, uma correlação positiva mais forte é observada para o grau de entrada, sugerindo que a atividade da rede é em boa parte determinada pelo seu grau médio de entrada, ou seja, o quanto de ativação os neurônios recebem. Curiosamente, após o crescimento que segue a percolação já observado, existe uma ligeira queda desta correlação, que pode ser entendida como o fato de que, quando a rede está já bem desenvolvida e conectada, o acréscimo de conexões de entrada não necessariamente significa no aumento da taxa de disparo, que tende a saturar (neurônios ativados a cada época).

A correlação entre o coeficiente de agrupamento e a taxa média de disparos é ilustrada nas quintas linhas das figuras. Novamente, após uma grande variação no intervalo de épocas que antecede a percolação do componente fraco, os valores desta correlação tendem a zero, indicando que esta medida topológica não se relaciona, ao menos para esses casos, com a dinâmica de ativação das redes.

Para investigar o efeito do raio do alcance nas correlações, repetimos as simulações anteriores, utilizando raio 10 ao invés de 5 . Os resultados obtidos são discutidos apresentados nas fig. 3.15, 3.16, 3.17. Nesses três casos observa-se que as percolações acontecem por volta da época 300, ao invés de 400 como nos casos anteriores.

Portanto, o aumento do raio implicou numa evolução mais rápida da rede, o que é também refletido nas medidas de topologia, dinâmica e correlações para as três células consideradas.

\subsection{Correlações dinâmica $x$ topologia em relação ao crescimento das redes: médias sobre redes}

Enquanto na seção anterior realizamos uma primeira verificação sobre as propriedades topológicas, dinâmicas, e respectivas correlações considerando-se células individuais de cada uma das três categorias, nesta seção apresentamos resultados obtidos para um número maior de células piramidais daquelas categorias. Foram considerados um total de 15 neurônios por 
MEDIDAS TOPOLOGICAS E DINÂMICAS REDE DE NEURÔNIOS CÓRTEX DE MACACO

Raio de alcance 10
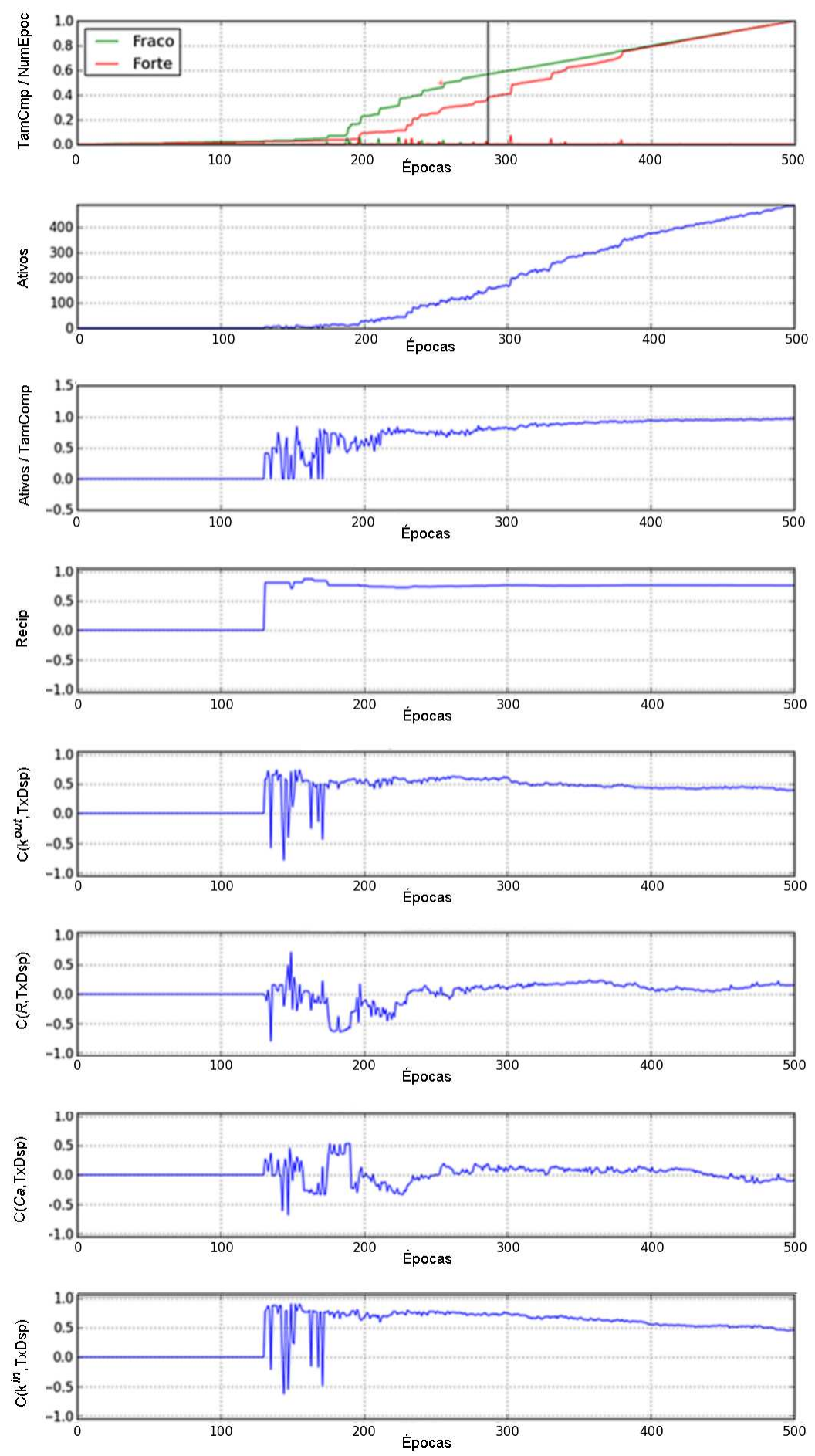

Figura 3.15 - Medidas de topologia e dinâmica com raio de alcance do axônio igual a 10, de neurônios do córtex do macaco. 

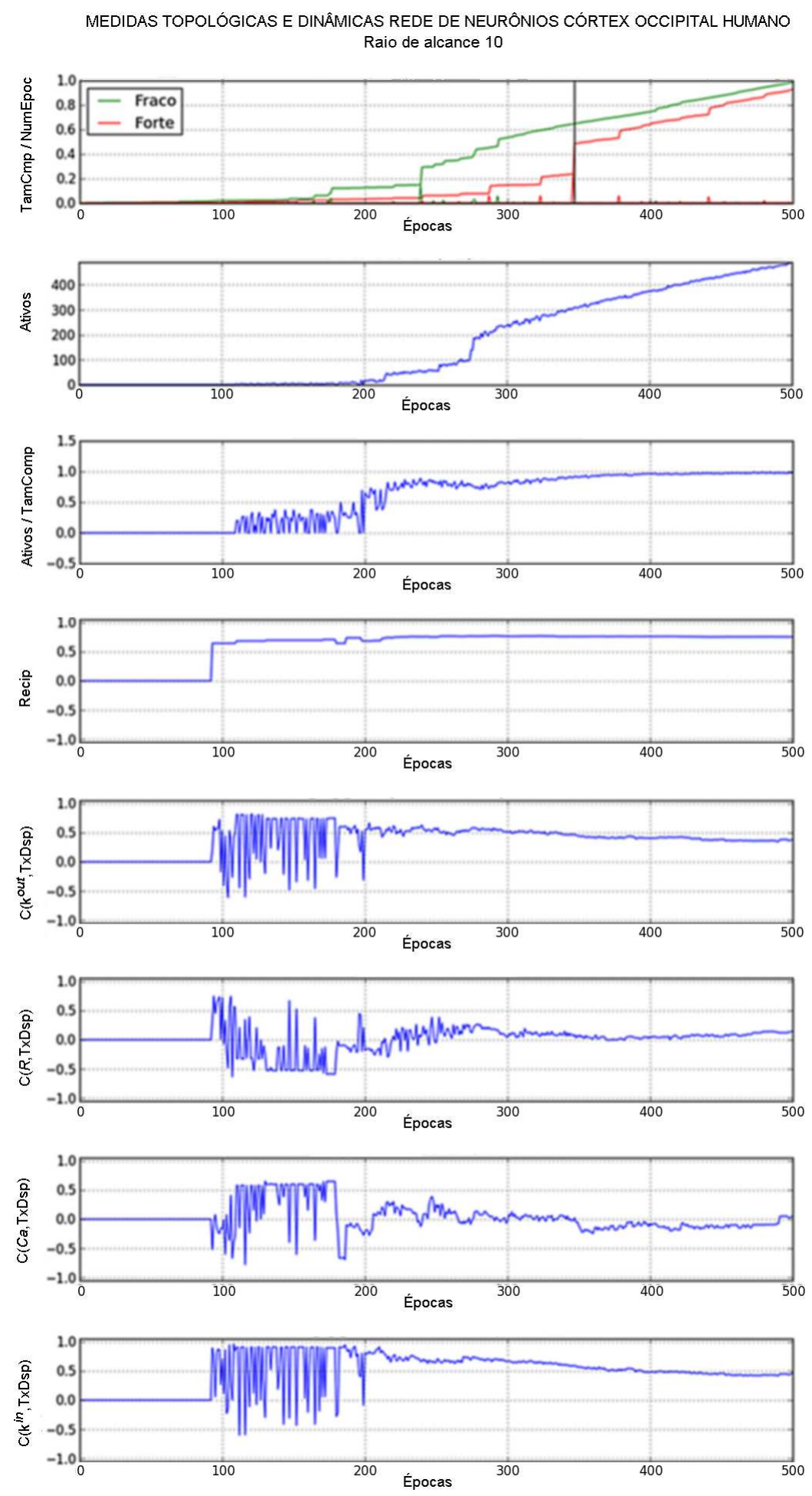

Figura 3.16 - Medidas de topologia e dinâmica com raio maior de neurônios occipital humano. 
MEDIDAS TOPOLÓGICAS E DINÂMICAS REDE DE NEURÔNIOS CÓRTEX DE PRÉ-FRONTAL HUMANO

Raio de alcance 10
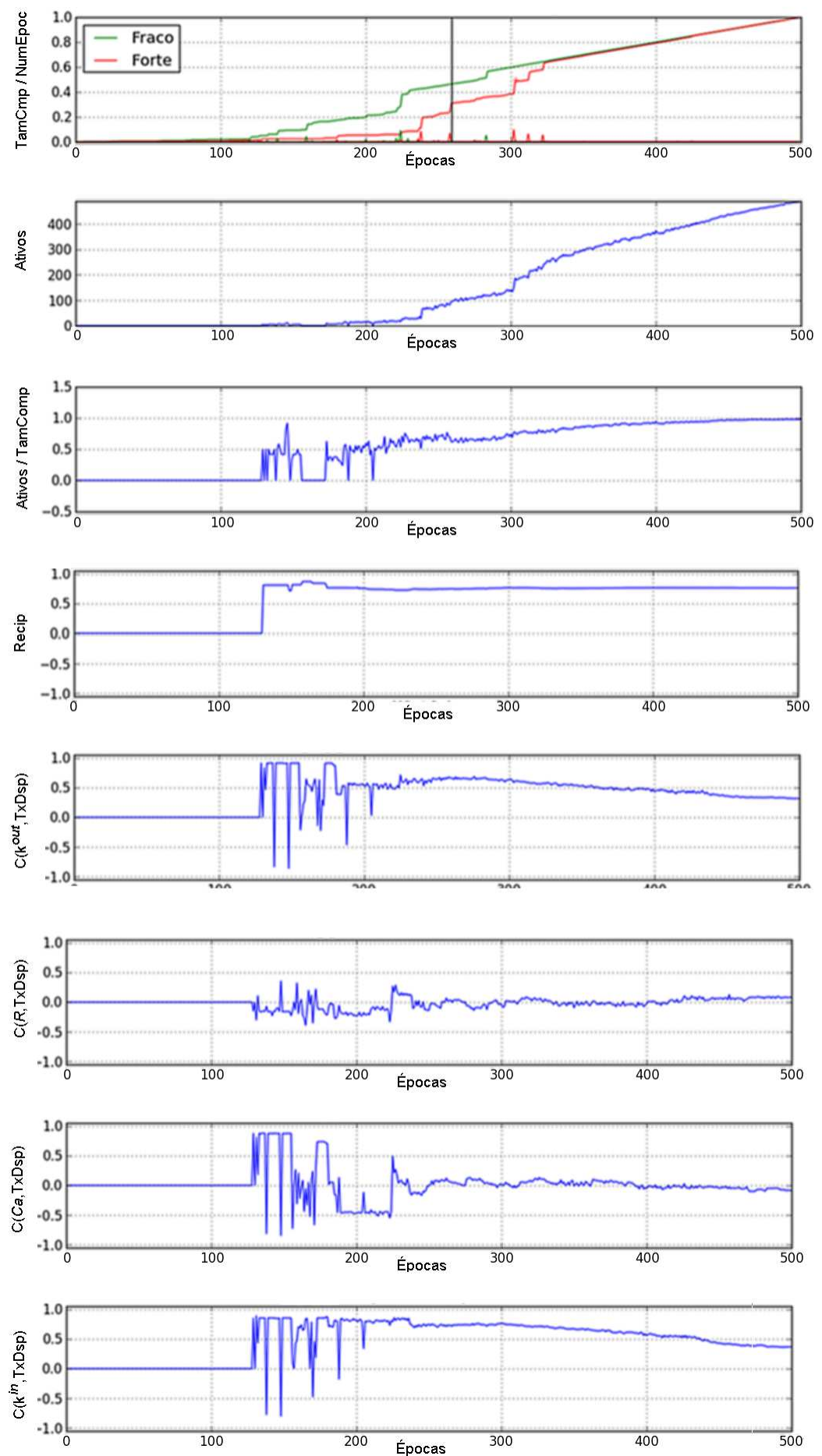

Figura 3.17 - Medidas de topologia e dinâmica com raio maior de neurônios pré-frontal humano. 
categoria. Cada célula foi utilizada para crescer em 50 redes (simulações), e a dinâmica de integra-e-dispara foi simulada para cada uma das 500 épocas de desenvolvimento das redes. Temos assim, um total de 45×50×500 simulações de dinâmica de ativação. Essas análises foram repetidas para o conjunto completo de células utilizadas (261 células occipitais e 318 células pré-frontais de humano e 80 células de macaco), obtendo-se resultados semelhantes.

A fig. 3.18 apresenta o número de neurônios ativos (primeira linha), reciprocidade média das conexões (segunda linha) e média de disparos (terceira linha). As curvas médias com barras de desvio padrão - mostradas em preto, verde e vermelho - referem-se à cada uma das três categorias de neurônios piramidais. Observa-se grande semelhança nas evoluções obtidas para as três categorias de neurônios, com as células do macaco apresentando valores levemente menores para as três medidas. Nota-se também boa semelhança com os resultados obtidos para uma única célula descritos na seção anterior. Grande variação entre os três tipos de células é observada para a reciprocidade da rede entre as épocas 100 e 200.

A fig. 3.19 apresenta as médias e desvios para correlações entre medidas topológicas. Novamente, a variação entre as simulações, expressa nas barras de erro, mostra-se mais acentuada entre as épocas intermediárias (a partir de 100), diminuindo ao longo de épocas posteriores. Observa-se pouca separação entre as três curvas. Valores relativamente altos de correlação de Pearson foram obtidos apenas entre os graus médios de entrada e saída (em torno de 0.6) e para a correlação entre o coeficiente de agregação e a reciprocidade das conexões (valores entre 0.3 e 0.4$)$.

As correlações entre as medidas dinâmicas utilizadas é apresentada na fig. 3.20. Essas correlações apresentam comportamento compatível ao que poderia ser esperado, ou seja, a taxa de disparo média tende a ser inversamente proporcional ao intervalo médio entre disparos.

A fig.3.21 ilustra as correlações de maior interesse neste trabalho, ou seja, entre propriedades dinâmicas e topológicas. Em linhas gerais, o comportamento qualitativo dessas curvas corrobora aquele para células individuais discutido na seção anterior: as correlações entre os graus médios de entrada e saída e a taxa média de disparos são, respectivamente, próximas a 0.7 e 0.5 para as épocas finais, enquanto o coeficiente de agregação e reciprocidade resultam pouco relacionados com a taxa de disparos. Pouca diferença é observada entre as três categorias, com valores ligeiramente menores para as correlações com os graus médios de entrada e saída. De forma semelhante às correlações anteriores, a variação maior é observada entre as épocas a partir de 100 até aproximadamente 350, decrescendo subsequentemente. 

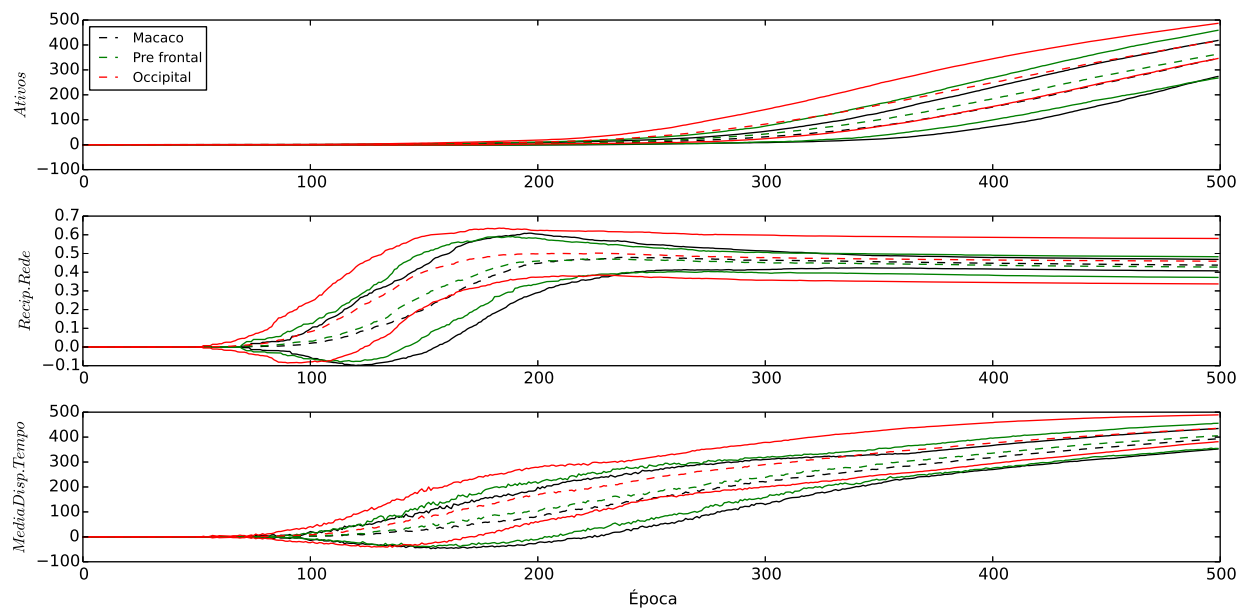

Figura 3.18 - Médias e desvios padrão do número de neurônios ativos; reciprocidade da rede e média de disparos no tempo ao longo das épocas para as três categorias de neurônios piramidais.
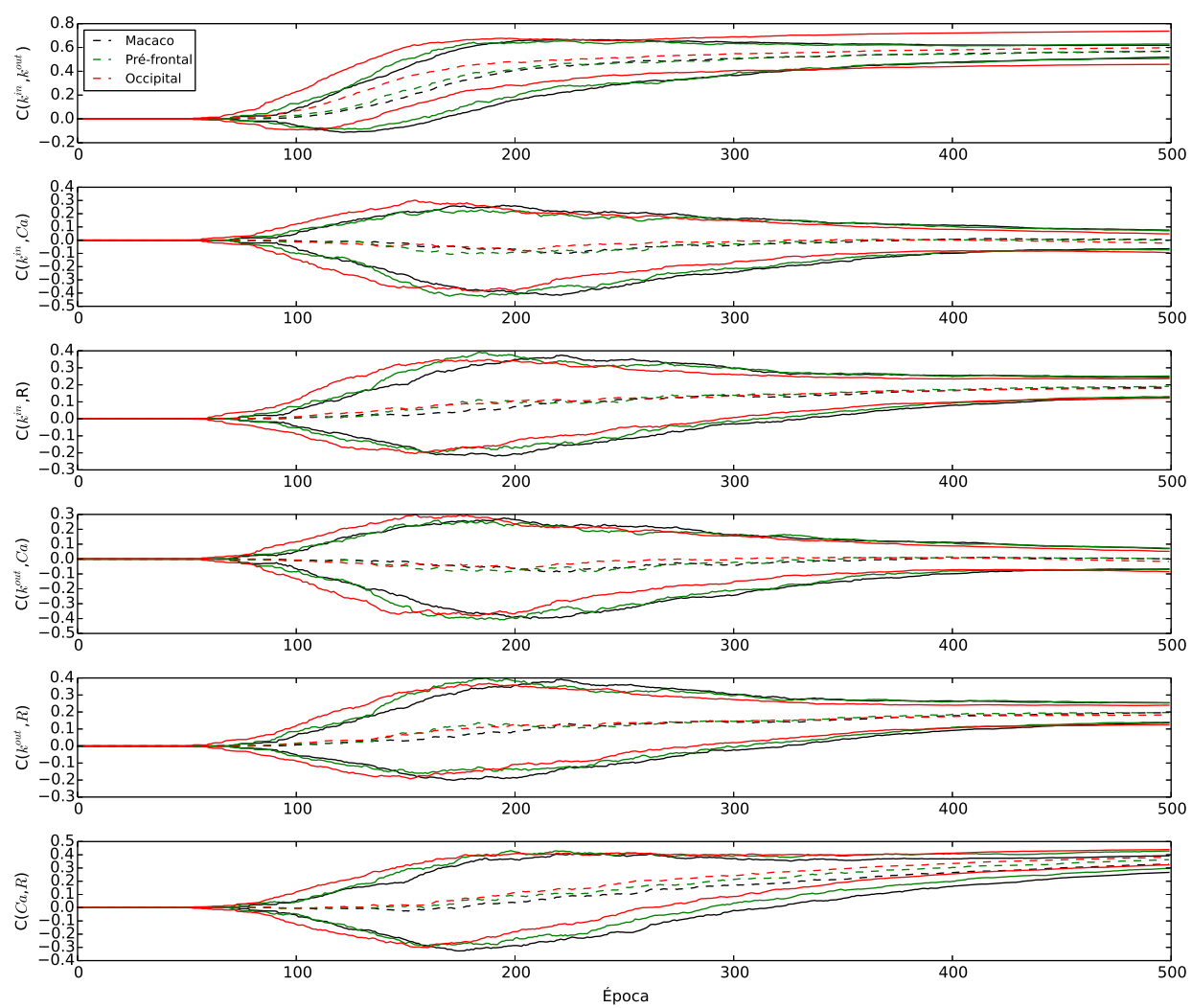

Figura 3.19 - Médias e desvios padrão para as correlações de Pearson entre as medidas topológicas ao longo das épocas de desenvolvimento para as três categorias de neurônios piramidais 

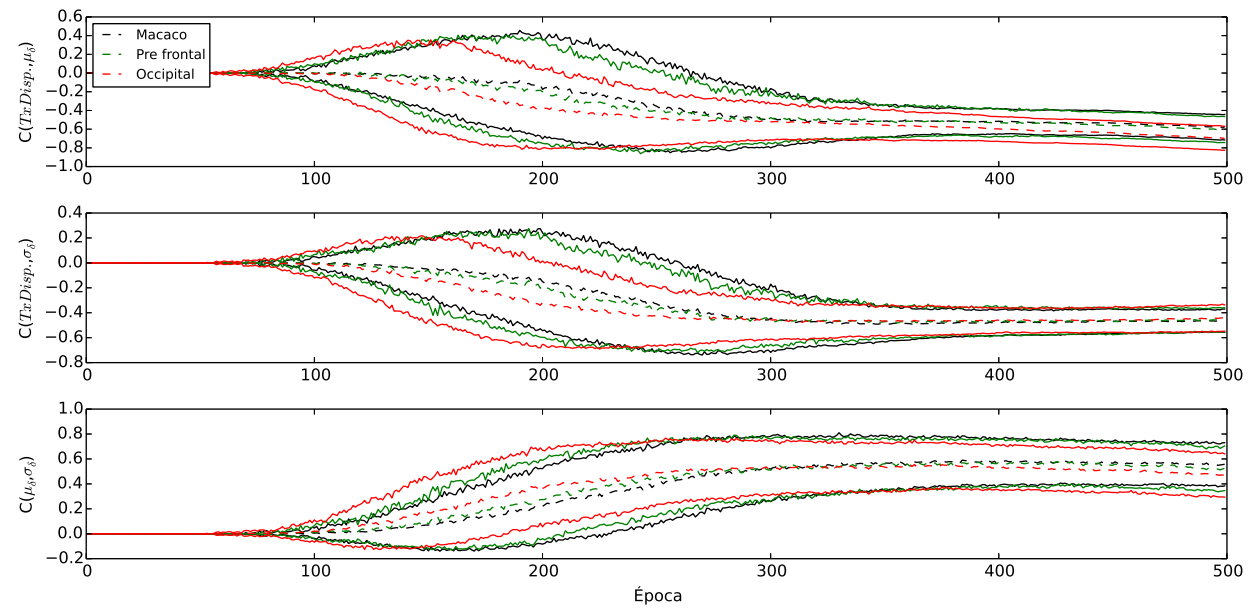

Figura 3.20 - Médias e desvios padrão para as correlações Pearson entre as medidas dinâmicas ao longo das épocas de desenvolvimento para as três categorias de neurônios piramidais.
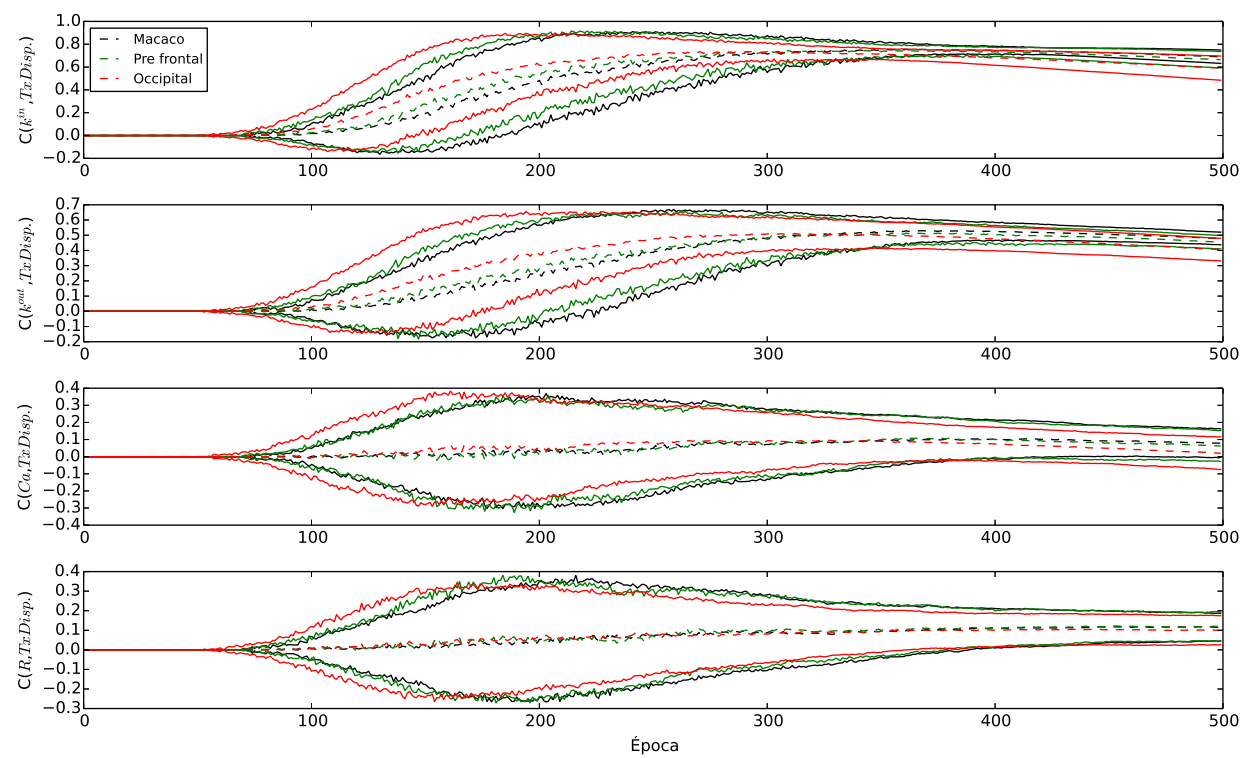

Figura 3.21 - Médias e desvios padrão das correlações as correlações entre as medidas dinâmicas e topológicas ao longo das épocas de desnvolvimento para as três categorias de neurônios piramidais. 


\subsection{Discriminação das categorias neuronais a partir dos perfis das medidas e correlações}

Um outro aspecto interessante a ser investigado quando dispomos das medidas e correlações de aspectos da topologia e da dinâmica é até que ponto a consideração de tais valores ao longo das épocas, em contraste com medidas morfológicas diretas dos neurônios, pode contribuir para a diferenciação das categorias. Para tanto, tomamos as curvas médias das várias medidas e correlações ao longo das épocas e as utilizamos como vetores de atributos, que foram então analisados por componentes principais (PCA).

A fig. 3.22 ilustra os PCAs obtidos considerando-se apenas medidas gerais da rede, mais especificamente o número de neurônios ativos, reciprocidade e média de disparos. Observa-se alguma separação entre os neurônios occipitais, que espalham-se pelo gráfico, diferentemente das outras duas categorias. A fig. 3.23 apresenta os resultados obtidos quando as correlações entre medidas topológicas ao longo das épocas são consideradas como vetores de atributos. As células de macaco separam-se um pouco para a correlação coeficiente de agregação e reciprocidade. Novamente as células occipitais apresentam uma maior variação no gráfico.

A fig. 3.24 ilustra os resultados de PCA obtidos para correlações entre medidas dinâmicas. Finalmente, a fig. 3.25 mostra os resultados de PCA para as correlações entre medidas topológicas e dinâmicas. Novamente, a correlação que envolve o coeficiente de agregação mostra um espalhametno maior das células occipitais humanas em relação aos outros dois casos.
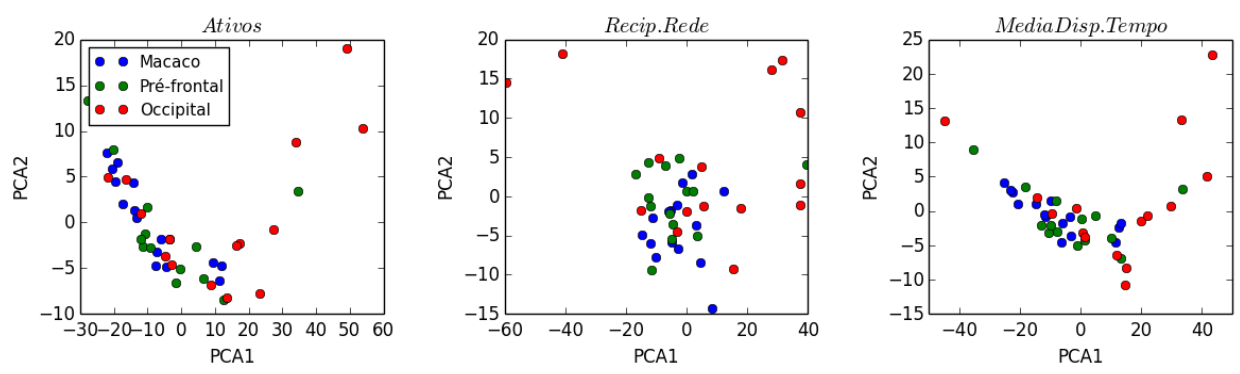

Figura 3.22 - Análise de componentes principais tomando-se medidas o número de neurônios ativos; reciprocidade da rede e média de disparos no tempo ao longo das épocas. 

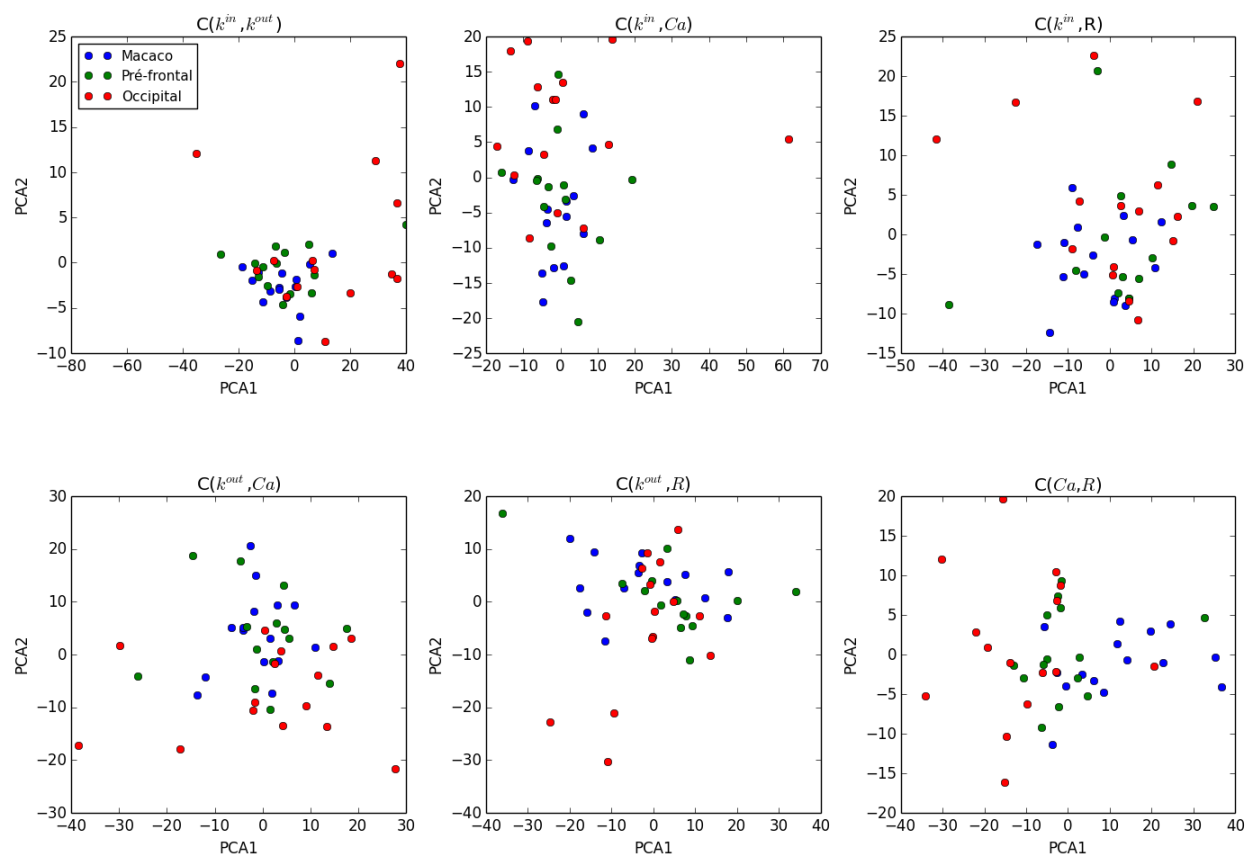

Figura 3.23 - Análise de componentes principais tomando-se como vetores de atributos as correlações entre medidas topológicas ao longo das épocas.
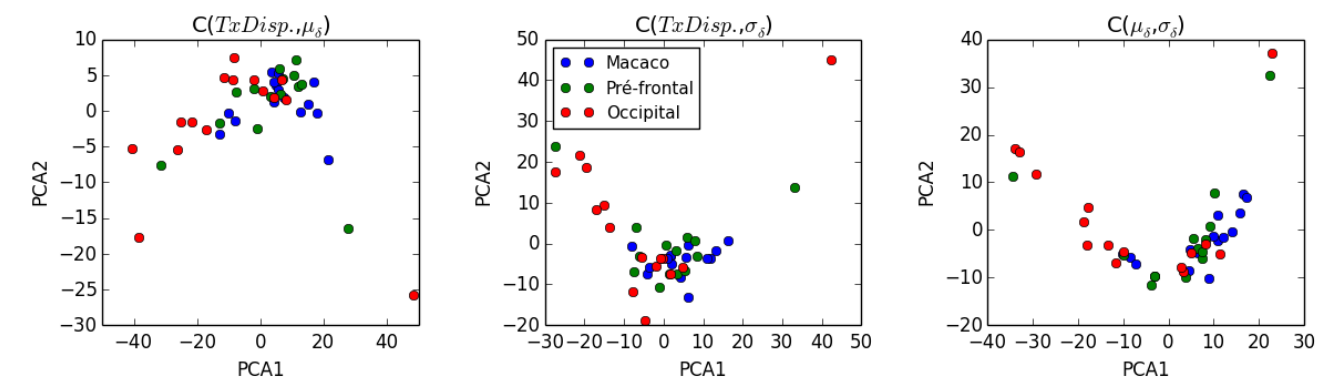

Figura 3.24 - Análise de componentes principais tomando-se como vetores de atributos as correlações entre medidas dinâmicas ao longo das épocas. 

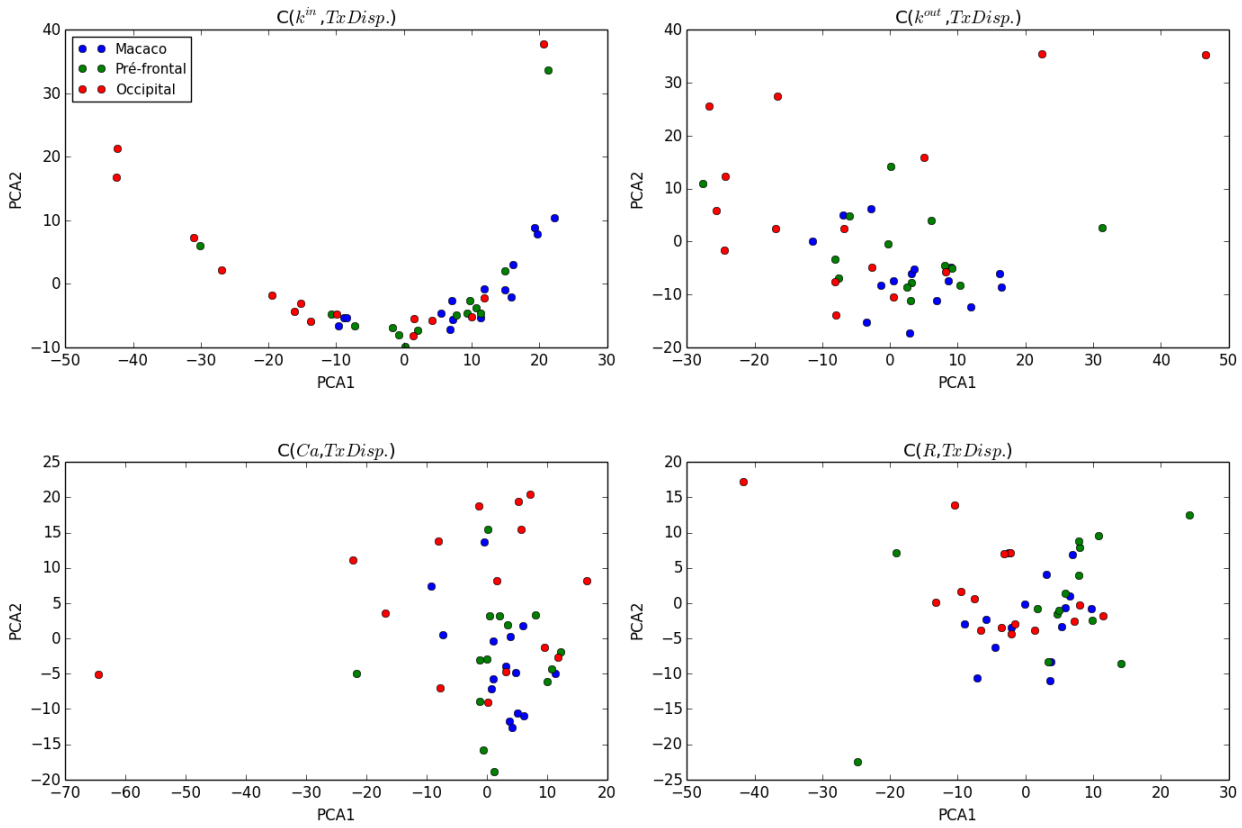

Figura 3.25 - Análise de componentes principais tomando-se como vetores de atributos as correlações entre medidas topológicas e dinâmicas ao longo das épocas. 


\section{Conclusões}

Este trabalho abordou o tema do relacionamento entre forma, topologia e dinâmica de ativação ao longo de épocas de desenvolvimento de redes neuronais tridimensionais morfologicamente realistas, derivadas da base Neuromorpho. Foram utilizados três tipos de neurônios piramidais: dois de humanos (occipitais e pré-frontais) e um de macacos (macaco Rhesus), que foram caracterizados morfologicamente através de histogramas de medidas e análise de componentes principais. Redes neuronais foram crescidas com neurônios dessas categorias selecionadas, e a dinâmica de ativação integra-e-dispara foi simulada em cada época ao longo do desenvolvimento. O relacionamento entre dinâmica e topologia foi então quantificado em termos de correlações de Pearson entre várias medidas. Diversos resultados interessantes foram obtidos. Correlações significativas foram obtidas entre a taxa média de disparos e o grau médio de entrada e saída em todos os casos. A primeira destas taxas mostrou-se maior que o valor típico de 0.5 obtido entre o grau médio de saída e a taxa média de disparos. Correlação próxima a zero foi obtida entre o coeficiente de aglomeração médio e a taxa média de disparos.

Observou-se também variações intensas das correlações em intervalos de épocas que precedem a percolação do componente fracamente conectado, seguidas de rápida convergência para valores típicos. No caso da correlação entre a taxa média de disparos e o grau médio de entrada, observou-se uma ligeira diminuição para valores elevados das épocas, sugerindo uma saturação da ativação da rede, que passa a não refletir variações no grau médio de entrada.

Investigou-se ainda como o uso dos perfis de evolução das várias correlações par-a-par pode ser utilizado para discriminação entre os três tipos de células piramidais.

As principais contribuições inovadoras deste trabalho podem ser sumarizadas como:

1. Desenvolvimento de um arcabouço computacional para investigação do relacionamento entre morfologia, topologia e dinâmica neuronal. Este arcabouço permitiu que a dinâmica de integra-e-dispara seja simulada para cada uma das épocas do desenvolvimento das conexões da rede em um espaço tridimensional, enquanto medidas da topologia da rede são obtidas;

2. Comparação das propriedades morfológicas de três tipos de células piramidais em termos de histogramas e análise de componentes principais (PCA). Verificou-se que os dois 
tipos de células piramidais dos humanos (occipitais e pré-frontais) apresentam propriedades morfológicas muito semelhantes entre si e, ao mesmo tempo, substancialmente diferentes das células piramidais do macaco. Desta forma, esta escolha permitiu a consideração tanto de grupos morfologicamente semelhantes como distintos nas investigações subsequentes;

3. Caracterização, em termos de medidas respectivas, da topologia das redes produzidas por estes três tipos de células ao longo das épocas de desenvolvimento, incluindo a identificação do momento da percolação lado-a lado e da evolução dos tamanhos dos componentes fraca e fortemente conectados;

4. Caracterização da dinâmica integra-e-dispara ao longo da evolução das redes em termos de medidas relacionadas à taxa de disparo e intervalos entre disparos. Verificou-se que o número de neurônios disparando tende a aumentar com o desenvolvimento da rede;

5. Estudo da relação entre características topológicas em termos do coeficiente de correlação de Pearson ao longo das épocas. Observou-se pouca separação entre as três categorias.

6. Estudo da relação entre características dinâmicas (de ativação) em termos do coeficiente de correlação de Pearson ao longo das épocas. Neste caso, o relacionamento tendeu a ser definido pela ligação intrínseca natural entre a taxa média de disparo e o intervalo médio entre disparos, que tendem a ser negativamente correlacionados;

7. Estudo da relação entre características dinâmicas e topológicas através do coeficiente de correlação de Pearson ao longo das épocas. Verificou-se que existe uma correlação significativa entre a dinâmica de ativação e os graus de entrada e saída médios, sendo mais forte no primeiro caso. Notou-se, ainda, que essas correlações apresentam evolução caracterizada por um período de ampla variação (antecedendo a percolação do componente fraco), crescendo suavemente após esta percolação e depois decrescendo para épocas posteriores. Acreditamos que este decréscimo indique saturação da ativação da rede, que passa a tornar menos relevante o relacionamento entre o grau de entrada e a média de ativação. Não se observou relacionamento significativo entre o coeficiente de aglomeração médio e a taxa média de ativação. $O$ mesmo resultado foi obtido respectivamente à reciprocidade das conexões.

8. Investigou-se, ainda, como os valores das correlações entre as várias medidas de dinâmica de ativação e topologia consideradas ao longo de todas as épocas (de 0 a 500) pode contribuir para a discriminação entre os três tipos de neurônios piramidais considerados. Acreditamos que a consideração dos valores de cada medida ao longo das épocas como vetor de atributo na categorização dos tipos neuronais apresenta bom potencial para representações mais completas das propriedades de conexão, ou mesmo de dinâmica, das células neuronais consideradas. 
Vários são os trabalhos futuros que podem ser realizados utilizando-se os recursos desenvolvidos. Em relação ao estudo dos três tipos de neurônios piramidais, incluem-se as seguintes possibilidades de pesquisas complementares:

1. Maior número de neurônios e condições de fronteira diferentes, como toroidais;

2. Estudo de outras dinâmicas, como epidemias e sincronização;

3. Verificar efeitos de outros aspectos das redes simuladas nas correlações, como conexões de longo alcance;

4 Consideração das ramificações axonais.

São bastante amplas as perspectivas do uso do arcabouço também em outras pesquisas, incluindo:

1. Investigar outros tipos de neurônios, inclusive de outras espécies e regiões;

2. Modelar outras estruturas do sistema nervoso, como núcleos, hipocampo, etc.;

3. Considerar o estado de ativação nas conexões, por exemplo através da regra do rico fica mais rico;

4. Utilizar neurônios sintéticos que possam desenvolver seus ramos ao longo das épocas. 


\section{REFERÊNCIAS}

1 CAJAL, S. Recollections of my life. Massachussets: MIT Press, 1989.

2 DE FELIPE, J. Sesquicentenary of the birthday of Santiago Ramón y Cajal, the father of modern neuroscience. Trends in Neurosciences, v. 25, n. 9, p. 481-484, 2002.

3 COSTA, L.; MANOEL, E. A percolation approach to neural morphometry and connectivity. Neuroinformatics, v. 1, n. 1, p. 65-80, 2003.

4 PEREZ-RECHE, F.; TARASKIN, S.; COSTA, L.; NERI, F.; GILLICAN, C. Complexity and anysotropy in host morphology make populations less susceptible to epidemic outbreaks. Journal of the Royal Society Interface, v. 7, n. 48, p. 1083-1092, 2010.

5 LUNDY-EKMAN, L. Neuroscience: fundamentals for rehabilitation. 3rd. ed. St. Louis: Saunders/Elsevier, 2007.

6 DOWLING, J. Neurons and networks: an introduction to neuroscience. Harvard: Harvard University Press, 1992.

7 KANDEL, E.; SCHWARTZ, J.; JESSELL, T.; SIEGELBAUM, S.; HUDSPETH, A. Principles of neural science. 5th. ed. New York: McGraw-Hill Education, 2012.

8 HALL, J. Guyton and Hall textbook of medical physiology: enhanced e-book. Philadelphia: Elsevier/Saunders, 2010.

9 LENT, R. Cem bilhões de neurônios. São Paulo: Atheneu, 2001.

10 GERSTNER, W.; KISTLER, W. M. Spiking neuron models. Cambridge: Cambridge University Press, 2002.

11 SCHMOLESKY, M. The primary visual cortex, Jan 2013. Disponível em: $<$ http://webvision.med.utah.edu/book/part-ix-psychophysics-of-vision/the-primary-visualcortex/>. Acesso em: 2 jan. 2013.

12 PURVES, D. Body and brain: a trophic theory of neural connections. Cambridge: Harvard University Press, 1998.

13 COELHO, R. C. Síntese, modelagem e simulação de estruturas neurais morfologicamente realísticas. 1998. 261 p. Tese (Doutorado em Física) - Instituto de Física de São Carlos Universidade de São Paulo, São Carlos, 1998. 
14 CANNON, R.; TURNER, D.; PYAPALI, G.; WHEAL, H. An on-line archive of reconstructed hippocampal neurons. Journal of Neuroscience Methods, v. 84, n. 1-2, p. 49-54, 1998.

15 MINGOTI, S. A. Análise de dados através de métodos de estatística multivariada: uma abordagem aplicada. Belo Horizonte: Editora UFMG, 2007.

16 BARABÁSI, A. L.; FRANGOS, J. Linked: the new science of networks. Cambridge: Perseus, 2002.

17 NEWMAN, M. E. J. Networks: an introduction. Oxford: Oxford University Press, 2010.

18 COSTA, L.; Oliveira Junior, O. N.; TRAVIESO, G.; RODRIGUES, F. A.; BOAS, P. R.; ANTIQUEIRA, L.; VIANA, M. P.; ROCHA, L. E. C. Analyzing and modeling real-world phenomena with complex networks: A survey of applications. Advances in Physics, London, v. 60, n. 3, p. 329-412, 2011.

19 GALVÃO, V. M. Um modelo para neuplasia utilizando redes complexas. 2006. 106 p. Dissertação (Mestrado em Ciências) - Universidade Federal da Bahia, Salvador, 2006.

20 MONTElRO, L. H. A. Sistemas dinâmicos complexos. São Paulo: Livraria da Física, 2010.

21 BONDY, J. A.; MURTY, U. S. Graph theory with applications. London: Macmillan, 1979.

22 GARLASCHELLI, D.; LOFREDO, M. I. Patterns of link reciprocity in directed networks. Physical Reviews Letters, v. 93, p. 268701, 2004.

23 ERDÕS, P.; RÉNYI, A. On the evolution of random graphs. p. 17-61, 1960. Disponível em: <http://www.renyi.hu/ p_erdos/1961-15.pdf>. Acesso em: 15 jan. 2013.

24 STAUFFER, D.; AHARONY, A. Introduction to percolation theory. Boca Raton: CRC Press, 1994.

25 MILGRAM, S. The small world problem. Psychology Today, v. 2, n. 1, p. 60-67, 1967.

26 WATTS, D. Six degrees: the science of a connected age. New York: Norton, 2004.

27 BARABÁSI, A.; BONABEAU, E. Scale-free networks. Scientific American, v. 288, p. 50-59, 2003.

28 MORENO, Y.; PASTOR-SATORRAS, R.; VESPIGNANI, A. Epidemic outbreaks in complex heterogeneous networks. The European Physical Journal B - Condensed Matter and Complex Systems, v. 26, n. 4, p. 521-529, 2002. 
29 BARTHÉleMY, M. Spatial networks. Physics Reports, v. 499, n. 1-3, p. 1-101, 2011.

30 Ahnert, S. E.; TRAVEnÇOLO, B. A.; COSTA, L. F. Connectivity and dynamics of neuronal networks as defined by the shape of individual neurons. New Journal of Physics, v. 11, n. 10 , p. 1-20, 2009.

31 GÓMEZ-GAVIRO, M. V.; SCOTT, C. E.; K., S. A.; MATHEU, A.; BOOTH, S.; GALICHET, C.; LOVELL-BADGE, R. Betacellulin promotes cell proliferation in the neural stem cell niche and stimulates neurogenesis, 2012. Disponível em:< http://www.ncbi.nlm.nih.gov/pmc/articles/PMC3268286/pdf/pnas.201016199.pdf>. Acesso em: 10 abril 2013.

32 COSTA, L. Avalanches of activation and apikes in neuronal complex networks. 2008. Disponível em: <http://arxiv.org/pdf/0802.0421v1.pdf>. Acesso em: 10 maio 2013.

33 FUNABASHI, Y.; KAWAMURA, K.; ICHI OSHIO, K.; MORITA, S.; OSANA, Y.; AKIYAMA, E.; OKA, K. Native response of c.elegans encoded in its neuron network. $v$. 70, p. 1164-1171, 2001.

34 TOMÉ, T.; OlIVEIRA, M. J. D. Dinâmica estocástica e irreversibilidade. São Paulo: , 2001.

35 HANDFORD, T. P.; PEREZ-RECHE, F. J.; TARASKIN, S. N.; COSTA, L. D. F.; MIAZAKI, M.; NERI, F. M.; GILLIGAN, C. A. Epidemics in networks of spatially correlated three-dimensional root-branching structures. Journal of The Royal Society Interface, v. 8, n. 56, p. 423-434, 2011.

36 COMIN, C.; BUNORO, J.; VIANA, M.; COSTA, L. Unveiling the relationship between structure and synamics in complex networks. ArXiv e-prints, set 2011.

37 COMIN, C. H.; BATISTA, J.; VIANA, M. P.; COSTA, L.; TRAVENÇOLO, B.; KAISER, $M$. Structure and dynamics: the transition from nonequilibrium to equilibrium in integrateand-fire dynamics. International Journal of Bifurcation and Chaos, v. 22, n. 07, p. 1250174 , 2012.

38 HODGKIN, A.; HUXLEY, A. A quantitative description of membrane current and its application to conduction and excitation in nerve. The Journal of Physiology, v. 117, n. 4, p. 500-544, 1952.

39 ROSE, R. M.; HINDMARSH, J. L. The assembly of ionic currents in a thalamic neuron. ithe three-dimensional model. v. 237, n. 1288, p. 267-288, 1989.

40 IZHIKEVICH, E. M. Which model to use for cortical spiking neurons? IEEE Transactions on In Neural Networks, v. 15, n. 5, p. 1063-1070, 2004. 
41 COSTA, L. Comunities in neuronal complex networks revealed by activation patterns. 2008. Disponível em: <http://arxiv.org/pdf/0801.4684v1.pdf>. Acesso em: 30 abr. 2013.

42 COMIN, C. H.; VIANA, M. P.; COSTA, L. The relationship between structure and function in locally observed complex networks. New Journal of Physics, v. 15, n. 1, p. 013048, 2013.

43 COSTA, L.; CÉSAR JÚNIOR, R. Shape analysis and classification: theory and practice. 2007.

44 CONSIGLIO, R.; BAKER, D. R.; PAUL, G.; STANLEY, H. E. Continuum percolation thresholds for mixtures of spheres of different sizes. Physica A: Statistical Mechanics and its Applications, v. 319, p. 49-55, 2003.

45 DUDA, R.; HART, P.; STORK, D. Pattern classification. New York: Wiley-Interscience, 2001. 